\title{
ANISOTROPIA DE RESISTIVIDADE ELÉTRICA EM FILMES FINOS NANOESTRUTURADOS
}

Dissertação apresentada à Escola Politécnica da Universidade de São Paulo para obtenção do título de Mestre em Engenharia.

Área de Concentração:

Engenharia de Sistemas Eletrônicos Microeletrônica

Orientador: Prof. Associado Ronaldo Domingues Mansano 
Este exemplar foi revisado e alterado em relação à versão original, sob responsabilidade única da autora e com anuência do seu orientador.

São Paulo, 14 de junho de 2007

Assinatura da autora

Assinatura do orientador

\section{FICHA CATALOGRÁFICA}

Teixeira, Fernanda de Sá

Anisotropia de resistividade elétrica em filmes finos nanoestruturados / F. de S. Teixeira. -- ed.rev. -- São Paulo, 2007.

$92 \mathrm{p}$.

Dissertação (Mestrado) - Escola Politécnica da Universidade de São Paulo. Departamento de Engenharia de Sistemas Eletrônicos.

1.Litografia 2.Materiais nanoestruturados 3.Microscopia eletrônica de varredura 4.Plasma (Microeletrônica) I.Universidade de São Paulo. Escola Politécnica. Departamento de Engenharia de Sistemas Eletrônicos II.t. 
Este trabalho é dedicado às moças do meu coração, minha mãe Valdete e minha irmã Caroline. 


\section{AGRADECIMENTOS}

Ao orientador Prof ${ }^{\mathrm{o}}$. Ronaldo Domingues Mansano pela confiança e pelas sugestões e discussões construtivas acerca desse trabalho e também sobre assuntos diversos relacionados à pesquisa científica.

Ao Laboratório de Filmes Finos do Instituto de Física da USP e ao Laboratório de Sistemas Integráveis da Escola Politécnica da USP pela infra-estrutura disponível.

Ao Prof ${ }^{o}$ Mauro Cattani (IFUSP) pelos esclarecimentos sobre o conteúdo teórico durante o curso do trabalho, pela discussão dos resultados e por todo o apoio.

Ao Prof ${ }^{\circ}$ Ian G. Brown (Lawrence Berkeley National Laboratory) pelas sugestões e pela participação na etapa experimental do trabalho.

A todos os atuais alunos e também ex-bolsistas do Laboratório de Filmes Finos (IFUSP) pelas interessantes experiências profissionais.

À Prof ${ }^{a}$ Maria Cecília Salvadori (IFUSP) pelas tantas oportunidades dadas a mim,

pelos conhecimentos constantemente passados e, acima de tudo, pela confiança e reconhecimento do meu trabalho.

À minha irmã pelo amor, carinho, amizade e companheirismo. À minha mãe pela sua luta e apoio constantes. Agradeço a ela pelo amor incondicional que sempre tivemos. Isto também está agregado a este trabalho.

A todos que contribuíram de alguma forma para a realização deste trabalho.

À FAPESP e CNPq pelo apoio financeiro. 


\section{RESUMO}

O objetivo principal deste trabalho foi desenvolver um dispositivo de filme fino com anisotropia de resistividade elétrica. A idéia foi usar um efeito quântico presente em filmes muito finos de materiais condutores ou semicondutores com morfologia anisotrópica na superfície. A morfologia foi um perfil unidirecional quase-senoidal. As resistividades foram determinadas medindo-se as resistências elétricas destes materiais em direções ortogonais, levando-se em conta a geometria da amostra e suas dimensões. O material condutor usado foi Polimetilmetacrilato (PMMA) com ouro implantado na superfície. A profundidade média de implantação foi $2,7 \mathrm{~nm}$. Na fabricação do dispositivo foi utilizada micro e nanolitografia, caracterização por Microscopia Eletrônica de Varredura e Microscopia de Força Atômica e implantação de ouro por MePIIID (Metal Plasma Immersion Ion Implantation and Deposition).

Palavras-chave: Resistividade elétrica. Microfabricação. Nanofabricação. Nanolitografia. Microscopia de Força Atômica. Deposição por Plasma. Novos Materiais. 


\begin{abstract}
The main purpose of this work was to develop a thin film device with electrical anisotropic resistivity. The idea was to use a quantum effect which is present in very thin films of conductor or semiconductor materials with anisotropic morphology on the surface. The morphology was a sinusoidal-like unidirectional profile. The resistivities were determined measuring the electrical resistances of theses materials in orthogonal directions, taking in account the sample geometry and dimensions. The conductive material used was Polymethylmethacrylate (PMMA) with gold implanted on the surface. The average implanted depth was $2.7 \mathrm{~nm}$. In the device fabrication were used micro and nanolithography, characterization by Scanning Electron Microscopy and Atomic Force Microscopy and gold implantation by MePIIID (Metal Plasma Immersion Ion Implantation and Deposition).
\end{abstract}

Keywords: Electrical Resistivity. Microfabrication. Nanofabrication. Nanolithography. Atomic Force Microscopy. Plasma Deposition. New Materials. 


\section{LISTA DE FIGURAS}

Figura 1.1 - Ordem de grandeza da resistividade elétrica dos materiais [1] ............................................ 15

Figura 1.2 - Fatores de anisotropia de resistividade em função da espessura dos filmes de platina ......... 17

Figura 1.3 - Geometria proposta para a fabricação de nanocomponente com anisotropia na resistividade elétrica. Ao longo do eixo y a superfície deverá apresentar um perfil típico dos filmes nanoestruturados 18

Figura 2.1 - Campo elétrico aplicado em um material bulk ............................................................. 21

Figura 2.2 - Representação da trajetória de um elétron na presença de um campo elétrico aplicado ...... 21

Figura 2.3 - Esquema de bandas de energia para o Au .............................................................................. 26

Figura 2.4 - Gráfico da função de distribuição de Fermi .......................................................................... 27

Figura 2.5 - Secção de um filme fino ........................................................................................................... 30

Figura 3.1 - a-) Microscópio Jeol 6460 LV e b-) Esquema da coluna óptico-eletrônica ............................. 39

Figura 3.2 - Volumes de interação entre o feixe de elétrons e a amostra para a-) Carbono $15 \mathrm{kV}$

b-) Carbono 30 kV c-) Ouro 15kV d-) Ouro 30kV ............................................................... 40

Figura 3.3 - Ciclo de controle do sistema NPGS acoplado ao MEV ............................................................41

Figura 3.4 - Nanoscope IIIA - Digital Instruments .................................................................................... 42

Figura 3.5 - Força de Van der Waals em função da distância entre ponta e amostra ................................. 43

Figura 3.6 - Interação ponta-superfície para AFM de contato e AFM de contato intermitente ................ 44

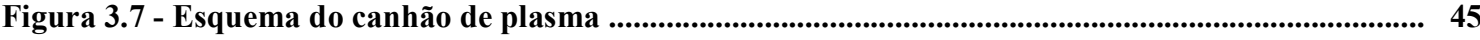

Figura 3.8 - Plasma passando por filtro de partículas para a) um material e b) dois materiais ................ 46

Figura 3.9 - Dispositivos para experimento de anisotropia de resistividade ............................................... 47

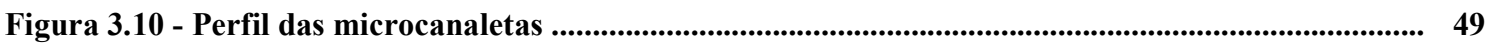

Figura 3.11 - Placas quentes e spin-coater instalados dentro de ambiente de fluxo laminar ...................... 50

Figura 3.12 - Cadeia polimérica do PMMA ….......................................................................................... 51

Figura 3.13 - a) Dimensões principais para se fabricar um Faraday cup e b) Corte do arranjo ............... 53

Figura 3.14 - Detalhe da abertura do Faraday Cup .................................................................................. 53

Figura 3.15 - a) Resultado obtido com desvio de orientação de $-16^{\circ}$ e b) solução rotacionando-se o desenho CAD de $16^{\circ}$

Figura 3.16 - Imagem do perfil obtido pela microlitografia por feixe de elétrons ...................................... 55

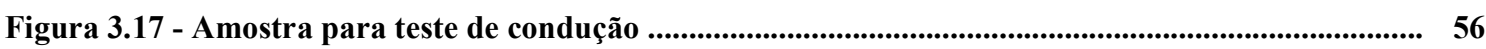

Figura 3.18 - Ponta de silício para AFM ..............................................................................................................57

Figura 3.19 - Exemplo de gráfico de calibração de força do AFM de contato ............................................ 59

Figura 3.20 - Esquema de varredura para obtenção de imagens .......................................................60

Figura 3.21 - Arranjo experimental com os três dispositivos e respectivos conectores. As regiões de micro e nanolitografia estão representadas nos dispositivos 1 e 2 fora de escala

Figura 3.22 - a-) Flange com fios para medição de resistências b-) conexão com módulo eletrônico e c-) módulo de aquisição de dados 
Figura 3.23 - Esquema de medição de espessura de filmes finos - a) Pedaços de silício com traço de tinta, b) após deposição e c) após remoção da tinta

Figura 3.24 - a) Seleção de região livre de bordas, b) Seleção de região do filme fino a ser depositado posteriormente, c-) Deposição de camada espessa e d-) Amostras prontas para deposição do filme fino

Figura 3.25 - Montagem do porta amostra em suporte de inox ........................................................64

Figura 4.1 - Imagem sem processamento mostrando alinhamento de aglomerados ..................................66

Figura 4.2 - Imagem sem processamento para observação da uniformidade da periodicidade ................. 66

Figura 4.3 - Análise de seção da imagem processada de região nanolitografada ...................................... 67

Figura 4.4 - Esquema dos dispositivos após deposição do filme fino ............................................................. 68

Figura 4.5 - a) Medidas de mascaramento (em $\mathrm{mm}$ ) e b) medidas das regiões onde se depositou os filmes finos

Figura 4.6 - Resistividade em função da espessura para dispositivo 3 ........................................................ 71

Figura 4.7 - Resistividade em função da espessura para dispositivos 1 e 2 ........................................... 71

Figura 4.8 - Gráfico da resistividade utilizando modelos teóricos, segundo Eq.(2.53) ............................... 72

Figura 4.9 - Resistividades obtidas para experimento de comprovação de resultados ............................... 73

Figura 4.10 - Simulação da penetração dos íons de ouro com energia cinética de 49 eV na

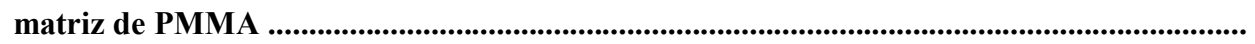

Figura 4.11 - a) Quatro estruturas de $30 \mu \mathrm{m} \times 100 \mu \mathrm{m}$ usadas na litografia por feixe de elétrons, b-) Perfil gerado no PMMA sobre vidro e c-) Representação do perfil após deposição de $100 \mathrm{~nm}$ de ouro

Figura 4.12 - Anisotropia $\rho_{1} / \rho_{2}$ em função da espessura 76

Figura 4.13 - Curva V-I de amostra com o equivalente em espessura de $1,95 \mathrm{~nm}$ de Au implantado no PMMA 


\section{LISTA DE TABELAS}

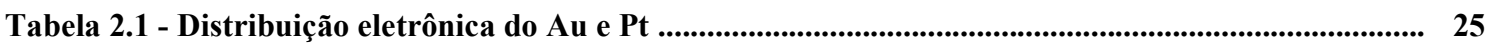

Tabela 2.2 - Valores relacionados à energia de Fermi para Au e Pt ................................................ 29

Tabela 2.3 - Condições para efeitos quânticos em filmes finos para Pt e Au .............................................. 32

Tabela 3.1 - Principais características do Jeol 6460-LV e acessórios .........................................................38

Tabela 3.2 - Capacidades do Nanoscope IIIa (Digital Instruments) ..................................................... 42

Tabela 3.3 - Resumo dos processos de preparação dos dispositivos ..................................................... 48

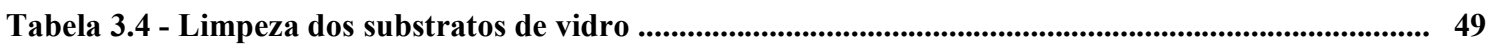

Tabela 3.5 - Dados da nanolitografia por AFM de contato dependentes da ponta utilizada .................... 59

Tabela 4.1 - Periodicidades e amplitudes associadas presentes em região nanolitografada

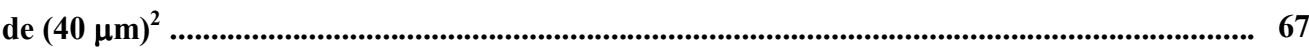

Tabela 4.2 - Média das medidas de altura dos degraus de PMMA antes e após deposição de ouro

Tabela 4.3 - Fatores de anisotropia para morfologia dos nanocomponentes 


\section{LISTA DE ABREVIATURAS}

$\begin{array}{ll}\text { MEMS } & \text { Micro Electro Mechanical Systems } \\ \text { NEMS } & \text { Nano Electro Mechanical Systems } \\ \text { RTD } & \text { Resistive Temperature Detector } \\ \text { STM } & \text { Scanning Tunneling Microscope/Microscopy } \\ \text { MEV } & \text { Microscópio Eletrônico de Varredura } \\ \text { EDS } & \text { Energy Dispersive Spectroscopy } \\ \text { NPGS } & \text { Nanometer Pattern Generation System } \\ \text { CAD } & \text { Computer Aided Design } \\ \text { CDA } & \text { Conversor Digital para Analógico } \\ \text { SPM } & \text { Scanning Probe Microscope/Microscopy } \\ \text { AFM } & \text { Atomic Force Microscope/Microscopy } \\ \text { MFM } & \text { Magnetic Force Microscope/Microscopy } \\ \text { EFM } & \text { Electrical Force Microscope/Microscopy } \\ \text { MePIIID } & \text { Metal Plasma Immersion Ion Implantation and Deposition } \\ \text { DLC } & \text { Diamond-like Carbon } \\ \text { PMMA } & \text { Polimetilmetacrilato }\end{array}$




\section{LISTA DE SÍMBOLOS}

$\Lambda$

$\rho$

V

$\mathrm{m}_{\mathrm{e}}$

A

$\mathrm{L}_{\mathrm{c}}$

V

F

$\overrightarrow{\mathrm{E}}$

q

$\mathrm{v}_{0}$

$\mathrm{v}_{\mathrm{d}}$

$\mathrm{t}$

$\tau$

a

Q

$\mathrm{n}_{\mathrm{e}}$

R

$\sigma$

$\ell_{0}$

$\rho_{0}$

n

$l$

$m$

comprimento de onda da modulação senoidal

amplitude da modulação senoidal

espessura de um filme fino

resistividade elétrica

velocidade térmica de Maxwell-Boltzmann

constante de Boltzmann

temperatura absoluta

massa do elétron

área da secção de um condutor

comprimento de um condutor

diferença de potencial elétrico

força aplicada nos elétrons causada por um campo elétrico

campo elétrico

carga do elétron

velocidade inicial

velocidade média de migração dos elétrons

tempo

tempo livre médio entre duas colisões sucessivas

aceleração dos elétrons causada por campo elétrico

carga elétrica

corrente elétrica

densidade de corrente elétrica

número total de portadores de carga por unidade de volume

resistência elétrica

condutividade elétrica

livre caminho médio dos elétrons

resistividade elétrica quando $\mathrm{T} \rightarrow 0$

energia geral dos elétrons

momento angular dos elétrons

projeções do vetor momento angular $l$ em relação ao eixo z (ou campo magnético externo) 


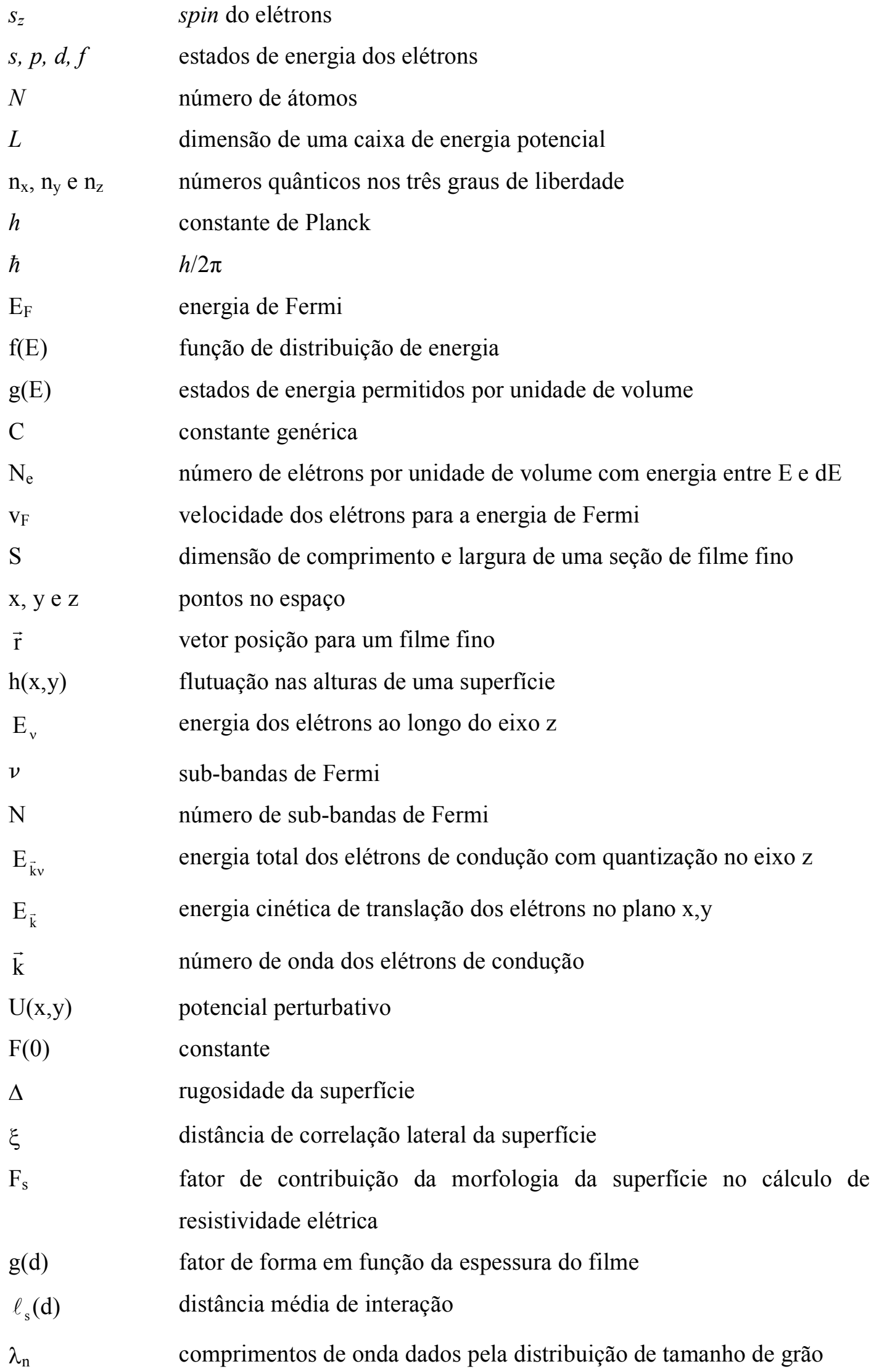




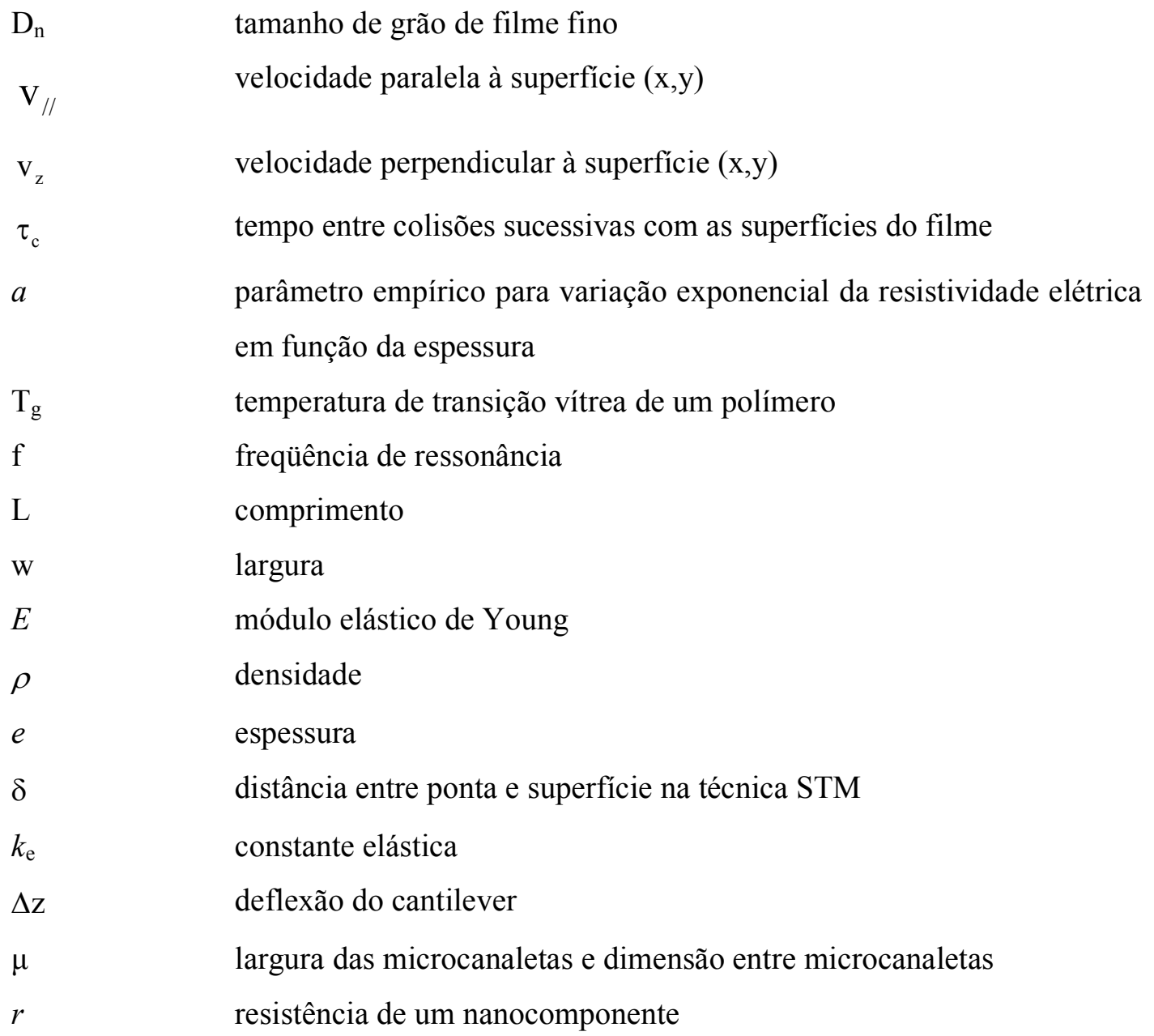




\section{SUMÁRIO}

CAPÍTULO I - INTRODUÇÃO ............................................................ 15

1.1. Motivação ............................................................................................................................. 15

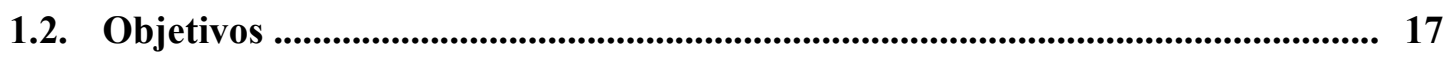

1.3. Importância Tecnológica .............................................................................................. 18

CAPÍTULO II - RESISTIVIDADE ELÉTRICA ........................................... 20

2.1. Modelo clásssico para condução elétrica ….......................................................... 20

2.2. Modelo de bandas de energia ..................................................................... 24

2.3. Condução elétrica em filmes finos metálicos ............................................................. 29

CAPÍTULO III - MATERIAIS E MÉTODOS ............................................. 38

3.1. Microscópio eletrônico de varredura (MEV) ..................................................... 38

3.1.1. Sistema de geração de padrões litográficos ............................................ 41

3.2. Microscopia de força atômica e tunelamento ........................................................... 41

3.3. Metal Plasma Immersion Ion Implantation and Deposition (MePIIID) ............. 44

3.4. Desenvolvimento dos dispositivos para medida de anisotropia de

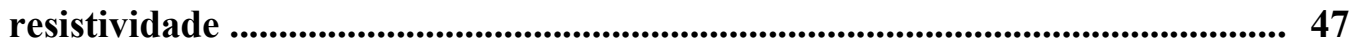

3.4.1. Preparação dos substratos ...................................................................................... 48

3.4.2. Definição das microcanaletas ..................................................................... 49

3.4.3. Nanolitografia por AFM de contato ............................................................ 56

3.4.4. Montagem do arranjo experimental .................................................................60 60

3.4.5. Deposição do filme espesso .................................................................... 62

CAPÍTULO IV - RESULTADOS E DISCUSSÃO ................................... 65

4.1. Nanolitografia por AFM de contato ........................................................................... 65

4.2. Deposição do filme fino de ouro ................................................................................. 67

CAPÍTULO V - Conclusões ........................................................................ 80

5.1. Sugestão para trabalhos futuros .................................................................................. 80

Referências Bibliográficas ............................................................. 82

ANEXO A - Artigo publicado no periódico Review of Scientific Instruments 


\section{CAPÍTULO I INTRODUÇÃO}

As espessuras em escala nanométrica dos filmes finos, mesmo quando estes apresentam extensões superficiais em dimensões macroscópicas, lhes conferem propriedades exóticas que podem ser justificadas apenas pela física quântica.

A resistividade elétrica é uma propriedade muito interessante que varia muitas ordens de grandeza desde o mais isolante dos materiais até o mais condutor (figura 1.1). Para materiais na forma de bulk já existem modelos bem definidos que explicam tanto qualitativamente como quantitativamente esta propriedade.

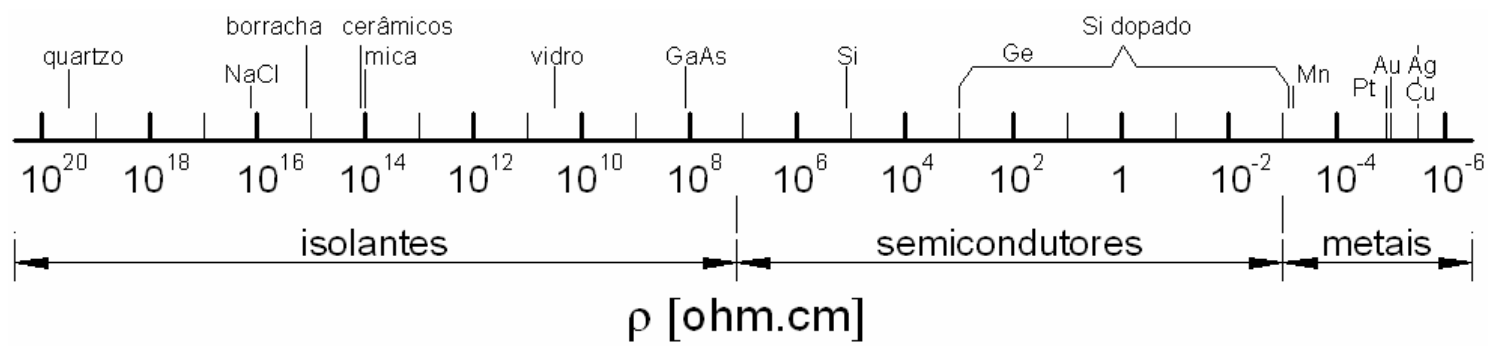

Figura 1.1 - Ordem de grandeza da resistividade elétrica dos materiais [1].

O mecanismo de resistividade de um filme fino, e também o seu valor, é diferente daquele do material na forma de bulk. A resistividade elétrica $(\rho)$ em materiais na forma de filmes finos apresenta efeitos quânticos quando a espessura do filme é menor ou da ordem de grandeza do livre caminho médio dos elétrons e quando há uma quantização acentuada dos níveis de energia ao longo da espessura do filme. Para filmes de ouro e platina com espessuras entre $1,8 \mathrm{~nm} \leq \mathrm{d} \leq 10,5 \mathrm{~nm}$ e $1,3 \mathrm{~nm} \leq \mathrm{d} \leq 11 \mathrm{~nm}$, respectivamente, estas condições são satisfeitas.

Existem muitos modelos que explicam a dependência da resistividade com relação à espessura dos filmes. Entretanto, os efeitos morfológicos da superfície que possam influenciar no transporte eletrônico ainda não foram incorporados satisfatoriamente nestes modelos.

\subsection{Motivação}

Materiais nanoestruturados vêm despertando enorme interesse científico e tecnológico desde a última década [2 - 4]. Estes materiais são compostos por estruturas com 
pelo menos duas dimensões na faixa de 1 a $100 \mathrm{~nm}$, os quais podem ser na forma de clusters, cristais ou moléculas. Os materiais nanoestruturados destacam-se dos demais por apresentarem propriedades elétricas, ópticas, mecânicas e magnéticas surpreendentemente distintas dos mesmos materiais na forma bulk $[5,6]$.

Os efeitos elétricos [7] e mecânicos gerados em filmes finos mono e nanocristalinos têm sido objeto de investigação já há muitos anos. Como estas propriedades não são bem conhecidas ou compreendidas, elas são objeto de pesquisa tanto na área experimental como na área teórica. Alguns exemplos de propriedades peculiares de materiais nanoestruturados são cerâmicas dúcteis [8], metais com alta dureza [9], metais com módulo elástico inferior ao conhecido para a forma de bulk $[4,11$ - 13] e resistividade elétrica variando com a espessura de filmes finos metálicos [7, 13 - 21].

As discussões sobre propriedades dos materiais nanoestruturados têm sido feitas com base em tamanhos de grão, interfaces de grãos [10, 11, 22, 23], fases presentes em intergrãos, porosidade e densificação, porém não se sabe perfeitamente o que ocorre.

A importância do estudo de filmes finos nanoestruturados, além do aspecto de física básica envolvida, está no fato de serem muito utilizados na fabricação de MEMS e NEMS (Micro e Nano Electro Mechanical Systems), o que leva a uma urgência tecnológica em se conhecer suas propriedades.

A resistividade elétrica, mais especificamente, é uma propriedade ainda não totalmente explorada no que diz respeito aos filmes finos. Seu cálculo é dado por uma expressão que é função da espessura do filme e também de um fator relacionado à sua morfologia, o qual representa diretamente a interação dos elétrons de condução com a superfície rugosa do filme (espalhamento eletrônico).

Baseado em um efeito quântico, foi sugerido através de um pré-experimento que, além da rugosidade, uma modulação senoidal unidirecional na superfície do filme também pode interferir no valor da resistividade elétrica. Esta modulação senoidal é caracterizada por um comprimento de onda $\Lambda$ e amplitude h. Medindo-se a resistência elétrica em direções ortogonais em filmes de platina com esta modulação de superfície (plano x,y), foram calculadas as resistividades correspondentes e determinados fatores de anisotropia $\rho_{\mathrm{x}} / \rho_{\mathrm{y}}$. De acordo com o gráfico mostrado na figura 1.2, obteve-se que a anisotropia de resistividade é maior para espessuras menores. 


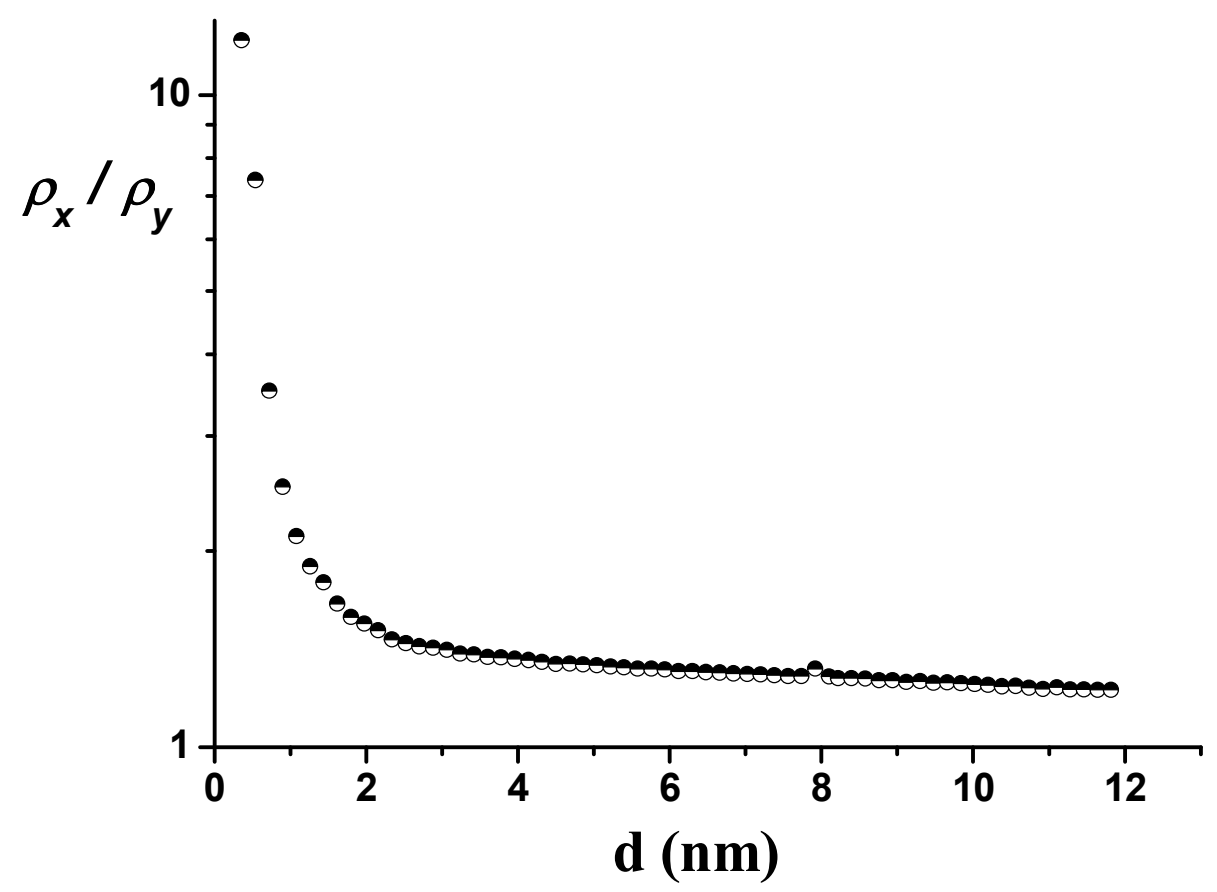

Figura 1.2 - Fatores de anisotropia de resistividade em função da espessura dos filmes de platina.

Os comprimentos de onda foram gerados em superfícies de substratos de vidro (rugosidade RMS da superfície não polida $\sim 0,5 \mathrm{~nm}$ ) através do seu polimento com pó de diamante com granulação $1 / 4 \mu \mathrm{m}$. Por este motivo ainda pode ser questionado se as características morfológicas que geram a anisotropia são mesmo as relacionadas às modulações senoidais, uma vez que o fator de morfologia que deve ser incluído no cálculo da resistividade elétrica de filmes finos é discutido por vários pesquisadores [7, 13 - 21].

\subsection{Objetivos}

O objetivo principal deste trabalho foi fornecer dados experimentais para a comprovação de modelos teóricos que predizem a influência da morfologia na resistividade elétrica de filmes ultrafinos condutores e semicondutores (espessura $<3 \mathrm{~nm}$ ). O projeto baseou-se no efeito quântico de espalhamento eletrônico em que a anisotropia da morfologia deve gerar anisotropia na resistividade elétrica.

Para isto foram fabricados filmes finos de PMMA (Polimetilmetacrilato) com superfície anisotrópica. O material foi implantado com íons de $\mathrm{Au}$, o que o tornou condutor. O PMMA é um material de extrema importância para micro e nanofabricação, pois, além de 
ser um polímero sensível à radiação ultra-violeta, é ainda o elétron-resiste de maior resolução utilizado em nanolitografia por feixe de elétrons.

Os filmes finos nanofabricados (nanocomponentes) para determinação da resistividade têm a morfologia mostrada na figura 1.3. A geometria proposta apresenta superfície com perfil senoidal ao longo do eixo $x$, tal que $h(x)=h \cdot \cos (2 \pi x / \Lambda)$, onde $h$ é a amplitude e $\Lambda$ é o comprimento de onda correspondente. Ao longo do eixo y a superfície apresenta um perfil típico de filmes nanoestruturados com caráter granular. Portanto, deve-se esperar o efeito de anisotropia de resistividade elétrica em direções ortogonais no plano $(\mathrm{x}, \mathrm{y})$.

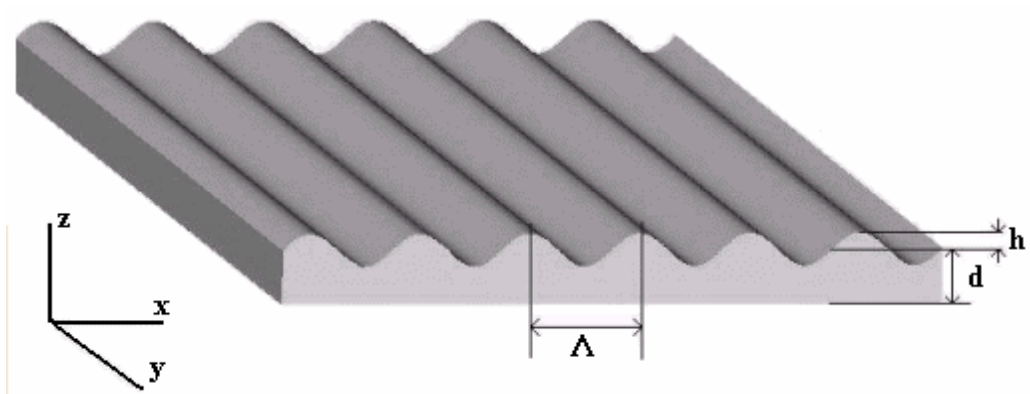

Figura 1.3 - Geometria proposta para a fabricação de nanocomponente com anisotropia na resistividade elétrica. Ao longo do eixo y a superfície deverá apresentar um perfil típico dos filmes nanoestruturados.

Os filmes foram fabricados utilizando implantação/deposição por plasma metálico em arco [24 - 27]. As dimensões inicialmente envolvidas no projeto foram $20 \mathrm{~nm}<\Lambda<$ $40 \mathrm{~nm}, 0,8 \mathrm{~nm}<\mathrm{h}<1,5 \mathrm{~nm}$ e d $<5 \mathrm{~nm}$. Assim fica claro que o trabalho envolveu precisão nanométrica e exigiu uso de técnicas de micro e nanofabricação [28] no seu desenvolvimento, além de caracterizações por microscopia de força atômica e por microscopia eletrônica de varredura. Arranjos experimentais específicos foram necessários para as medidas de resistência elétrica envolvidas nesse trabalho.

\subsection{Importância tecnológica}

Os filmes ultrafinos condutores vêm sendo utilizados nas mais diversas aplicações em que suas propriedades elétricas são exploradas, como seu uso em sensores, nanoatuadores acionados eletricamente e dispositivos micro e nanoeletrônicos. É extremamente importante conhecer e entender os mecanismos corretos e ordem de grandeza da resistividade elétrica destes filmes. 
A resistividade elétrica é usada como mecanismo transdutor em sensores de temperatura (RTD - Resistive Temperature Detector) e em sensores de gases que se baseiam em filmes ultrafinos [29 - 35]. As vantagens do uso de filmes finos são a simplicidade e redução de custos, uma vez que pouco material é utilizado, miniaturização, resposta rápida e alta precisão para faixas específicas de detecção. Filmes de platina são comumente usados como sensores RTD, inclusive com confiabilidade na tecnologia MEMS, e como sensores de gás hidrogênio. Filmes de ouro são tipicamente usados na detecção de mercúrio.

Na referência [34] foi estudado o efeito da morfologia de filmes ultrafinos de platina (1,5 nm e 2,5 nm) usados como sensores de imunidade, ainda baseado no efeito de alteração da resistividade elétrica. Constatou-se que a estrutura com ilhas discretas de platina sobre uma camada de óxido de silício determinava o comportamento e resposta do sensor. Em outro trabalho [35], sobre filmes de platina de 3,5 nm usados como sensores de gás hidrogênio, com detecção na faixa de 10-1000 ppm, também foram observadas alterações no comportamento do sensor devido a morfologias diversas. Porém as especulações de ambos os trabalhos não se baseiam em modelos teóricos confiáveis ou mesmo em caracterizações adequadas da morfologia.

Portanto, é justificada a importância em se conhecer as propriedades dos filmes finos de materiais condutores e semicondutores corretamente para sua aplicação no desenvolvimento de dispositivos que utilizam filmes ultrafinos.

Além do resultado principal do trabalho, o desenvolvimento dos processos utilizados, principalmente de técnicas de nanolitografia, contribui com relevância do ponto de vista tecnológico, dada a sua vasta aplicação no ramo de nanotecnologia como ferramenta de desenvolvimento. 


\section{CAPÍTULO II RESISTIVIDADE ELÉTRICA}

Neste capítulo são apresentados os conceitos bem estabelecidos sobre condução elétrica de materiais ôhmicos na forma de bulk, dados pela física clássica e pelo modelo de bandas de energia, os quais são essenciais para o entendimento dos mecanismos básicos da resistividade elétrica. Após essa introdução ao assunto é apresentada a base teórica do transporte elétrico em filmes finos de materiais condutores. $\mathrm{O}$ modelo quântico atualmente mais aceito $[17,18]$ considera os efeitos da morfologia da superfície no espalhamento dos elétrons. Entretanto, um novo modelo quântico [13 - 16] trata de maneira mais detalhada a influência das superfícies do filme neste processo.

\subsection{Modelo clássico para condução elétrica}

Considera-se inicialmente isolado um fio de material condutor. Segundo o modelo clássico, esta substância possui elétrons de condução disponíveis, que são os elétrons de valência de cada átomo do cristal. Esses elétrons podem ser tratados como um gás neutro ideal. Assim movem-se livremente por uma rede cristalina de íons positivos, estando confinados pelos limites físicos do material e sujeitos à estatística de Maxwell-Boltzmann.

Esses elétrons, que estão em constante movimento randômico, colidem com os íons positivos do metal. A velocidade entre colisões sucessivas corresponde à velocidade térmica de Maxwell-Boltzmann [36, 37], dada por:

$$
\mathrm{v}=\sqrt{\frac{3 k \mathrm{~T}}{\mathrm{~m}_{\mathrm{e}}}}
$$

onde $\mathrm{T}$ é a temperatura absoluta e $k$ é a constante de Boltzmann. Para $\mathrm{T} \cong 300 \mathrm{~K}, \mathrm{v} \cong 1,17 \mathrm{x}$ $10^{5} \mathrm{~m} / \mathrm{s}$.

Como as velocidades $\overrightarrow{\mathrm{v}}$ ocorrem em todas as direções e sentidos possíveis na ausência de um campo elétrico $(<\overrightarrow{\mathrm{v}}>=0)$, não há nenhum fluxo de cargas, ou seja, nenhuma corrente elétrica.

Para aparecer uma corrente elétrica deve haver uma força que atue sobre esses elétrons de condução. Aplicando-se uma diferença de potencial V entre as extremidades de 
uma amostra de comprimento $L_{c}$ e área de secção reta transversal A (figura 2.1), cria-se um campo elétrico $\overrightarrow{\mathrm{E}}$. Este campo adiciona ao movimento caótico dos elétrons um movimento em direção preferencial com velocidade escalar média de deriva $\mathrm{v}_{\mathrm{d}}$ (figura 2.2).

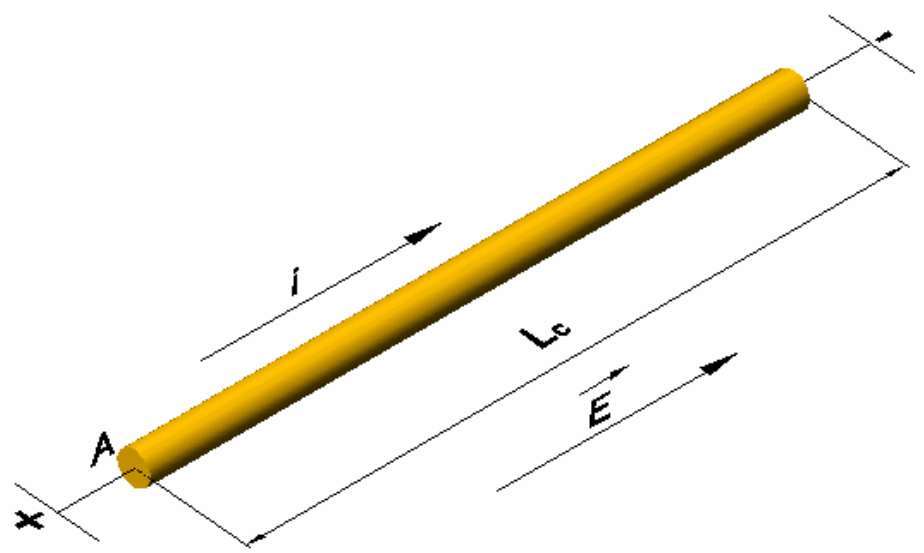

Figura 2.1 - Campo elétrico aplicado em um material bulk.
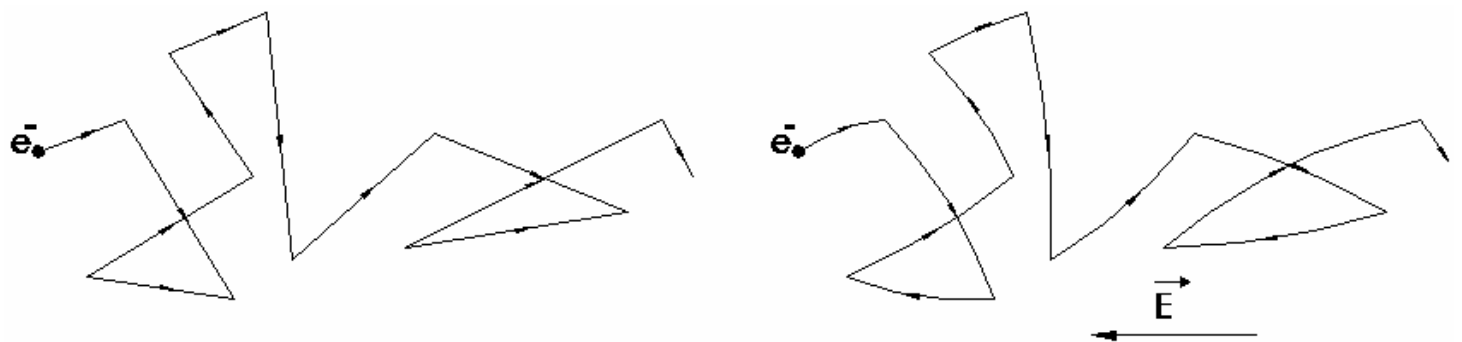

Figura 2.2 - Representação da trajetória de um elétron na presença de um campo elétrico aplicado.

A aceleração causada pelo campo elétrico aplicado é dada pela Lei de Newton:

$\mathrm{a}=\frac{\mathrm{F}}{\mathrm{m}_{\mathrm{e}}}=\frac{\mathrm{Eq}}{\mathrm{m}_{\mathrm{e}}}$

onde E q é a força gerada pelo campo elétrico aplicado, sendo q a carga do elétron.

A velocidade de migração $\mathrm{v}_{\mathrm{d}}$ dos elétrons é dada por:

$\mathrm{v}_{\mathrm{d}}=\mathrm{v}_{0}+\mathrm{at}=\frac{\mathrm{Eq}}{\mathrm{m}_{\mathrm{e}}} \tau$

onde $\tau$ é o tempo médio entre colisões sucessivas. Como as velocidades iniciais estão randomicamente distribuídas no espaço, o valor médio de $\mathrm{v}_{0}$ é nulo. 
A velocidade de migração dos elétrons é muitas ordens de grandeza menor do que a velocidade $\mathrm{v}$ entre colisões $\left(\mathrm{v}_{\mathrm{d}} \sim 10^{-4} \mathrm{~m} / \mathrm{s}\right)$.

A corrente elétrica média então estabelecida pelo campo elétrico $\overrightarrow{\mathrm{E}}$ pode ser definida como:

$\mathrm{i}=\frac{\Delta \mathrm{Q}}{\Delta \mathrm{t}}$

em que $\Delta \mathrm{Q}$ é a carga que flui através da seção A do condutor em um intervalo de tempo $\Delta \mathrm{t}$.

Para descrever o fluxo de carga utiliza-se o conceito de densidade de corrente:

$\mathrm{J}=\frac{\mathrm{i}}{\mathrm{A}}$

O número de portadores de carga é $\mathrm{n}_{\mathrm{e}} \mathrm{AL}_{\mathrm{c}}$, onde $\mathrm{n}_{\mathrm{e}}$ é o número de portadores de carga por unidade de volume. Desta maneira, a corrente elétrica que atravessa esse volume em um tempo $\Delta \mathrm{t}$, com a velocidade de migração $\mathrm{v}_{\mathrm{d}}$, pode ser escrita como:

$\mathrm{i}=\frac{\Delta \mathrm{Q}}{\Delta \mathrm{t}}=\frac{\mathrm{n}_{\mathrm{e}} \mathrm{AL}_{\mathrm{c}} \mathrm{q}}{\mathrm{L}_{\mathrm{c}} / \mathrm{v}_{\mathrm{d}}}=\mathrm{n}_{\mathrm{e}} \mathrm{Aqv}_{\mathrm{d}}$

Substituindo a Eq.(2.6) na Eq.(2.5) obtém-se a densidade de corrente em função da velocidade de deriva $\mathrm{v}_{\mathrm{d}}$ e da carga dos elétrons $\mathrm{q}$ :

$\mathrm{J}=\mathrm{n}_{\mathrm{e}} \mathrm{qv}_{\mathrm{d}}$

A relação entre a diferença de potencial aplicada $\mathrm{V}$ e o campo elétrico criado é $\mathrm{E}=$ $\mathrm{V} / \mathrm{L}_{\mathrm{c}}$. A diferença de potencial pode ser expressa considerando a resistência do condutor, segundo a Lei de Ohm:

$\mathrm{V}=\mathrm{R} . \mathrm{i}$ 
A Lei de Ohm, observada experimentalmente para materiais ôhmicos, incluindo a maioria dos metais, diz que a densidade de corrente $\mathrm{J}$ é proporcional ao campo elétrico $\overrightarrow{\mathrm{E}}$ aplicado e também pode ser escrita como:

$E=\rho J$

onde $\rho$ é a resistividade elétrica.

Resolvendo-se a expressão anterior para a resistividade obtém-se:

$\rho=\frac{E}{J}=\frac{V}{L_{c}} \frac{A}{i} \Leftrightarrow \rho=R \frac{A}{L_{c}}$

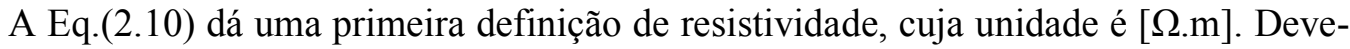
se notar que esta grandeza pode ser calculada com facilidade a partir das dimensões do material e do valor de resistência entre extremidades, medido por um multímetro.

Combinando-se agora a Eq.(2.9) com as Eqs.(2.7) e (2.3) obtém-se uma definição de resistividade em um contexto microscópico:

$\rho=\frac{m_{e}}{n_{e} q^{2} \tau}$

Esta definição mostra que a resistividade é uma propriedade intrínseca e constante dos materiais ôhmicos na forma de bulk, pois não depende da geometria do material e nem do campo elétrico $\overrightarrow{\mathrm{E}}$, não dependendo portanto da presença de corrente elétrica.

A condutividade $\sigma$ é definida como o inverso da resistividade:

$\sigma=\frac{1}{\rho}=\frac{\mathrm{n}_{\mathrm{e}} \mathrm{e}^{2} \tau}{\mathrm{m}_{\mathrm{e}}}$

Pode-se ainda relacionar a velocidade térmica média $\overline{\mathrm{v}}$ e o tempo livre médio entre colisões sucessivas $\tau$ pela relação: 
$\tau=\frac{\ell_{0}}{\overline{\mathrm{V}}}$

onde $\ell_{0}$ é o livre caminho médio entre duas colisões.

Usando-se as Eqs.(2.1) e (2.13) na Eq.(2.11) a resistividade é dada ainda por:

$\rho=\frac{\left(3 k \mathrm{~T} / \mathrm{m}_{\mathrm{e}}\right)^{1 / 2}}{\mathrm{n}_{\mathrm{e}} \mathrm{q}^{2} \ell_{0}}$

Embora a Eq.(2.14) mostre que a resistividade elétrica é proporcional a $\mathrm{T}^{1 / 2}$, experimentalmente é constatado que, para metais, a resistividade aumenta linearmente com a elevação da temperatura, para uma ampla faixa de temperaturas. Quando $\mathrm{T} \rightarrow 0$ verifica-se que a resistividade tende a um valor finito $\rho_{0}$.

Nesse modelo a origem da resistividade elétrica é explicada pelas colisões dos elétrons com imperfeições e com os íons da rede cristalina, os quais vibram em torno de suas posições, devido à energia térmica. As sucessivas colisões geram uma força de resistência ao movimento dos portadores de carga com a velocidade de migração $\mathrm{v}_{\mathrm{d}}$.

\subsection{Modelo de bandas de energia}

Para determinar os níveis de energia dos elétrons em um sólido, deve-se primeiramente entender o que ocorre com os níveis de energia dos elétrons nos átomos quando estes são unidos formando um sólido.

Os estados de energia dos elétrons nos átomos são representados por quatro números quânticos. O número quântico principal $n(n=1,2,3, \ldots)$ representa a energia do elétron. $\mathrm{O}$ segundo número quântico $l$ está ligado ao momento angular orbital dos elétrons e assume valores $l=0,1, \ldots, n$-1. Os estados de energia são representados por símbolos que utilizam os valores de $n$ e $l$. Assim, para $l=0$ tem-se o estado $s$, para $l=1$ estado $p$, para $l=2$ estado $d$ e para $l=3$ estado $f$.

O terceiro número quântico $m$ diz respeito às projeções do vetor momento angular $l$ em relação ao eixo z (ou campo magnético externo). O número $m$ assume valores $m=-l,-l$ $+1, \ldots, 0, \ldots, l-1, l$. O quarto número quântico $s_{z}$ está relacionado com o spin dos elétrons. Pelo 
princípio de exclusão de Pauli, cada estado pode ser preenchido apenas com dois elétrons que têm spin opostos $\left(s_{z}= \pm 1 / 2\right)$.

Como exemplo, as distribuições dos 79 elétrons do $\mathrm{Au}$ (ouro) e dos 78 elétrons da $\mathrm{Pt}$ (platina) são mostradas na tabela 2.1. Deve-se notar que os átomos destes dois metais possuem um elétron de valência no subnível de energia $6 s$. Como será visto a seguir, os elétrons de valência $(6 s)$ são os que têm maior chance de adquirir a energia necessária para participar do processo de condução.

Tabela 2.1 - Distribuição eletrônica do Au e Pt.

\begin{tabular}{|l|l|l|l|l|l|l|l|l|l|l|l|l|l|l|l|l|l|}
\hline $\boldsymbol{n}$ & $\mathbf{( 1 )}$ & \multicolumn{2}{|c|}{$(\mathbf{2})$} & \multicolumn{3}{|c|}{$\mathbf{( 3 )}$} & \multicolumn{4}{|c|}{$\mathbf{( 4 )}$} & \multicolumn{4}{|c|}{$\mathbf{( 5 )}$} & \multicolumn{3}{|c|}{$(\mathbf{6 )}$} \\
\hline $\boldsymbol{l}$ & $\mathbf{1 s}$ & $\mathbf{2 s}$ & $\mathbf{2 p}$ & $\mathbf{3 s}$ & $\mathbf{3 p}$ & $\mathbf{3 d}$ & $\mathbf{4 s}$ & $\mathbf{4 p}$ & $\mathbf{4 d}$ & $\mathbf{4 f}$ & $\mathbf{5 s}$ & $\mathbf{5 p}$ & $\mathbf{5 d}$ & $\mathbf{5 f}$ & $\mathbf{6 s}$ & $\mathbf{6 p}$ & $\mathbf{6 d}$ \\
\hline elétrons Au & 2 & 2 & 6 & 2 & 6 & 10 & 2 & 6 & 10 & 14 & 2 & 6 & 10 & 0 & 1 & 0 & 0 \\
\hline elétrons Pt & 2 & 2 & 6 & 2 & 6 & 10 & 2 & 6 & 10 & 14 & 2 & 6 & 9 & 0 & 1 & 0 & 0 \\
\hline
\end{tabular}

As bandas de energia são o resultado da interação destes níveis de energia dos elétrons nos átomos quando estes estão reunidos para formar um sólido $\left(\sim 10^{28}\right.$ átomos $\left./ \mathrm{m}^{3}\right)$. As bandas eletrônicas nos sólidos usam a mesma nomenclatura, sendo que da mesma forma que existe o subnível de energia $2 p$ existe também a banda $2 p$.

Se um sólido contém $N$ átomos, cada uma das bandas de energia contém $N$ níveis de energia. Há uma quantização de energia, mas como estes níveis estão muito próximos, uma vez que $N$ é muito grande, formam praticamente bandas contínuas de energia.

Os níveis de energia que estão totalmente preenchidos resultam em bandas cheias. Estas bandas cheias são chamadas de "bandas de valência". Um nível cujo momento angular dos elétrons é $l$ pode ter $2(2 l+1)$ elétrons. $O$ fator 2 vem da possibilidade de 2 orientações de spin do elétron enquanto que o fator $2 l+1$ corresponde ao número de possíveis orientações $m$ do momento angular orbital $l$. Então, as bandas $1 s$ e $2 s$ contém $2 N$ elétrons $(l=0)$, enquanto que a banda $2 p$ tem $6 N$ elétrons $(l=1)$.

Para o exemplo do ouro e da platina, o subnível $6 s$, de maior energia, é uma banda que não está totalmente preenchida. Deveria ter $2 N$ elétrons mas contém somente $N$ elétrons. A metade vazia da banda é chamada de "banda de condução" (figura 2.3). 


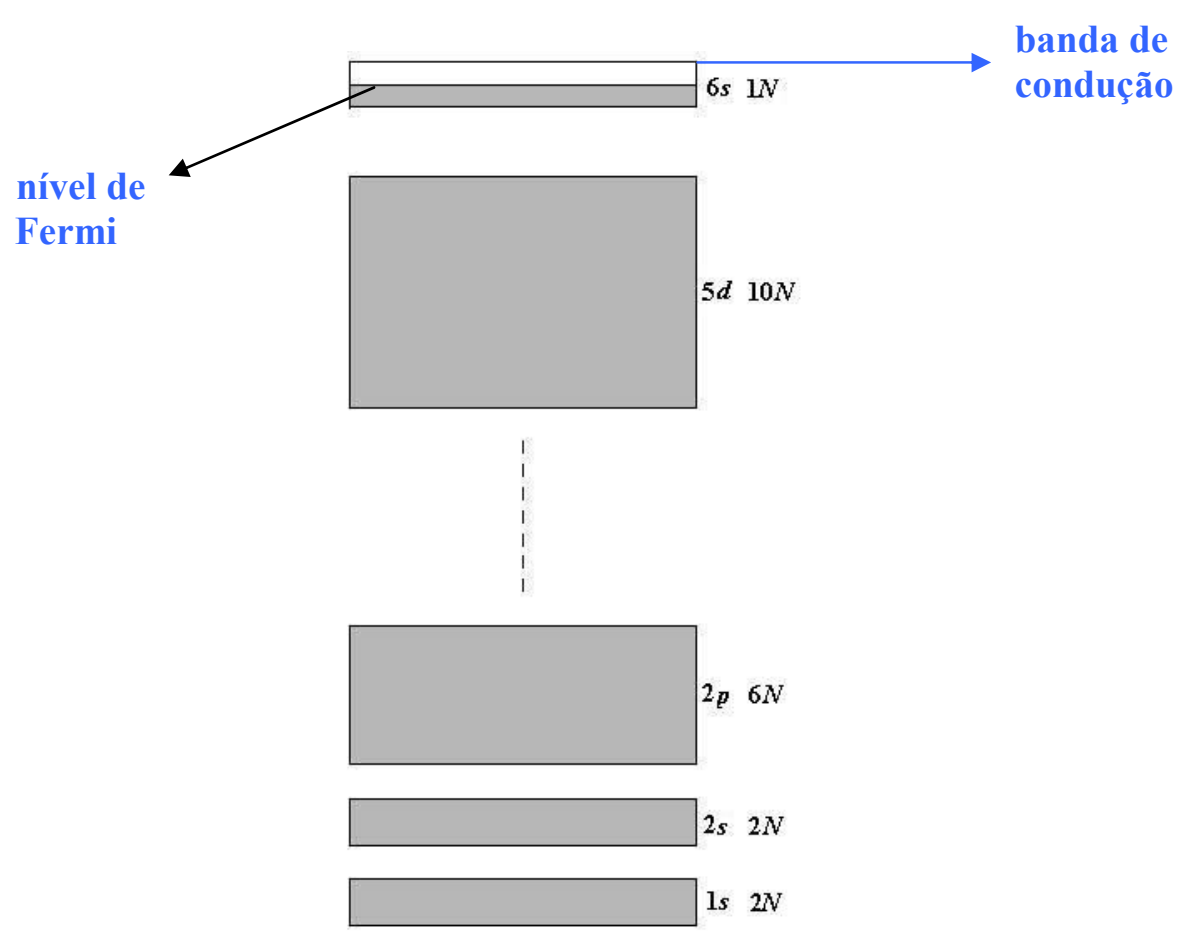

Figura 2.3 - Esquema de bandas de energia para o Au.

A "teoria quântica dos elétrons livres nos metais" [37, 38] admite que os elétrons de valência não estão firmemente ligados aos átomos, mas têm liberdade de se deslocar pelo metal confinados dentro de uma caixa cúbica com volume $L^{3}$. Estes elétrons são representados por funções de onda que são obtidas resolvendo a equação de Schrödinger que dá os seguintes valores para a energia $\mathrm{E}$ dos elétrons:

$\mathrm{E}=\frac{\hbar \pi^{2}}{2 \mathrm{~m}_{\mathrm{e}} L^{2}}\left(\mathrm{n}_{\mathrm{x}}^{2}+\mathrm{n}_{\mathrm{y}}^{2}+\mathrm{n}_{\mathrm{z}}^{2}\right)$

onde $\mathrm{n}_{\mathrm{x}}, \mathrm{n}_{\mathrm{y}}$ e $\mathrm{n}_{\mathrm{z}}$ são os números quânticos que assumem valores $\mathrm{n}_{\mathrm{x}}, \mathrm{n}_{\mathrm{y}}, \mathrm{n}_{\mathrm{z}}=0,1,2,3 \ldots$ e $\hbar=$ $h / 2 \pi$, em que $h$ é a constante de Planck.

Essa expressão mostra que os níveis de energia são quantizados e que cada nível de energia, ou estado de energia, é caracterizado por este conjunto de três números quânticos, um para cada grau de liberdade $(\mathrm{x}, \mathrm{y}, \mathrm{z})$. Assim, o valor dos degraus de energia $\Delta \mathrm{E}$ entre níveis adjacentes pode portanto ser aproximado por: 


$$
\Delta \mathrm{E} \cong \frac{\hbar \pi^{2}}{2 \mathrm{~m}_{\mathrm{e}} L^{2}}
$$

Para tratar o conjunto de elétrons de um metal adota-se a estatística de Fermi-Dirac, em que a probabilidade de se encontrar um elétron em um certo nível de energia $\mathrm{E}$ é dado por:

$$
\mathrm{f}(\mathrm{E})=\frac{1}{\exp \left(\frac{\mathrm{E}-\mathrm{E}_{\mathrm{F}}}{k \mathrm{~T}}\right)+1}
$$

onde $\mathrm{E}_{\mathrm{F}}$ é a energia de Fermi, a qual será mostrada a seguir.

Se o nível de energia $E$ é completamente ocupado por elétrons, $\mathrm{f}(\mathrm{E})=1$; para um nível de energia vazio $f(E)=0$. Para temperaturas maiores do que zero Kelvin (mesmo milhares de Kelvin), quando $E=E_{F}, f(E)=1 / 2$ (figura 2.4). Apenas uma pequena fração de níveis com energias mais elevadas do que a energia de Fermi está ocupada. Da mesma forma uma pequena fração de níveis abaixo da energia de Fermi fica vazia.

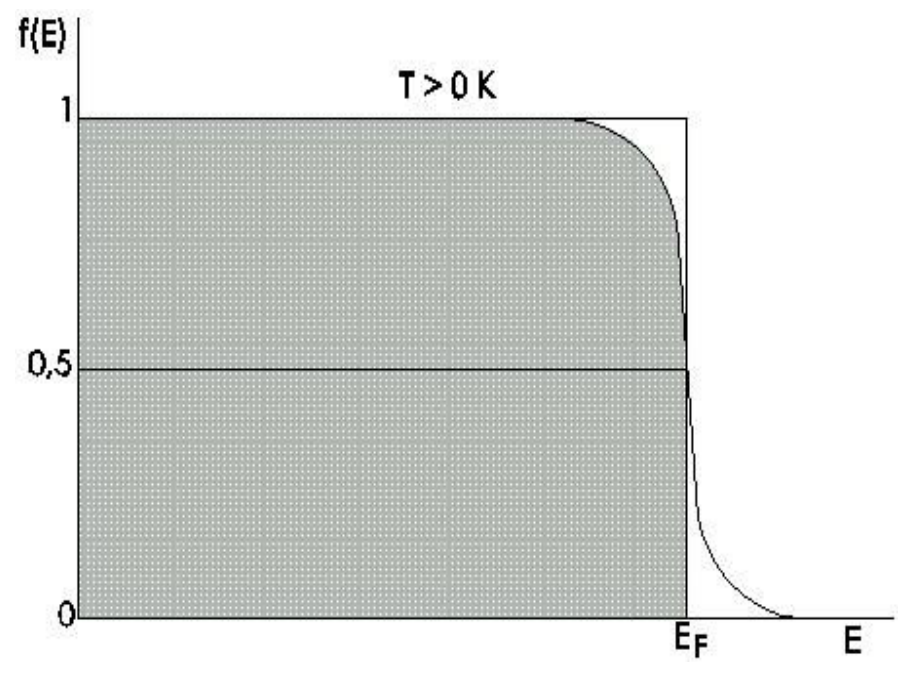

Figura 2.4 - Gráfico da função de distribuição de Fermi.

A densidade de estados, ou o número de estados de energia permitidos por unidade de volume $\mathrm{g}(\mathrm{E})$, com energias entre $\mathrm{E}$ e $\mathrm{E}+\mathrm{dE}$, pode ser calculado considerando os números quânticos da Eq. (2.15) como variáveis contínuas, no limite $L>>1$, obtendo-se:

$\mathrm{g}(\mathrm{E}) \mathrm{dE}=\mathrm{CE}^{1 / 2} \mathrm{dE}$ 
onde $\mathrm{C}=\frac{8 \sqrt{2} \pi \mathrm{m}_{\mathrm{e}}^{3 / 2}}{\hbar^{3}}$

Portanto, o número de elétrons por unidade de volume $\mathrm{N}_{\mathrm{e}}$, com energia entre $\mathrm{E}$ e $\mathrm{dE}$, é igual ao do produto do número de estados permitidos por unidade de volume $\mathrm{g}(\mathrm{E})$ pela probabilidade de se encontrar um elétron em um dado estado de energia $\mathrm{f}(\mathrm{E})$, resultando em:

$$
\mathrm{N}_{\mathrm{e}}(\mathrm{E}) \mathrm{dE}=\mathrm{C} \frac{\mathrm{E}^{1 / 2} \mathrm{dE}}{\exp \left(\frac{\mathrm{E}-\mathrm{E}_{\mathrm{F}}}{k \mathrm{~T}}\right)+1}
$$

Para se calcular o número total de elétrons $\mathrm{n}_{\mathrm{e}}$ por unidade de volume, com energia de 0 até a energia de Fermi $\mathrm{E}_{\mathrm{F}}$, basta integrar a função anterior entre estes valores, lembrando-se que $f(E)$ para $E_{F}$ é igual a $1 / 2$ :

$\mathrm{n}_{\mathrm{e}}=\mathrm{C} \int_{0}^{\mathrm{E}_{\mathrm{F}}} \mathrm{E}^{1 / 2} \mathrm{dE} \rightarrow \mathrm{n}_{\mathrm{e}}=\frac{8 \sqrt{2} \pi \mathrm{m}_{\mathrm{e}}^{3 / 2}}{\hbar^{3}} \mathrm{E}_{\mathrm{F}}^{3 / 2}$

Isolando-se na Eq.(2.20) a energia de Fermi $E_{F}$, obtém-se:

$$
\mathrm{E}_{\mathrm{F}}=\frac{h^{2}}{2 \mathrm{~m}_{\mathrm{e}}}\left(\frac{3 \mathrm{n}_{\mathrm{e}}}{8 \pi}\right)^{2 / 3}
$$

A expressão anterior mostra que a energia de Fermi está diretamente relacionada ao número de elétrons da banda de valência do condutor. Assim, quando é aplicado um campo elétrico $\vec{E}$, os elétrons com energias vizinhas da energia de Fermi só precisam de uma pequena quantidade de energia adicional, proveniente do campo elétrico, para atingir os estados de energia vizinhos vazios, permitindo sua mobilidade.

Assim, os elétrons com energias muito próximas do nível de Fermi deslocam-se na banda de condução com velocidade próxima a $\mathrm{V}_{\mathrm{F}}$ (devido à aplicação do campo elétrico), dada por: 


$$
\mathrm{v}_{\mathrm{F}}=\left(\frac{2 \mathrm{E}_{\mathrm{F}}}{\mathrm{m}_{\mathrm{e}}}\right)^{\frac{1}{2}}
$$

Fazendo-se os cálculos segundo as Eqs.(2.21) e (2.22) para o ouro e para a platina, usando suas densidades eletrônicas correspondentes, são obtidos os seguintes valores:

Tabela 2.2 -Valores relacionados à energia de Fermi para Au e Pt.

\begin{tabular}{|c|c|c|c|}
\hline Metal & Número de elétrons $\mathbf{n}_{\mathbf{e}}$ & Energia de Fermi $\mathbf{E}_{\mathbf{F}}$ & ${\text { Velocidade de Fermi } \mathbf{v}_{\mathbf{F}}}^{\mathrm{Au}}$ \\
\hline $\mathrm{Pt}$ & $6,9 \times 10^{28} \mathrm{e}^{-} / \mathrm{m}^{3}$ & $5,49 \mathrm{eV}$ & $1,39 \times 10^{6} \mathrm{~m} / \mathrm{s}$ \\
\hline $\mathrm{e}^{-} / \mathrm{m}^{3}$ & $5,93 \mathrm{eV}$ & $1,44 \times 10^{6} \mathrm{~m} / \mathrm{s}$ \\
\hline
\end{tabular}

Pode-se observar pela tabela 2.2 que a velocidade $\mathrm{v}_{\mathrm{F}}$ obtida pelo modelo de bandas de energia tem a mesma ordem de grandeza da velocidade térmica média $\mathrm{v}=1,17 \times 10^{5} \mathrm{~m} / \mathrm{s}$, dada pela distribuição de Maxwell-Boltzmann.

Toda essa teoria brevemente revisada mostra conceitos básicos para o entendimento do processo de resistividade elétrica de materiais condutores na forma de bulk, onde os efeitos de superfície são desprezíveis.

\subsection{Condução elétrica em filmes finos metálicos}

A resistividade elétrica de filmes finos metálicos não pode ser determinada apenas pela resistividade de bulk do material. No caso de um filme fino policristalino, a principal contribuição para a condutividade elétrica é devido ao espalhamento gerado pela rugosidade da superfície [15 - 16].

Uma secção de um filme fino é mostrada na figura 2.5. O filme tem área $\mathrm{S}^{2}$ no plano $(\mathrm{x}, \mathrm{y})$ e $\mathrm{z}$ é o eixo perpendicular ao plano. A sua espessura é $\mathrm{d}$, tal que $-\mathrm{d} / 2 \leqslant \mathrm{z} \leqslant \mathrm{d} / 2$. A superfície do filme fino pode ser modelada por:

$$
z(x, y)= \pm \frac{d}{2}+h(x, y)
$$

onde $\mathrm{h}(\mathrm{x}, \mathrm{y})$ é a flutuação nas alturas da superfície do filme. 


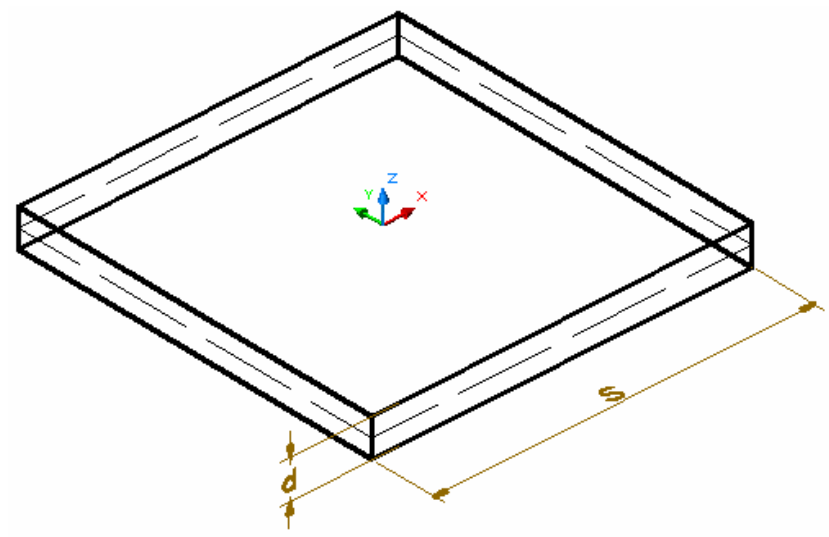

Figura 2.5 - Secção de um filme fino.

Será considerada aqui uma superfície isotrópica, onde r é o módulo do vetor posição $\vec{r}=x \vec{i}+y \vec{j}$ no plano (x,y) definido pela superfície do filme. Ou seja:

$h(x, y)=h(r)$

onde $r=\left(x^{2}+y^{2}\right)^{1 / 2}$.

Como exposto anteriormente, no material em forma de bulk, a banda de condução é constituída por níveis contínuos de energia. Já em um filme fino a situação é distinta. Devido a uma quantização ao longo do eixo da espessura (z), a energia dos elétrons assume os seguintes valores de energia [39]:

$\mathrm{E}_{v}=\frac{\pi^{2} \hbar^{2} v^{2}}{2 \mathrm{~m}_{\mathrm{e}} \mathrm{d}^{2}}$

onde os números quânticos $v=1,2, \ldots \mathrm{N}$ caracterizam os níveis das " $\mathrm{N}$ subbandas de Fermi".

Desse modo, a energia total dos elétrons $\mathrm{E}_{\overrightarrow{\mathrm{k}} \mathrm{v}}$ é agora dada por:

$\mathrm{E}_{\overrightarrow{\mathrm{k} v}}=\frac{\hbar^{2} \overrightarrow{\mathrm{k}}^{2}}{2 \mathrm{~m}_{\mathrm{e}}}+\mathrm{E}_{v}$ 
onde $\frac{\hbar^{2} \overrightarrow{\mathrm{k}}^{2}}{2 \mathrm{~m}_{\mathrm{e}}}$ é a energia cinética de translação $\mathrm{E}_{\overrightarrow{\mathrm{k}}}$ dos elétrons no plano $\mathrm{x}, \mathrm{y}$, sendo $\overrightarrow{\mathrm{k}}$ o número de onda correspondente aos elétrons de condução $\left(\overrightarrow{\mathrm{k}}=\overrightarrow{\mathrm{k}}_{\mathrm{x}}+\overrightarrow{\mathrm{k}}_{\mathrm{y}}\right)$.

O máximo valor possível para $v$ é $\mathrm{N}$ dado por $\mathrm{E}_{\mathrm{N}} \cong \mathrm{E}_{\mathrm{F}}$, ou seja:

$\mathrm{E}_{\mathrm{F}} \cong \frac{\pi^{2} \hbar^{2}}{2 \mathrm{~m}_{\mathrm{e}} \mathrm{d}^{2}} \mathrm{~N}^{2}$

Portanto, para a energia de Fermi $\mathrm{E}_{\mathrm{F}}$, dada pela Eq.(2.21), obtém-se o seguinte valor máximo N:

$\mathrm{N} \cong \mathrm{d}\left(\frac{3 \mathrm{n}_{\mathrm{e}}}{\pi}\right)^{1 / 3}$

onde $\mathrm{N}$ deve ser um número inteiro pequeno.

Assim para os elétrons de condução, que estão com a energia máxima $\mathrm{E}_{\mathrm{F}}$, vale a relação:

$\mathrm{E}_{\mathrm{F}}=\frac{\hbar^{2} \overrightarrow{\mathrm{k}}^{2}}{2 \mathrm{~m}_{\mathrm{e}}}+\mathrm{E}_{v}$

Note que quando $\mathrm{d} \rightarrow \infty, \mathrm{E}_{\mathrm{v}}=\frac{\hbar^{2} \overrightarrow{\mathrm{k}}_{\mathrm{z}}{ }^{2}}{2 \mathrm{~m}_{\mathrm{e}}}$, que dá a energia cinética dos elétrons ao longo do eixo z e, conseqüentemente,

$\mathrm{E}=\frac{\hbar^{2}\left(\overrightarrow{\mathrm{k}}_{\mathrm{x}}^{2}+\overrightarrow{\mathrm{k}}_{\mathrm{y}}^{2}+\overrightarrow{\mathrm{k}}_{\mathrm{z}}^{2}\right)}{2 \mathrm{~m}_{\mathrm{e}}}$

Como já dito, a teoria da mecânica quântica é necessária para tratar a resistividade elétrica $(\rho)$ em materiais na forma de filmes finos quando ocorrem as seguintes condições:

a) A espessura do filme (d) é menor ou da ordem de grandeza do caminho livre médio dos elétrons de condução $\left(\ell_{0}\right)$; 
b) Há quantização acentuada dos níveis de energia ao longo do eixo de espessura do filme para pequenos valores de $\mathrm{N}$. Quando $\mathrm{N}>$ 1, os efeitos quânticos tornam-se muito pequenos.

A tabela 2.3 mostra as duas condições expostas acima satisfeitas para o ouro e platina, sendo portanto esperados efeitos quânticos na resistividade elétrica para filmes finos destes metais $[17,18]$ nos intervalos de espessuras citados.

Tabela 2.3 - Condições para efeitos quânticos em filmes finos para Pt e Au.

\begin{tabular}{|l|c|c|c|c|}
\hline \multirow{2}{*}{ Metal } & \multicolumn{3}{|c|}{ Condições para efeitos quânticos } \\
\cline { 2 - 5 } & \multicolumn{2}{|c|}{ Condição a) } & \multicolumn{2}{c|}{ Condição b) } \\
\cline { 2 - 5 } & $\mathrm{d}(\mathrm{nm})$ & $\ell_{0}(\mathrm{~nm})$ & $\mathrm{n}_{\mathrm{e}}\left(\mathrm{m}^{-3}\right)$ & $\mathrm{N}$ \\
\hline Pt & $1,3 \leq \mathrm{d} \leq 11,7$ & $\sim 10$ & $6,6 \times 10^{28}$ & $5<\mathrm{N}<47$ \\
\hline Au & $1,8 \leq \mathrm{d} \leq 10,5$ & $\sim 50$ & $5,9 \times 10^{28}$ & $7<\mathrm{N}<41$ \\
\hline
\end{tabular}

Uma vez satisfeitas as condições quânticas, a morfologia tem papel fundamental na resistividade do filme fino, como será visto no desenvolvimento a seguir. Nos exemplos de $\mathrm{Au}$ e Pt estudados os comprimentos de onda de Fermi são 0,52 nm e 0,50 nm, respectivamente, e os valores de rugosidade estão na faixa de $0,3 \mathrm{~nm}<\Delta<0,7 \mathrm{~nm}[13,15]$.

A condução elétrica ocorre através do processo de espalhamento. O espalhamento eletrônico é gerado por um potencial perturbativo $\mathrm{U}(\mathrm{x}, \mathrm{y})$ o qual se dá devido às flutuações de altura das superfícies do filme, de acordo com a expressão [39]:

$\mathrm{U}(\mathrm{x}, \mathrm{y}) \approx\left(\frac{\partial \mathrm{E}}{\partial \mathrm{d}}\right) \mathrm{h}(\mathrm{x}, \mathrm{y})=\frac{\pi^{2} \hbar^{2} v^{2}}{\mathrm{~m} \mathrm{~d}^{3}} \mathrm{~h}(\mathrm{x}, \mathrm{y})$

Levando-se em conta a flutuação de alturas em $\mathrm{h}(\mathrm{x}, \mathrm{y})$, através de cálculos extensos $[14,17,18]$, a seguinte expressão é obtida para condutividade elétrica de filmes finos induzida pela superfície:

$\sigma_{\mathrm{s}}(\mathrm{d}) \approx \frac{\mathrm{q}^{2}}{\hbar} \frac{\mathrm{d}^{5}}{2 \pi^{6} \Delta^{2} \xi^{2}} \frac{\pi}{\mathrm{F}(0)} \frac{6}{\mathrm{~N}(\mathrm{~N}+1)(2 \mathrm{~N}+1)} \sum_{v=1}^{\mathrm{N}} \frac{\overrightarrow{\mathrm{k}}_{v}^{2}}{v^{2}}$

em que: 
$\overrightarrow{\mathrm{k}}_{v}^{2}=\frac{2 \mathrm{~m}_{\mathrm{e}}}{\hbar^{2}}\left(\mathrm{E}_{\mathrm{F}}-\mathrm{E}_{v}\right)$

e

$\mathrm{F}(0)=\pi$ para o modelo gaussiano e $\mathrm{F}(0)=4$ para o modelo exponencial

$\Delta$ : rugosidade da superfície

$\xi$ : distância de correlação lateral da superfície

Para o caso dos metais, ou seja, quando $\mathrm{N}$ >> 1, é obtida a expressão:

$\sigma_{\mathrm{s}}(\mathrm{d}) \approx \frac{3^{-1 / 3}}{4 \pi^{2 / 3}} \frac{\mathrm{q}^{2} \mathrm{n}_{\mathrm{e}}^{-1 / 3} \mathrm{~d}^{2}}{\hbar \Delta^{2} \xi^{2} \mathrm{~F}(0)}\left[1-\frac{6}{\left(3 \mathrm{n}_{\mathrm{e}} \pi^{5}\right)^{1 / 3} \mathrm{~d}}\right]$

A Eq.(2.34) mostra que a condutividade induzida pela superfície é dependente da espessura do filme. Além disso, nos trabalhos realizados por Fishman e Calecki [17, 18], a morfologia é contabilizada através dos parâmetros morfológicos rugosidade $\Delta$ e distância de correlação lateral $\xi$. Porém, quando este modelo é confrontado com dados experimentais, os ajustes de curva exigem que as distâncias de correlação $\xi$ sejam da ordem de fração de nanometro. Esta é a mesma ordem de grandeza dos parâmetros de rede do metal. Os próprios autores admitem que não há sentido físico neste resultado.

As distâncias de correlação são parâmetros mensuráveis [13, 14, 15, 40] e para o caso de filmes de platina e ouro, para espessuras de $1 \mathrm{~nm}$ e $3 \mathrm{~nm}$, respectivamente, são $\xi_{\mathrm{Pt}}(\mathrm{d})$ $\approx 200 \mathrm{~nm} \mathrm{e} \xi_{\mathrm{Au}}(\mathrm{d}) \approx 40 \mathrm{~nm}$. Estes valores são diferentes daqueles obtidos por ajuste por Fishman e Calecki [17,18] para justificar dados experimentais. Isto mostra que o modelo proposto por eles não é totalmente satisfatório para explicar a condutividade em filmes finos de Au e Pt.

Por isso foi proposto um novo modelo por M. Cattani e M.C. Salvadori [14, 15] que considera de forma diferente os efeitos da morfologia da superfície. Neste modelo a condutividade induzida pela superfície é dada basicamente pela mesma Eq.(2.34), mas no lugar de $\xi^{2} \mathrm{~F}(0)$ aparece uma nova função $\mathrm{F}_{\mathrm{s}}$. Assim temos:

$\sigma_{\mathrm{s}}(\mathrm{d}) \approx \frac{\mathrm{q}^{2}}{\hbar} \frac{\mathrm{d}^{5}}{2 \pi^{6} \Delta^{2} \mathrm{~F}_{\mathrm{S}}} \frac{6}{\mathrm{~N}(\mathrm{~N}+1)(2 \mathrm{~N}+1)} \sum_{v=1}^{\mathrm{N}} \frac{\overrightarrow{\mathrm{k}}_{v}^{2}}{v^{2}}$ 
Do mesmo modo, para $\mathrm{N}>>1$, obtém-se [14]:

$$
\sigma_{\mathrm{s}}(\mathrm{d}) \approx \frac{3^{1 / 3}}{4 \pi^{5 / 3}} \frac{\mathrm{q}^{2}}{\hbar} \frac{\mathrm{n}_{\mathrm{e}}^{-1 / 3} \mathrm{~d}^{2}}{\Delta^{2} \mathrm{~F}_{\mathrm{S}}}\left[1-\frac{6}{\mathrm{~d}\left(3 \pi^{5} \mathrm{n}_{\mathrm{e}}\right)^{1 / 3}}\right]
$$

Assim, o termo $F_{\mathrm{s}}$ corresponde à contribuição da morfologia da superfície do filme no processo de condução. Esse termo depende de um fator de forma $g(d)$ e da distância média de interação $\ell_{\mathrm{s}}(\mathrm{d})$ de acordo com a expressão:

$\mathrm{F}_{\mathrm{s}}\left(\mathrm{g}, 1_{\mathrm{s}}\right)=\mathrm{g}(\mathrm{d}) \ell_{\mathrm{s}}(\mathrm{d})$

A nanoestrutura da superfície de filmes finos policristalinos de ouro e platina produzidos pela técnica de deposição por arco de plasma [24 - 27], que foi utilizada neste trabalho, foi bastante estudada [13, 15, 41]. Estes estudos revelaram dados morfológicos bastante detalhados que incluem rugosidade, comprimento de correlação lateral e tamanho de grão morfológico para filmes de ouro e platina. As medidas foram feitas a partir de imagens topográficas geradas por STM (Scanning Tunneling Microscopy).

A expressão que rege a rugosidade [13] em função da espessura dos filmes é dada por:

$$
\begin{aligned}
& \Delta_{\mathrm{Pt}}(\mathrm{d})=0,65 \mathrm{e}^{-0,95 \mathrm{~d}}+0,22+0,045 \mathrm{~d}^{0,68} \\
& \Delta_{\text {Au }}(\mathrm{d})=1,7 \mathrm{e}^{-0,28 \mathrm{~d}}-0,08+0,058 \mathrm{~d}^{0,72}
\end{aligned}
$$

A estrutura granular do filme fino muda com sua espessura [15, 41]. A estrutura granular é do tipo "couve-flor" [42], o que significa que grãos menores aglomeram-se em grãos maiores com o aumento da espessura.

O tamanho de grão morfológico pode ser definido como a dimensão do grão exposto na superfície do filme medida topograficamente, também através de STM. O tamanho médio dos grãos em função da espessura dos filmes de ouro e platina, para $2 \mathrm{~nm}<\mathrm{d}<45 \mathrm{~nm}$, é dada por [41]: 
$\mathrm{D}_{\mathrm{Pt}}(\mathrm{d}) \approx 15,5\left\{1-1.1 \exp \left(-0,9 \mathrm{~d}^{1,8}\right)-2,3 \exp \left[-0.001(\mathrm{~d}-45)^{2}\right]\right\}$

$\mathrm{D}_{\mathrm{Au}}(\mathrm{d}) \approx 12,8\left\{1-3 \exp \left(-0,7 \mathrm{~d}^{1,8}\right)-2,3 \exp \left[-0.001(\mathrm{~d}-40)^{2}\right]\right\}$

Através das características morfológicas apresentadas, pode-se definir o fator de forma $g(d)$, segundo a expressão [15]:

$\mathrm{g}(\mathrm{d})=\frac{1}{\mathrm{k}_{\mathrm{F}}} \sum_{\mathrm{n}}\left(\mathrm{h}_{\mathrm{n}} / \Delta\right)^{2}\left(\lambda_{\mathrm{F}} / \lambda_{\mathrm{n}}\right)^{2}$

onde $h_{n}$ e $\lambda_{n}$ correspondem a amplitudes e comprimentos de onda, respectivamente, em uma transformada de Fourier da morfologia da superfície [43, 44]:

$h(x, y)=\sum_{n} h_{n} \operatorname{sen}\left(\frac{2 \pi r}{\lambda_{n}}\right)$

No modelo proposto na referência [15] os comprimentos de onda $\lambda_{\mathrm{n}}$ são dados pelos tamanhos de grão $D_{n}$ do filme $\left(\lambda_{n} \approx D_{n}\right.$.). Somado a isso, ainda considerando que $\lambda_{n}=n \lambda_{F}$, para o ouro e platina obtemos:

$\mathrm{g}(\mathrm{d})_{\mathrm{Pt}} \approx 0,078 / \mathrm{D}_{\mathrm{Pt}}(\mathrm{d})$

$\mathrm{g}(\mathrm{d})_{\mathrm{Au}} \approx 0,0175 / \mathrm{D}_{\mathrm{Au}}(\mathrm{d})^{1,65}$

Assim, o fator g(d) leva em conta na expressão de resistividade para filmes finos os efeitos de espalhamento devido às características morfológicas do filme.

Como já dito, outro parâmetro que contribui no cálculo da resistividade é a distância média de interação $\ell_{\mathrm{s}}(\mathrm{d})$, também considerada no cálculo do espalhamento dos elétrons. Para esse parâmetro temos a expressão [14]:

$\ell_{\mathrm{s}}(\mathrm{d}) \approx \mathrm{v}_{/ /} \tau_{\mathrm{c}}$

onde 
$\mathrm{V}_{/ /}$é a velocidade paralela à superfície $(\mathrm{x}, \mathrm{y})$. Esta velocidade é definida por:

$\mathrm{v}_{/ /}^{2}=\mathrm{v}_{\mathrm{F}}^{2}-\mathrm{v}_{\mathrm{z}}^{2}$

sendo que

$\mathrm{v}_{\mathrm{F}}=\frac{\hbar}{\mathrm{m}_{\mathrm{e}}}\left(3 \pi^{2} \mathrm{n}_{\mathrm{e}}\right)^{1 / 3}$

e

$$
\mathrm{v}_{\mathrm{z}}=\frac{\pi \hbar \mathrm{v}}{\mathrm{m}_{\mathrm{e}} \mathrm{d}}
$$

O tempo de colisão, que corresponde ao intervalo de tempo que um elétron leva para colidir com a superfície, é dado por:

$\tau_{\mathrm{c}} \approx \mathrm{d} / \mathrm{v}_{\mathrm{z}}$

Desta maneira, $\ell_{\mathrm{s}}(\mathrm{d})$ é dada por:

$\ell_{\mathrm{s}}(\mathrm{d})=<\frac{\mathrm{v}_{/ 1}}{\mathrm{v}_{\mathrm{z}}}>\mathrm{d}=\left(\frac{\pi}{3 \mathrm{n}_{\mathrm{e}}}\right)^{1 / 3} \sum_{v}\left[\left(\frac{3 \mathrm{n}_{\mathrm{e}}}{\pi}\right)^{2 / 3}\left(\frac{\mathrm{d}}{v}\right)^{2}-1\right]^{1 / 2}$,

havendo uma dependência praticamente linear entre $\ell_{\mathrm{s}}$ e d.

Com este modelo, as resistividades de Pt e $\mathrm{Au}$, para filmes com espessuras entre $1 \mathrm{e}$ $10 \mathrm{~nm}$, foram calculadas mostrando excelente acordo com os dados experimentais [13, 14]. Assim, a contribuição da morfologia, sendo levada em conta através do fator de forma $g(d)$ e distância efetiva de interação $\ell_{\mathrm{s}}(\mathrm{d})$, mostrou-se mais adequada.

Finalizando, a resistividade total do filme fino $\rho(d)$ é dada pela soma [14]: 
$\rho(d)=\rho_{\text {bulk }}+\rho_{s}(d)$

onde

$\rho_{\text {bulk }}$ é a contribuição devido ao comportamento de bulk do material e

$\rho_{\mathrm{s}}(\mathrm{d})$ é a resistividade induzida pela superfície em função da espessura do filme

A razão $\rho(d) / \rho_{\text {bulk }}$ é dada por [14]:

$\frac{\rho(d)}{\rho_{\text {bulk }}}=1+\frac{C \Delta^{2}(d) g(d) \ell_{s}(d)}{d^{2}(1-0,15 / d)}$,

onde $\mathrm{C}$ é um parâmetro que depende de constantes fundamentais e da propriedade de bulk do condutor. No caso da platina, $\mathrm{C}_{\mathrm{Pt}}=6,261 \times 10^{3} \mathrm{~nm}^{-2}$ e no caso do ouro $\mathrm{C}_{\mathrm{Au}}=28,072 \times 10^{3}$ $\mathrm{nm}^{-2}$.

Espera-se também que, quando ocorrem efeitos quânticos, a condutividade seja regida pela seguinte expressão [17]:

$\rho(\mathrm{d}) \sim \frac{1}{\mathrm{~d}^{a}}$

onde $a$ é um parâmetro empírico que será $a \sim 1$ para casos semi-clássicos e $a>1$ para casos quânticos.

$\mathrm{Na}$ referência [13], com dados experimentais para filmes de platina $(1,31 \mathrm{~nm} \leqslant \mathrm{~d} \leqslant$ $11,66 \mathrm{~nm})$ e para filmes de ouro $(1,8 \mathrm{~nm} \leq \mathrm{d} \leq 10,5 \mathrm{~nm})$, a relação exponencial foi verificada. Para filmes de platina com $\mathrm{d}<2 \mathrm{~nm}$, foi determinado $a=2,9$, e para filmes de ouro com $\mathrm{d}<3$ $\mathrm{nm}, a=5,3$.

Uma vez que a morfologia é fortemente influente na resistividade de filmes ultrafinos, é proposta neste trabalho a fabricação de um nanocomponente em que a superfície de um filme fino condutor é nanofabricada com anisotropia. Espera-se portanto que seja gerada anisotropia no efeito de resistividade elétrica, baseado no modelo teórico apresentado e nos resultados experimentais que o comprovam [13 - 16]. 


\section{CAPÍTULO III MATERIAIS E MÉTODOS}

Neste capítulo serão descritos em detalhes todos os processos envolvidos na preparação dos dispositivos utilizados nos experimentos de anisotropia de resistividade elétrica, além dos equipamentos e técnicas empregados no desenvolvimento, utilização e caracterização destes dispositivos.

\subsection{Microscópio eletrônico de varredura (MEV)}

O Microscópio Eletrônico de Varredura Jeol 6460LV, instalado no Laboratório de Filmes Finos do IFUSP (figura 3.1a), possui as características [45] listadas na tabela 3.1:

Tabela 3.1 - Principais características do Jeol 6460-LV e acessórios.

\begin{tabular}{|c|c|}
\hline MEV Jeol 6460LV & Características \\
\hline Aumentos & $8 \mathrm{x}$ a $300.000 \mathrm{x}$ \\
\hline Corrente do feixe & $\sim 1 \mathrm{pA}$ a $1 \mu \mathrm{A}$ \\
\hline Resolução & $3 \mathrm{~nm}$ (alto vácuo) e 4 nm (baixo vácuo) \\
\hline Detectores & elétrons secundários e elétrons retroespalhados \\
\hline Alto Vácuo & $0,1 \mathrm{mPa}\left(1 \times 10^{-6} \mathrm{mbar}\right)$ \\
\hline Baixo Vácuo & 10 a $270 \mathrm{~Pa}(0,1$ a 2,7 mbar $)$ \\
\hline Acessórios & \\
\hline Microanálise química EDS & $\begin{array}{l}\text { - detecção de elementos a partir do boro } \\
\text { - resolução de } 132 \mathrm{eV}\end{array}$ \\
\hline Sistema de nanolitografia & $\begin{array}{l}\text { - velocidade de escrita - } 100 \mathrm{kHz} \\
\text { - interruptor de feixe (acionamento em } 1 \mu \mathrm{s} \text { ) } \\
\text { - campo máximo de transferência ( } 5 \text { a } 10 \mathrm{~mm} \text { ) }\end{array}$ \\
\hline
\end{tabular}

Dentro da coluna em alto vácuo (figura 3.1b), os elétrons são gerados a partir de um catodo termiônico de tungstênio e acelerados em direção ao sistema óptico-eletrônico, formado de bobinas eletromagnéticas, por uma diferença de potencial entre catodo e anodo de $0,3 \mathrm{kV}$ a $30 \mathrm{kV}$. O feixe gerado pelo canhão de elétrons passa por lentes alinhadoras e posteriormente por lentes condensadoras que reduzem o seu diâmetro. Bobinas de deslocamento corrigem o posicionamento do feixe de elétrons em x,y e também o 
astigmatismo é corrigido por bobinas específicas. As lentes objetivas focalizam o feixe sobre a superfície da amostra, montada em um estágio motorizado. Acima da lente objetiva existem dois estágios de bobinas eletromagnéticas responsáveis pela varredura do feixe sobre a amostra.
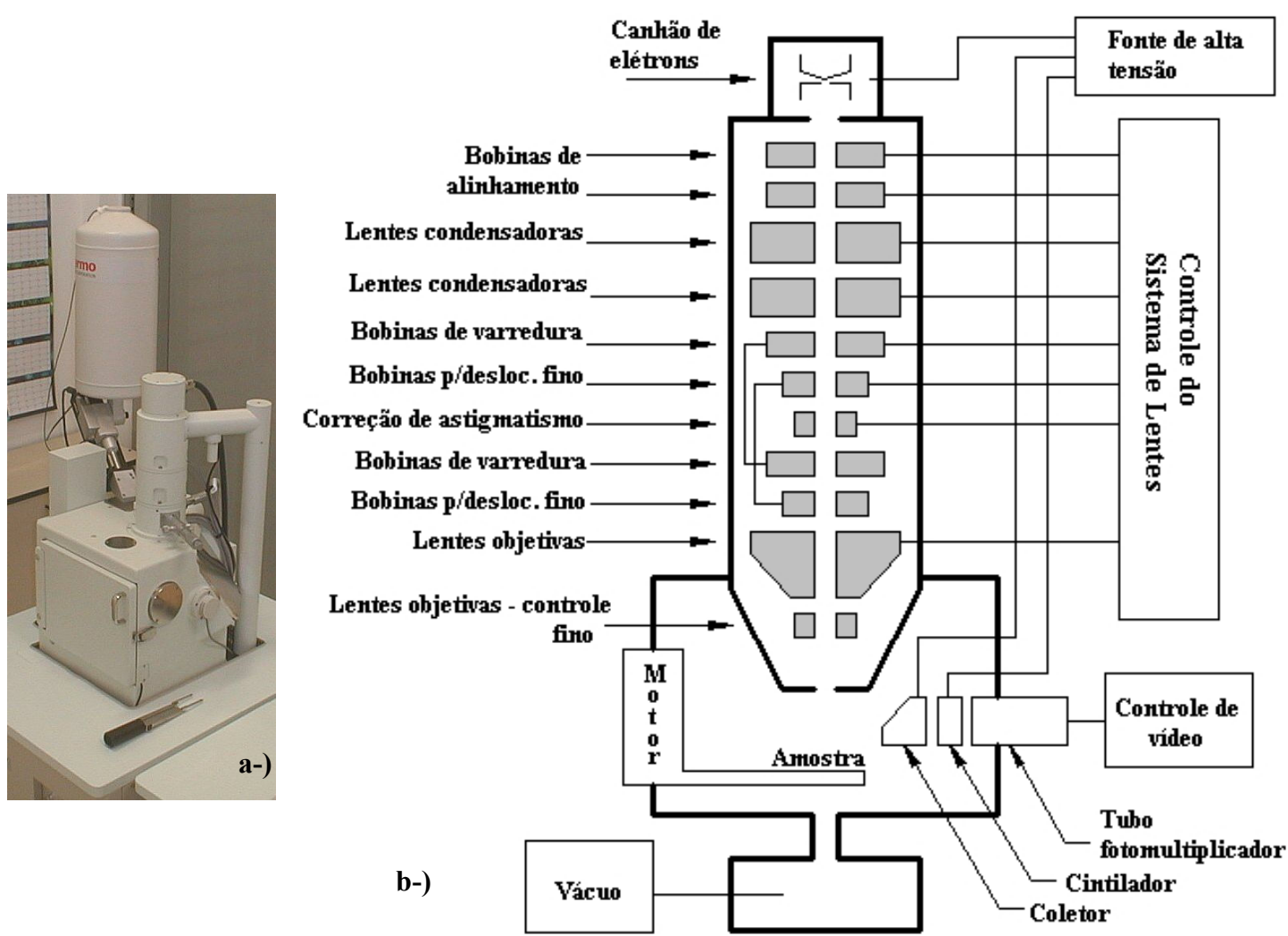

Figura 3.1 - a-) Microscópio Jeol 6460 LV e b-) Esquema da coluna óptico-eletrônica.

O feixe interage com a região de incidência na amostra até uma profundidade da ordem de um a poucos micrometros [46], dependendo do tipo de material da amostra e também da energia dos elétrons. Na figura 3.2 são mostrados exemplos de volumes de interação gerados a partir de simulações de Monte Carlo para dois diferentes tipos de materiais $(\mathrm{C}$ e $\mathrm{Au})$ e energias diferentes dos elétrons do feixe $(15 \mathrm{kV}$ e $30 \mathrm{kV})$.

Percebe-se que para o elemento mais leve, ou de número atômico menor, o feixe interage até uma profundidade maior e que, para os dois materiais, quanto maior a energia do feixe, maior a profundidade de interação. $O$ volume de interação formado pelo feixe na amostra pode ser dividido de acordo com os sinais gerados, como apontado na figura $2 \mathrm{c}$. 


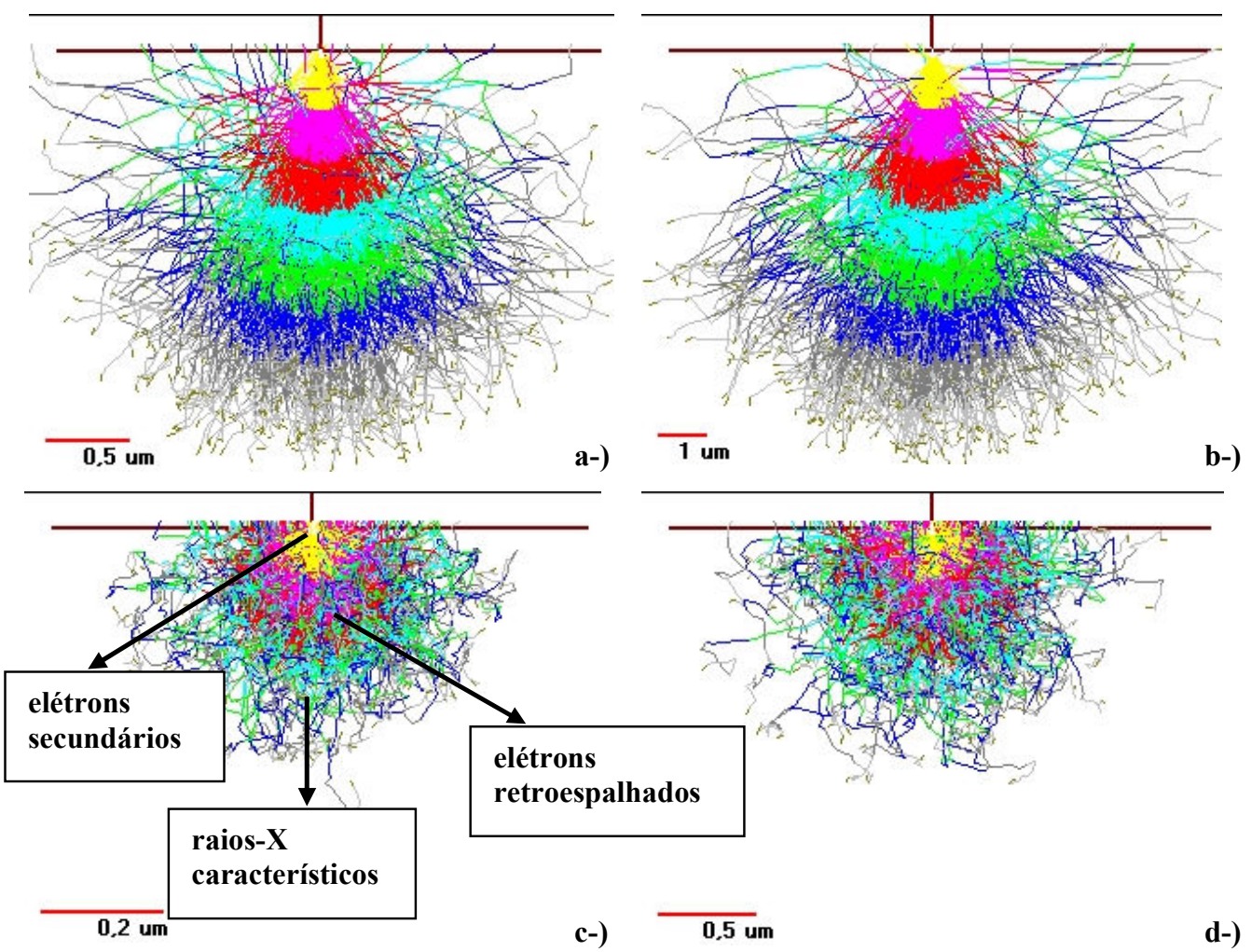

Figura 3.2 - Volumes de interação entre o feixe de elétrons e a amostra para a-) Carbono 15 kV b-) Carbono 30 kV c-) Ouro 15kV d-) Ouro 30kV.

Para a formação da imagem são detectados os elétrons secundários ou retroespalhados. $\mathrm{O}$ detector de elétrons retroespalhados é montado junto às lentes objetivas. Ele possui dois elementos semicondutores, os quais detectam os elétrons separadamente, de maneira que os sinais sejam processados e adicionados ou subtraídos para formar três tipos de imagens diferentes: sólida, topográfica e composicional. O detector de elétrons secundários utiliza um conjunto composto por coletor, cintilador, guia de luz e tubo fotomultiplicador para transformar os elétrons secundários em sinais elétricos [47].

O fluxo de informação do microscópio para o computador de controle consiste em sincronizar a varredura no plano $\mathrm{x}, \mathrm{y}$ sobre superfície da amostra com os sinais correspondentes fornecidos no seu volume de interação. Enquanto a amostra é varrida a uma determinada velocidade, a tela do display é varrida simultaneamente com correspondência de posições, utilizando as intensidades obtidas pelos detectores para cada ponto, a partir dos sinais captados. 
Os sinais de raios-X característicos são utilizados para microanálise química EDS (Energy Dispersive Spectroscopy), a qual identifica os elementos químicos presentes no volume de interação entre o feixe e amostra.

\subsubsection{Sistema de geração de padrões litográficos}

O sistema de nanolitografia NPGS (Nanometer Pattern Generation System) está diretamente acoplado ao MEV, de acordo com o diagrama da figura 3.3.

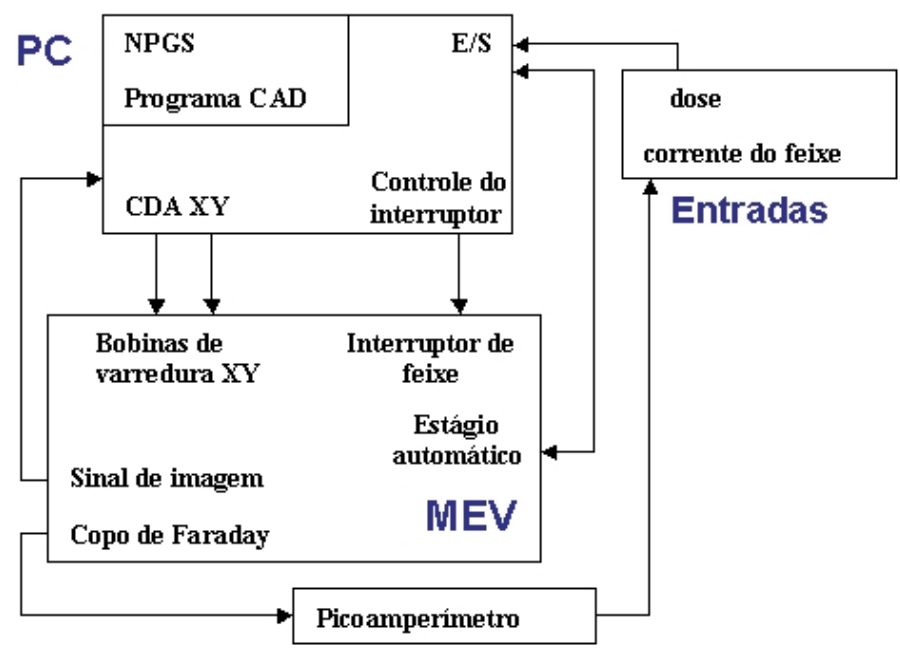

Figura 3.3 - Ciclo de controle do sistema NPGS acoplado ao MEV.

O sistema é composto de software e hardware que controlam as bobinas de varredura do microscópio para reproduzir desenhos de padrões definidos em um programa CAD (Computer Assisted Design). As coordenadas do desenho são transformadas nos comandos que controlam as bobinas de varredura, através de conversores de sinal digital para analógico (CDA), e o interruptor do feixe. Desta maneira as coordenadas $\mathrm{x}, \mathrm{y}$ do desenho são reproduzidas sobre a superfície lisa da amostra, utilizando o feixe de elétrons do MEV, com precisão nanométrica [48].

\subsection{Microscopia de força atômica e tunelamento}

O Scanning Probe Microscope (SPM) modelo Nanoscope IIIa da Digital Instruments (figura 3.4), instalado no Laboratório de Filmes Finos (IFUSP), possui as capacidades listada na tabela 3.2. 


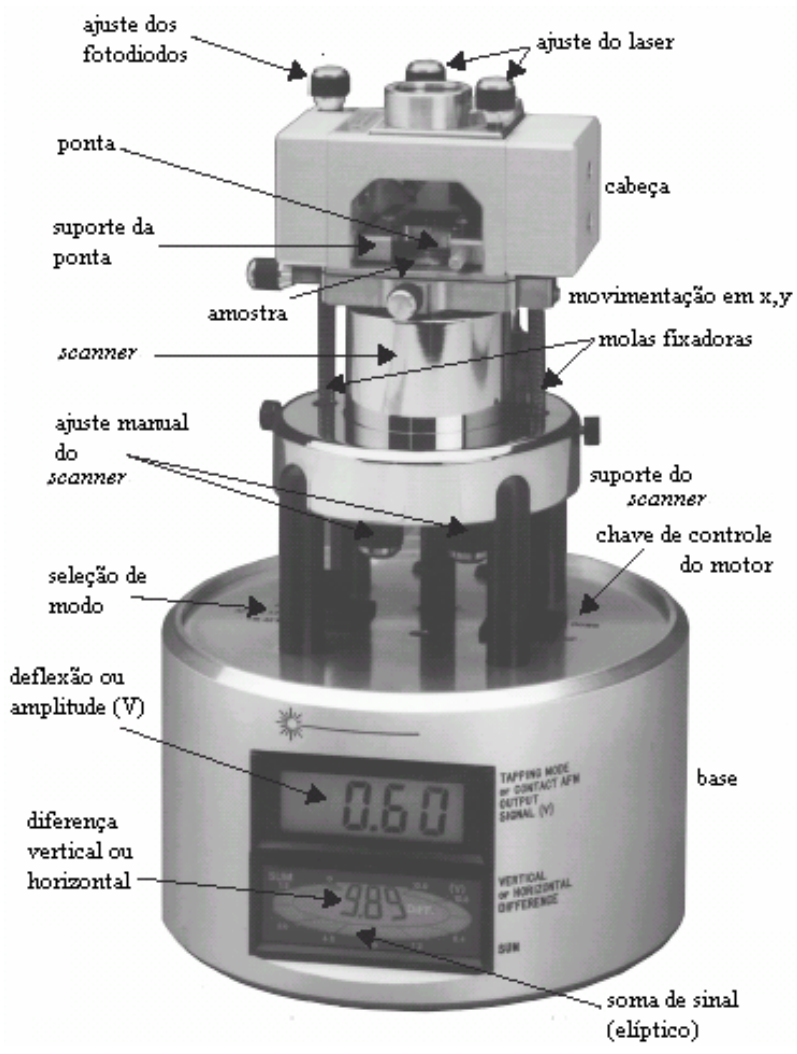

Figura 3.4 - Nanoscope IIIA - Digital Instruments.

Tabela 3.2 - Capacidades do Nanoscope IIIa (Digital Instruments).

\begin{tabular}{|c|c|}
\hline Nanoscope IIIa & Características \\
\hline Scanners J, E e A & $\begin{array}{l}\text { respectivas máximas janelas de varredura: } \\
160 \mu \mathrm{m}^{2}, 15 \mu \mathrm{m}^{2}, 1 \mu \mathrm{m}^{2}\end{array}$ \\
\hline Resolução lateral & atômica (STM), fração do raio da ponta (AFM) \\
\hline Resolução vertical & $\begin{array}{l}\text { fração de angstron (STM), fração de nanometro } \\
\text { (AFM) }\end{array}$ \\
\hline Modalidades padrão & STM e AFM (contato, contato intermitente) \\
\hline \multicolumn{2}{|l|}{ Acessórios } \\
\hline \multicolumn{2}{|c|}{ MFM (Magnetic Force Microscopy) - mapeamento de domínios magnéticos } \\
\hline \multicolumn{2}{|c|}{ EFM (Electrical Force Microscopy) - mapeamento de domínios elétricos } \\
\hline \multicolumn{2}{|c|}{ Nanolitografia - programação e controle dos movimentos do scanner em x,y e z } \\
\hline \multicolumn{2}{|c|}{ Célula para amostras imersas e fluidos } \\
\hline \multicolumn{2}{|l|}{ Célula eletroquímica } \\
\hline \multicolumn{2}{|c|}{ Cabeçote para atmosfera controlada } \\
\hline
\end{tabular}


O SPM consiste de uma família de modalidades de microscopia em que uma sonda muito fina varre a superfície da amostra enquanto algum tipo de interação entre sonda e amostra é monitorado $[49,50]$. Neste trabalho foi utilizada a técnica de AFM (Atomic Force Microscopy).

Na técnica de STM é medida a topografia dos estados eletrônicos de uma superfície usando corrente de tunelamento, que é dependente da distância entre uma ponta muito fina e a superfície de uma amostra condutora, de acordo com a relação:

$\mathrm{i} \sim \mathrm{Ve}^{-\mathrm{c} \delta}$

onde i (em cerca de $\mathrm{nA}$ ) é a corrente de elétrons, V (em cerca de centenas de $\mathrm{mV}$ ) é o potencial elétrico aplicado, $\delta$ (de aproximadamente fração de $\mathrm{nm}$ ) é a distância entre ponta e superfície e c é uma constante.

Para gerar imagens topográficas, a altura é registrada pelo sistema através do monitoramento da variação de corrente. Conforme a ponta passa por pontos de diferentes alturas, a corrente de tunelamento tende a variar e o scanner piezelétrico movimenta a amostra em z para manter seu valor para cada coordenada $\mathrm{x}, \mathrm{y}$. O conjunto dos pontos $(\mathrm{x}, \mathrm{y}, \mathrm{z})$ forma a imagem topográfica ao final da varredura. É possível também mapear as correntes para cada ponto, utilizando a altura como parâmetro constante.

Na modalidade AFM (Atomic Force Microscopy) é utilizada como sonda uma ponta piramidal presa à extremidade de um cantilever. Neste caso, a interação que ocorre entre ponta e superfície é a força atômica de Van der Waals (figura 3.5).

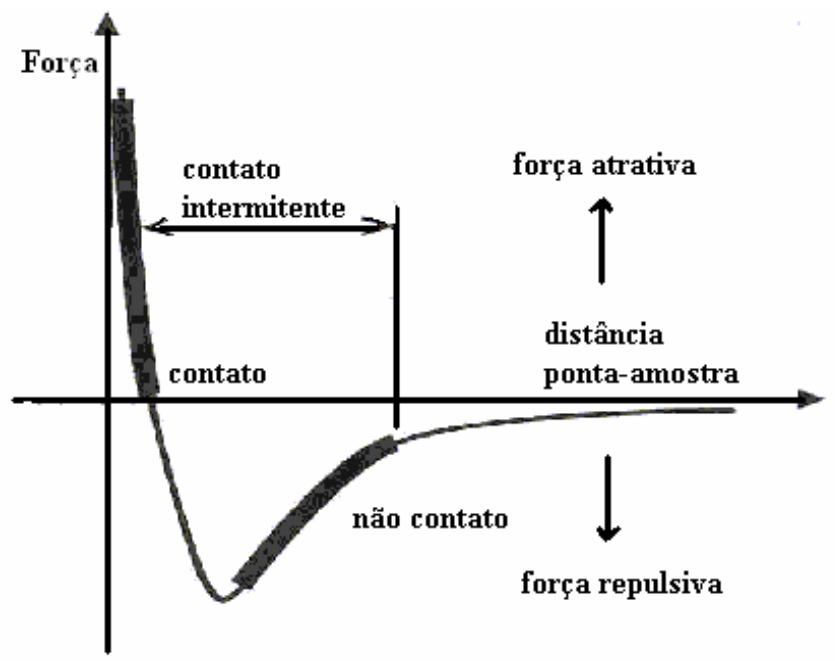

Figura 3.5 - Força de Van der Waals em função da distância entre ponta e amostra. 
No AFM de contato, quando a ponta é colocada em contato com a superfície, ela sofre uma força atômica repulsiva, a qual deflete o cantilever (figura 3.6a). Esta deflexão que deve ser mantida constante é monitorada através de um feixe de laser refletido na extremidade do cantilever e incidente em um conjunto de fotodiodos. Durante a varredura a ponta passa por pontos $\mathrm{x}, \mathrm{y}$ de alturas diferentes, o que faz com que o scanner piezelétrico prontamente faça movimentos na direção z para corrigir a deflexão. Assim como no STM, o conjunto de pontos $(\mathrm{x}, \mathrm{y}, \mathrm{z})$ forma a topografia da região varrida.

No modo AFM de contato intermitente, o cantilever oscila na sua freqüência de ressonância (figura 3.6b), em uma amplitude que deve ser mantida constante durante a varredura, e toca gentilmente a superfície para cada ponto $\mathrm{x}, \mathrm{y}$. Neste caso a força atômica, repulsiva ou atrativa, influencia na oscilação da ponta. Quando a ponta passa por pontos de altura diferentes, a amplitude de oscilação muda e o scanner faz seu movimento no eixo z para corrigir a variação. Analogamente às outras situações, a imagem topográfica é formada.

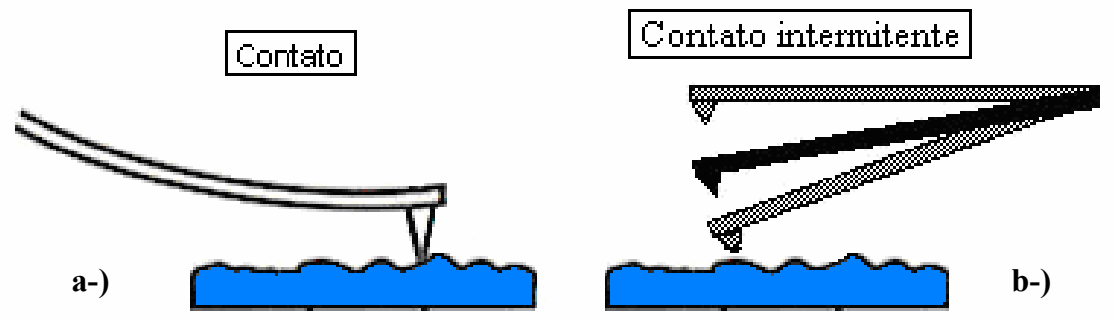

Figura 3.6 - Interação ponta-superfície para AFM de contato e AFM de contato intermitente.

É possível ainda realizar AFM de não contato, em que o cantilever oscila a uma distância maior da superfície. Neste caso a ponta não chega a tocar a amostra, mas sonda a superfície que exerce força atômica atrativa.

\subsection{Metal Plasma Immersion Ion Implantation and Deposition (MePIIID)}

Através da técnica MePIIID é possível depositar filmes finos de metais, óxidos, nitretos, carbetos e diamond-like livre de hidrogênio. A técnica ainda permite implantação iônica de baixa energia através de aplicação de polarização no porta objeto [24 - 27].

O equipamento consiste basicamente de um canhão de plasma, filtro de partículas e porta amostras dentro de um câmara em vácuo. $\mathrm{O}$ vácuo necessário para o processo de deposição é da ordem de $10^{-6}$ torr obtido através de um sistema de bombeamento composto de 
bomba turbomolecular e bomba criogênica, após pré-vácuo com bomba mecânica de dois estágios.

O canhão de plasma (figura 3.7) é formado por um catodo na forma de bastão cilíndrico feito do material do qual se deseja obter o filme fino, envolto em uma cerâmica que é posicionada dentro de um anodo cilíndrico de aço inoxidável. Um gatilho dispara uma descarga pulsada entre catodo e anodo, provocando um faiscamento distribuído aleatoriamente na superfície do catodo (cathode spots) e gerando o plasma de seu material.

O filtro de partículas consiste de uma bobina enrolada na forma de um tubo metálico curvado na forma de um quarto de toróide, também ligada em série com o canhão de plasma. Assim a corrente de descarga com cerca de 200 A passa por essa bobina, gerando um campo típico de $10 \mathrm{mT}$ em seu centro. $\mathrm{O}$ arco de plasma é guiado por este campo (figura 3.8) até o substrato posicionado na saída do filtro de partículas.

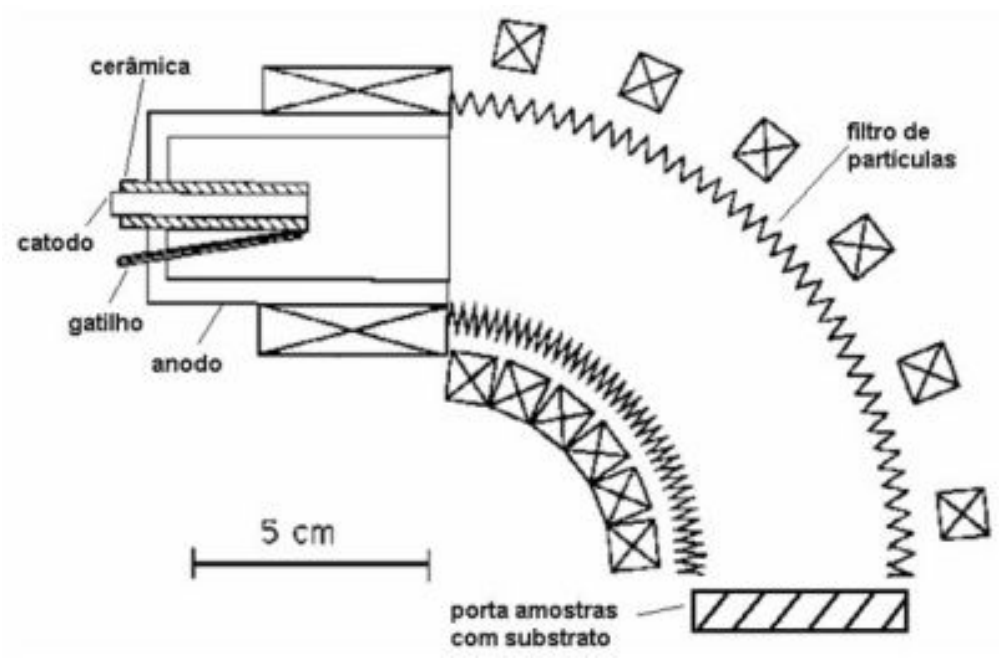

Figura 3.7 - Esquema do canhão de plasma.

As micropartículas, também ejetadas do catodo, têm trajetórias praticamente retas devido à sua grande inércia, chocando-se com as paredes do filtro. Assim, a deposição do filme ocorre livre de contaminação dessas micropartículas, com excelente homogeneidade e alta pureza.

Portanto, para a deposição de um filme metálico basta colocar o catodo do material desejado para o filme. Para deposição de diamond-like carbon (DLC), usa-se um catodo de grafite e polarização aplicada ao substrato. No caso de óxidos e nitretos, utiliza-se atmosfera de $\mathrm{O}_{2}$ ou $\mathrm{N}_{2}$, respectivamente, com entrada e saída contínuas do gás reagente, de forma a se 
obter pressão dinâmica em torno de $10^{-4}$ a $10^{-5}$ torr. Ligas metálicas e carbetos são depositados com o uso de dois canhões de plasma funcionando simultaneamente.
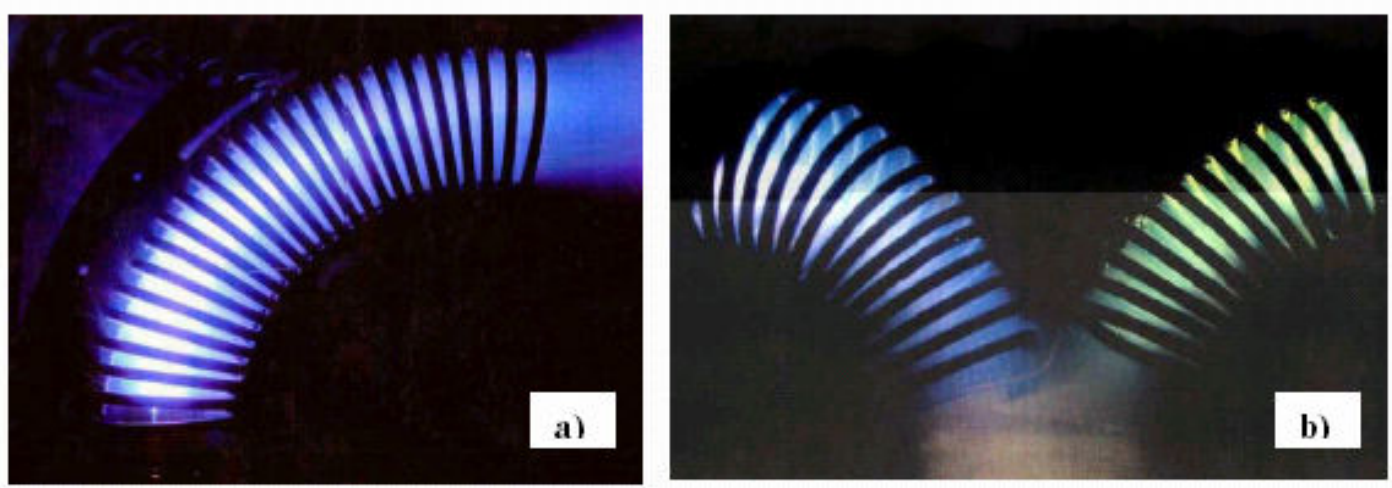

Figura 3.8 - Plasma passando por filtro de partículas para a) um material e b) dois materiais. 


\subsection{Desenvolvimento dos dispositivos para medida de anisotropia de resistividade}

Para cada experimento foram preparados três dispositivos (figura 3.9). Os dispositivos 1 e 2 possuem nanocomponentes (regiões nanolitografadas em PMMA de $20 \mu \mathrm{m}$ x $20 \mu \mathrm{m}$ ) com direções ortogonais de perfil senoidal, delimitados por duas microcanaletas. Essas microcanaletas têm a função de obrigar a corrente a passar pelas estruturas nanolitografadas. O terceiro dispositivo apenas possui um filme de PMMA e foi usado como dispositivo de compensação, como será explicado mais adiante. Após os processos de definição das estruturas, os três dispositivos receberam contatos elétricos e deposição de filme metálico espesso em suas extremidades.

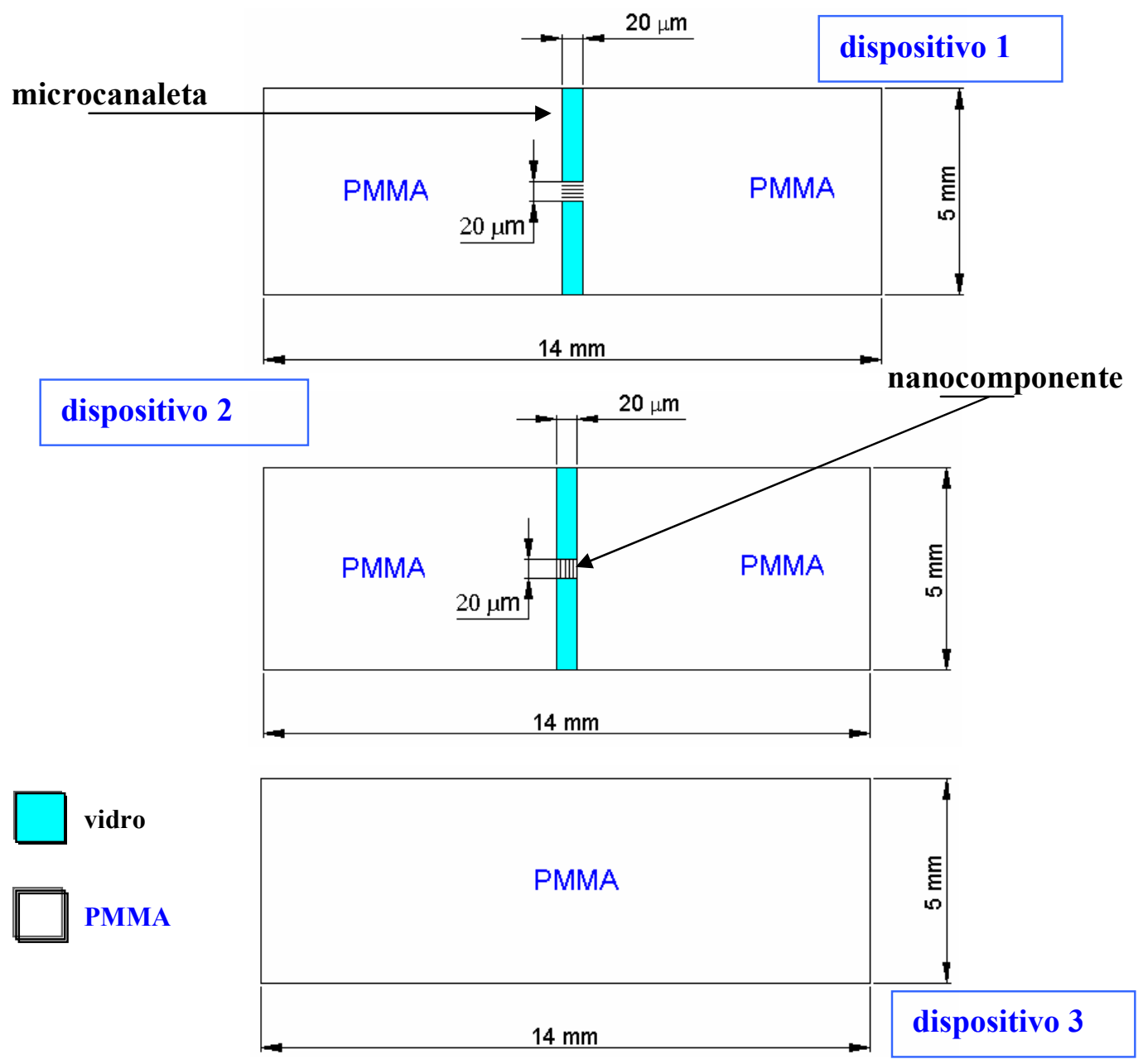

Figura 3.9 - Dispositivos para experimento de anisotropia de resistividade. 
As etapas de desenvolvimento dos dispositivos que antecederam a deposição do filme fino estão listadas na tabela 3.3 e serão descritas em detalhes nos itens a seguir.

Tabela 3.3 - Resumo dos processos de preparação dos dispositivos.

\begin{tabular}{|l|l|}
\hline Objetivo & Processos \\
\hline Preparação dos substratos & Corte e limpeza dos substratos de vidro \\
\hline Definição das microcanaletas & $\begin{array}{l}\text { Microlitografia por feixe de elétrons: } \\
\text { - Deposição de elétron-resiste PMMA } \\
\text { - Exposição por feixe de elétrons (NPGS) } \\
\text { - Revelação } \\
\text { Caracterização da microestrutura (MEV e AFM) }\end{array}$ \\
\hline Definição dos nanocomponentes & $\begin{array}{l}\text { Nanolitografia por AFM de contato } \\
\text { Caracterização da nanoestrutura (AFM) }\end{array}$ \\
\hline Montagem do arranjo experimental & $\begin{array}{l}\text { Montagem dos dispositivos norta-amostras } \\
\text { aplicação de contatos elétricos }\end{array}$ \\
\hline Deposição de filme espesso & $\begin{array}{l}\text { Determinação da taxa de deposição do MePIIID } \\
\text { Consolidação dos contatos com deposição de camada } \\
\text { espessa de ouro } \\
\text { Caracterização da espessura obtida (AFM) }\end{array}$ \\
\hline
\end{tabular}

\subsubsection{Preparação dos substratos}

Os substratos foram cortados no tamanho de aproximadamente $(14,0 \pm 0,1) \mathrm{mm} \times$ $(5,0 \pm 0,1) \mathrm{mm}$ a partir de lâminas comuns de microscopia (26 mm x $76 \mathrm{~mm}$ x $2 \mathrm{~mm}$ ). O corte foi feito utilizando cortadeira com disco de diamante (Modelo Minitom, Struers). Para facilitar o procedimento, a lâmina foi presa com cera de abelha a um pedaço de chapa de metal que pôde ser acoplada à cortadeira.

Depois de cortados os substratos tiveram que passar por uma limpeza para remover a resina, antes da limpeza própria para vidro (tabela 3.4). 
Tabela 3.4 - Limpeza dos substratos de vidro

\begin{tabular}{|c|c|}
\hline Remoção de resina & Limpeza para vidro \\
\hline $\begin{array}{l}\text { - } 5 \text { minutos em xylol em banho ultra-sônico } \\
\text { - } 5 \text { minutos em acetona em banho ultra- } \\
\text { sônico }\end{array}$ & $\begin{array}{l}\text { - } 10 \text { minutos em água deionizada } \\
\text { - } 10 \text { minutos em solução } 4 \mathrm{H}_{2} \mathrm{O}: 1 \mathrm{NH}_{4}: 1 \mathrm{H}_{2} \mathrm{O}_{2} \\
\text { - } 10 \text { minutos de enxágüe em água deionizada }\end{array}$ \\
\hline
\end{tabular}

\subsubsection{Definição das microcanaletas}

Além da função de delimitar a região de $(20 \mu \mathrm{m})^{2}$, posteriormente nanolitografada, as microcanaletas tiveram que evitar a passagem de corrente elétrica. Para isto foi fabricado o perfil sugerido na figura 3.10. Este tipo de perfil cria um "sombreamento" para os íons metálicos que chegam durante deposição do filme fino.

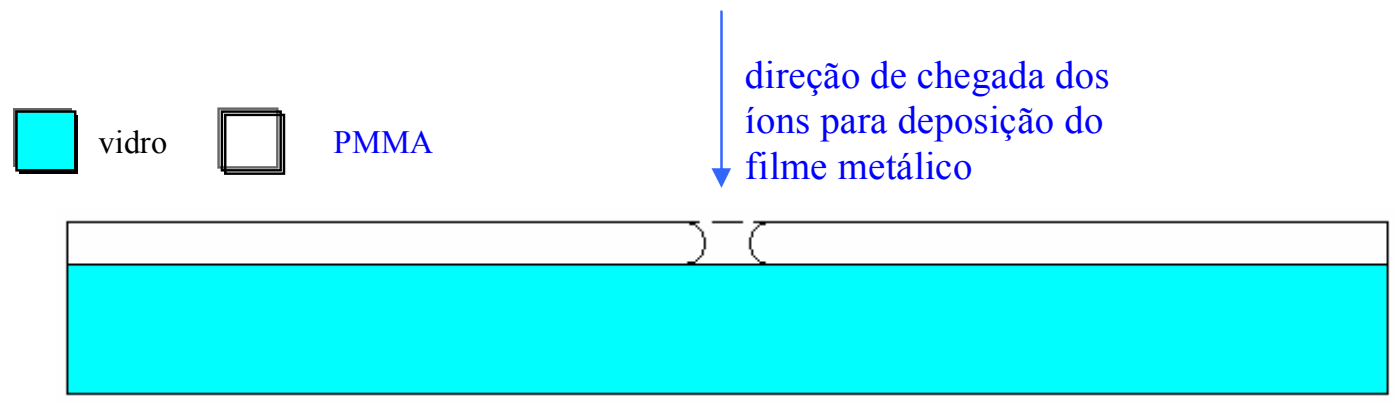

Figura 3.10 - Perfil das microcanaletas.

O sistema de geração de padrões litográficos NPGS, descrito anteriormente, foi utilizado em umas das etapas essenciais do processo de litografia por feixe de elétrons, a exposição. Entretanto, para se conseguir a estrutura final na amostra são tipicamente necessários outros procedimentos, resumidos a seguir:
a) Aquecimento do substrato para eliminação de umidade residual
b) Aplicação do elétron-resiste utilizando spin-coater
c) Cura do elétron-resiste aplicado para evaporação do solvente à temperatura de transição vítrea do polímero
d) Exposição por feixe de elétrons
e) Revelação
f) Inspeção e caracterização. 
O elétron-resiste, em solução líquida, é depositado utilizando o equipamento conhecido como spin-coater, neste caso modelo P6700 da empresa Specialty Coating Sistems INC. (figura 3.11).

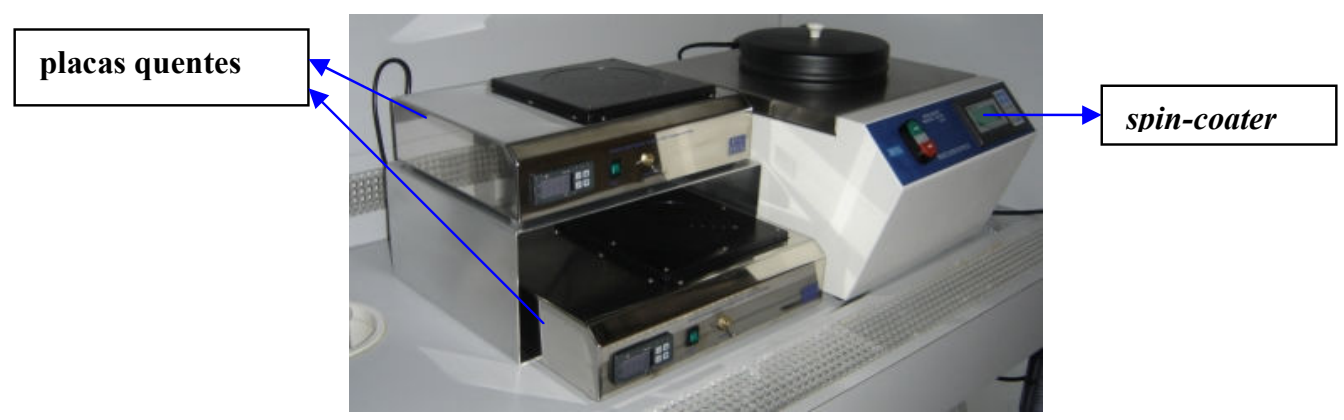

Figura 3.11 - Placas quentes e spin-coater instalados dentro de ambiente de fluxo laminar.

O spin-coater, ou spinner, possui um suporte que prende o substrato por diferença de pressão, promovida por uma linha ligada a uma bomba de vácuo. Logo que a solução é depositada sobre o substrato, o equipamento é acionado. O porta amostras, acoplado por um eixo ao motor de alta estabilidade, gira a velocidades angulares da ordem de milhares de rotações por minuto durante alguns segundos. Assim a solução é espalhada de maneira uniforme na superfície do substrato.

O elétron-resiste deve ser curado durante minutos utilizando também uma placa quente, evaporando assim o solvente. Nota-se na figura 3.11 a presença de duas placas de aquecimento, ambas necessárias, já que as temperaturas de aquecimento do substrato e de cura do polímero são diferentes. Estas placas (Electronic MicroSystems - Modelo 1000-1) alcançam máximo de $160^{\circ} \mathrm{C}$ e $200^{\circ} \mathrm{C}$ com precisão de $0,1^{\circ} \mathrm{C}$.

O elétron-resiste é um polímero sensível ao feixe de elétrons. Isto significa que processos físico-químicos ocorrem quando o feixe de elétrons incide sobre ele formando o volume de interação. Para que o polímero seja útil para a litografia deve existir uma solução reveladora que promova alta seletividade entre as regiões exposta e não exposta ao feixe, ou seja, uma das regiões deve ser praticamente insolúvel enquanto que a outra deve ser totalmente solúvel no tempo de revelação [51].

Quando a região exposta ao feixe é a insolúvel, o elétron-resiste é denominado como negativo; o desenho definido pelo feixe é a estrutura que permanece após a revelação. Um elétron-resiste negativo amplamente utilizado é o SU-8, desenvolvido inicialmente pela IBM no ano de 1992. Quando a região exposta é a totalmente retirada pelo revelador, o elétron- 
resiste é positivo [52]. O PMMA é um exemplo deste tipo de elétron-resiste e é o polímero utilizado neste trabalho.

O PMMA, ou polimetilmetacrilato, é o elétron-resiste de melhor resolução existente atualmente. Com ele é possível produzir trilhas menores do que $10 \mathrm{~nm}$, conciliando-se parâmetros específicos de exposição, revelação e feixes eletrônicos pequenos o suficiente para minimizar efeitos de proximidade [53 - 56]. Ele é formado por uma cadeia linear do tipo backbone ligada a uma cadeia éster e a um grupo metil $[57,58]$, como mostrado na (figura $3.12)$.

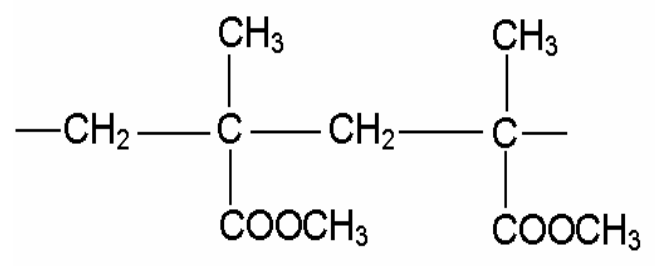

Figura 3.12 - Cadeia polimérica do PMMA.

Para seu uso como elétron-resiste, o PMMA é comercializado como solução líquida em clorobenzeno ou anisol [59, 62]. Ele pode ser selecionado de acordo com seu peso molecular, relacionado ao tamanho da cadeia polimérica, e sua concentração. O peso molecular influencia na resolução da litografia por feixe de elétrons: quanto maior seu valor, melhor a resolução [60]. Já a concentração influencia a espessura final do filme obtido utilizando-se o método de spinner. Menores espessuras são obtidas com soluções bem diluídas, de cerca de $2 \%$. A rugosidade RMS da superfície é tipicamente menor do que $0,5 \mathrm{~nm}$, medida por AFM de contato intermitente.

Na etapa de cura (pos-bake), o PMMA deve ser aquecido à temperatura maior do que $150^{\circ} \mathrm{C}$, acima de sua temperatura de transição vítrea $\left(\mathrm{T}_{\mathrm{g}}\right)$. Este procedimento permite que, além da evaporação do solvente, haja um recozimento que torna o filme de PMMA um material amorfo e com características próximas do vidro.

Quando o feixe de elétrons incide na superfície do PMMA, ele quebra as cadeias principais, contidas no volume de interação, em cadeias menores. As cadeias que são solúveis na química reveladora são formadas por cerca de dez monômeros [61], para qualquer peso molecular do PMMA escolhido. Por esta razão pesos moleculares maiores promovem maior resolução; a seletividade é maior. Assim, o elétron-resiste de 950k promove melhor resolução do que o de peso molecular 50k. Neste trabalho será utilizado o PMMA ARP671.06, de peso molecular $950 \mathrm{k}$ e concentração 6\%, do fabricante Allresist [62]. 
Após diversos testes e calibrações almejando-se um perfil de sombreamento para a deposição, obtiveram-se os seguintes parâmetros para as etapas de deposição do PMMA ARP671.06 (950 k):

- Aquecimento dos substratos na placa quente a $150{ }^{\circ} \mathrm{C}$ durante 10 minutos

- Primeira camada de elétron-resiste: solução de PMMA, em quantidade suficiente para cobrir a superfície do substrato é depositada. O spinner é programado para rotacionar a $4000 \mathrm{rpm}$ durante 50 segundos

- Primeira cura: placa quente a $180^{\circ} \mathrm{C}$ durante 10 minutos

- Segunda camada de elétron-resiste: mesmo que primeira camada

- Segunda cura: placa quente a $180^{\circ} \mathrm{C}$ durante 20 minutos

Para o processo de exposição, no MEV Jeol 6460LV, os principais parâmetros que devem ser calibrados são a corrente do feixe $(\mathrm{pA})$ e a dose $\left(\mu \mathrm{C} / \mathrm{cm}^{2}\right)$, além de parâmetros de correção do microscópio, como foco e astigmatismo. O processo de calibração envolve expor uma série de estruturas, neste caso quadrados de $20 \mu \mathrm{m}$ x $20 \mu \mathrm{m}$, com doses diferentes para uma mesma corrente escolhida, nas condições que devem ser usadas para a fabricação das microcanaletas. É escolhida a dose adequada para obtenção da estrutura que, ao mesmo tempo, melhor reproduza o desenho e retire todo o PMMA até o substrato após a revelação. A escolha da corrente é importante, uma vez que o tamanho do feixe é proporcional a ela e influencia diretamente no formato do perfil obtido.

Foi verificado que perfis reentrantes mais bem definidos eram obtidos para correntes menores, como 5 pA. Entretanto, quanto menor a corrente, maior o tempo de exposição para uma mesma dose. Para a corrente de 5 pA seria necessário um tempo de 13,43 h (tempo de exposição de cada ponto do feixe $=3621 \mu \mathrm{s}$ ). Buscou-se atingir um compromisso entre a qualidade do perfil e tempo de exposição, o que resultou em uma corrente de $50 \mathrm{pA}$, dose de $225 \mu \mathrm{C} / \mathrm{cm}^{2}$ e tempo de exposição de 81 minutos (tempo de exposição para cada ponto do feixe $=362,1 \mu \mathrm{s})$.

Como não é possível medir diretamente a corrente eletrônica que atinge a superfície da amostra, devido a perdas de elétrons retroespalhados e secundários que não escoam, é utilizado um Faraday Cup [46]. Um Faraday Cup consiste em um recipiente completamente fechado, como ilustrado na figura 3.13. O interior do furo de $2 \mathrm{~mm}$ de diâmetro é coberto com tinta de carbono. 

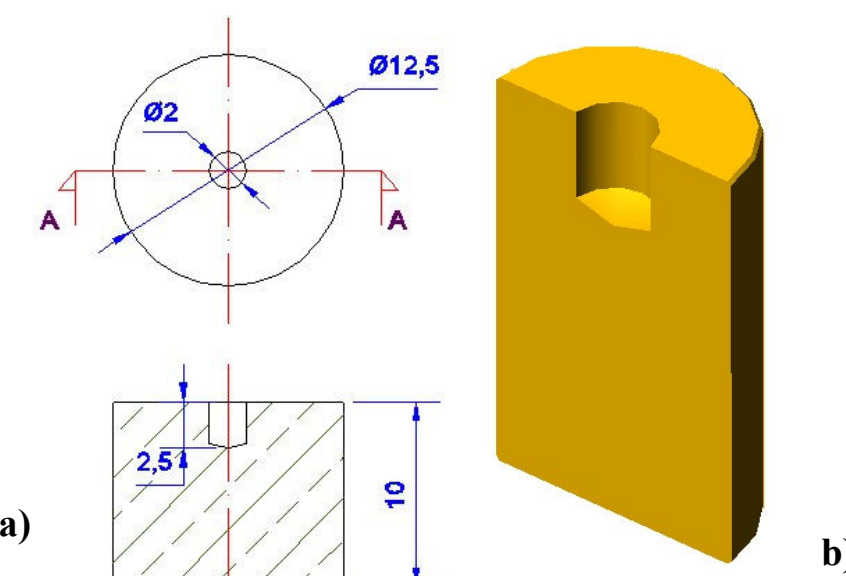

a)

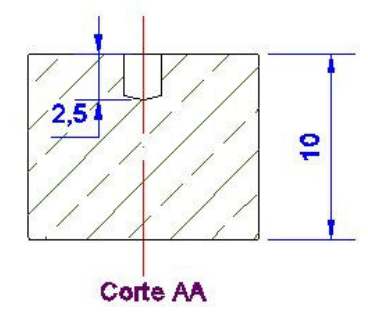

b)

Figura 3.13 - a) Dimensões principais para se fabricar um Faraday cup e b) Corte do arranjo.

Sobre o orifício maior (figura 3.13b) é coloca uma lâmina de cobre com diâmetro de abertura de cerca de $75 \mu \mathrm{m}$ (figura 3.14).

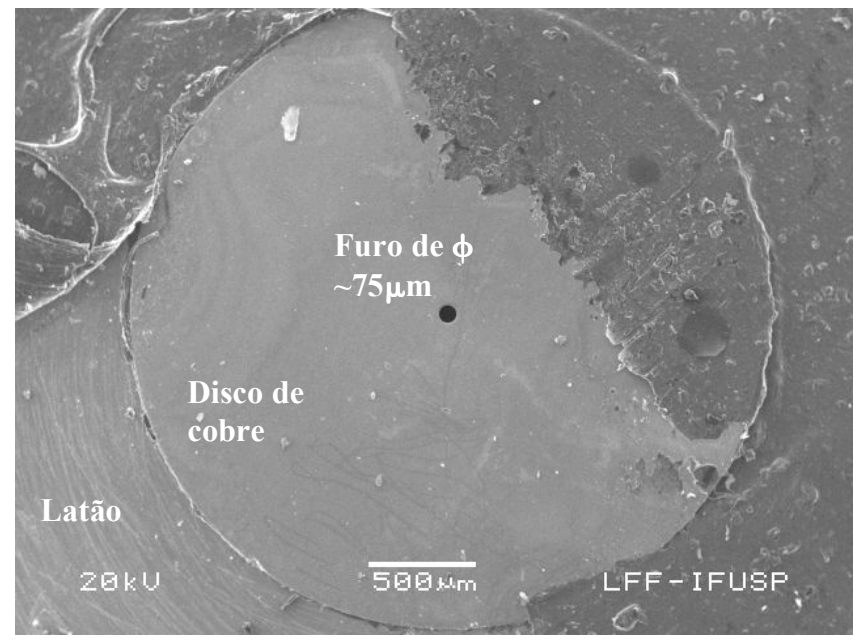

Figura 3.14 - Detalhe da abertura do Faraday Cup.

A seguir serão dados detalhes técnicos relacionados à exposição por feixe de elétrons para fabricação das microcanaletas. O aumento do microscópio a ser utilizado durante a exposição está diretamente relacionado ao tamanho da área que deve ser exposta, ou campo de transferência, segundo a relação:

campo de transferência $(\mu \mathrm{m})=\frac{\mathrm{C}}{\text { aumento }}$ 
onde C é uma constante obtida com a calibração do NPGS.

Portanto, quanto maior o campo de transferência, menor deve ser o aumento do microscópio, que por sua vez depende da distância entre o final da lente objetiva e a superfície da amostra (distância de trabalho). Para se conseguir exposições em comprimentos da ordem de $5 \mathrm{~mm}$ (que é o caso das microcanaletas), o aumento necessário está em $15 \mathrm{x}$, conseguido com uma distância de trabalho de pelo menos $29 \mathrm{~mm}$.

Considerando que distâncias de trabalho de 8 a $10 \mathrm{~mm}$ são ideais para uma boa resolução, o valor de $29 \mathrm{~mm}$ é bastante elevado. No entanto, essa distância de trabalho não foi prejudicial para a qualidade do perfil da microlitografia, assim como não foi também prejudicial a grande deflexão que o feixe teve que sofrer em y $(\sim 5 \mathrm{~mm})$.

Entretanto, devido ao próprio princípio de funcionamento das lentes eletromagnéticas, nesta distância de trabalho, a orientação da imagem visualizada possui um desvio de rotação da sua orientação real. Por isso, foram obtidas estruturas como ilustrado pela figura 3.15, com ângulo de rotação em relação ao centro das microcanaletas (igual ao centro do substrato), de aproximadamente $16^{\circ}$ para esquerda (figura 3.15 a). A solução foi simplesmente rotacionar o desenho $\mathrm{CAD} 16^{\circ}$ para direita para produção da estrutura na orientação correta (figura 3.15b). Adicionalmente, foram feitos desenhos de comprimento pouco maior que $5 \mathrm{~mm}$, para que seguramente as estruturas chegassem às bordas do substrato.

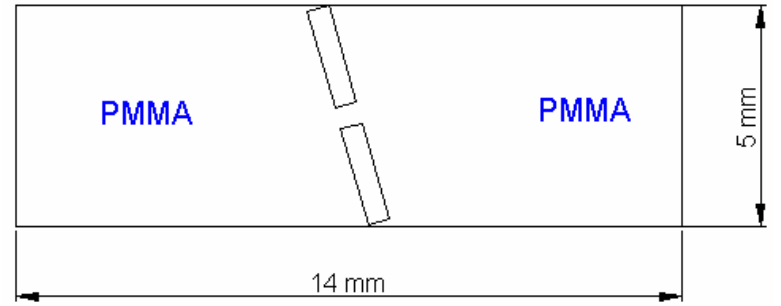

a)

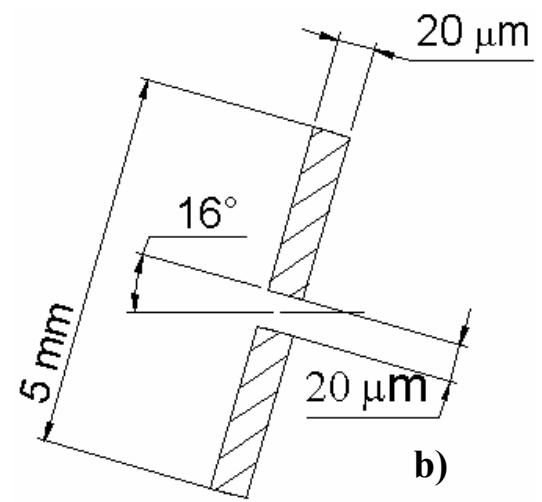

Figura 3.15 - a) Resultado obtido com desvio de orientação de $-16^{\circ}$ e b) solução rotacionando-se o desenho CAD de $16^{\circ}$.

Esta solução foi a maneira mais simples de lidar com o comprimento extenso da microcanaleta. Separar o padrão em blocos menores necessitaria de uma etapa adicional para definição de conjuntos de estruturas de alinhamento atravessando a amostra. Porém seria uma 
solução um pouco mais complicada e até indesejada, por ter que utilizar outro material por baixo do PMMA para obter contraste no MEV e encaixar as imagens das estruturas com quadros de alinhamento do software NPGS.

Após a exposição, as amostras 1, 2 e 3 foram agitadas moderadamente em química reveladora durante $1 \mathrm{~min}$ e $30 \mathrm{~s}$. O revelador utilizado foi diluição de 1 parte de metilisobutilcetona em três partes de álcool isopropílico, seguido de enxágüe em álcool isopropílico por $30 \mathrm{~s}$ para cessar o processo de revelação. Foi feita secagem em spinner a $3000 \mathrm{rpms}$ durante $20 \mathrm{~s}$. Note que a amostra 3, mesmo não passando por etapa de litografia, foi revelada. Isto porque o processo de revelação pode alterar um pouco a superfície do polímero e era desejável que o dispositivo 3 tivesse o mesmo tipo de superfície polimérica que os dispositivos 1 e 2 . Após a revelação, a amostra 3 foi estocada em dessecador.

Na figura 3.16 é mostrado o resultado obtido para a borda da microlitografia por feixe de elétrons em uma imagem de microscopia eletrônica de varredura. A imagem mostra claramente o perfil planejado para efeito de sombreamento durante a deposição.

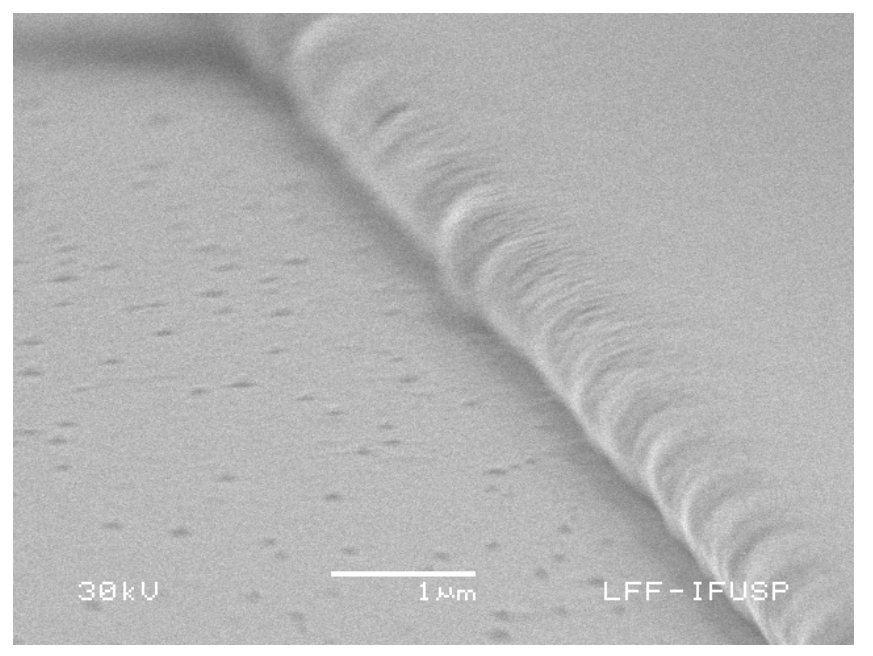

Figura 3.16 - Imagem do perfil obtido pela microlitografia por feixe de elétrons.

As medidas da altura por AFM de contato intermitente do filme de PMMA forneceram uma média de $934 \mathrm{~nm}$ de espessura da camada de PMMA.

Após esta caracterização inicial mais aprimorada, mantendo-se os mesmos parâmetros do processo, os resultados de exposições subseqüentes passaram apenas por uma inspeção "visual", na verdade utilizando um instrumento óptico com aumento suficiente que permitia checar os contornos e dimensões da estrutura. 
Para testar a eficiência deste desenho de perfil em evitar a passagem de corrente elétrica, foram feitas três amostras com a configuração da figura 3.17. Foram feitos contatos em suas extremidades e as amostras foram montadas em configuração semelhante a que será apresentada para medição de resistências. O objetivo do experimento foi garantir que, para as espessuras de interesse do experimento, não haveria condução elétrica através das microcanaletas.

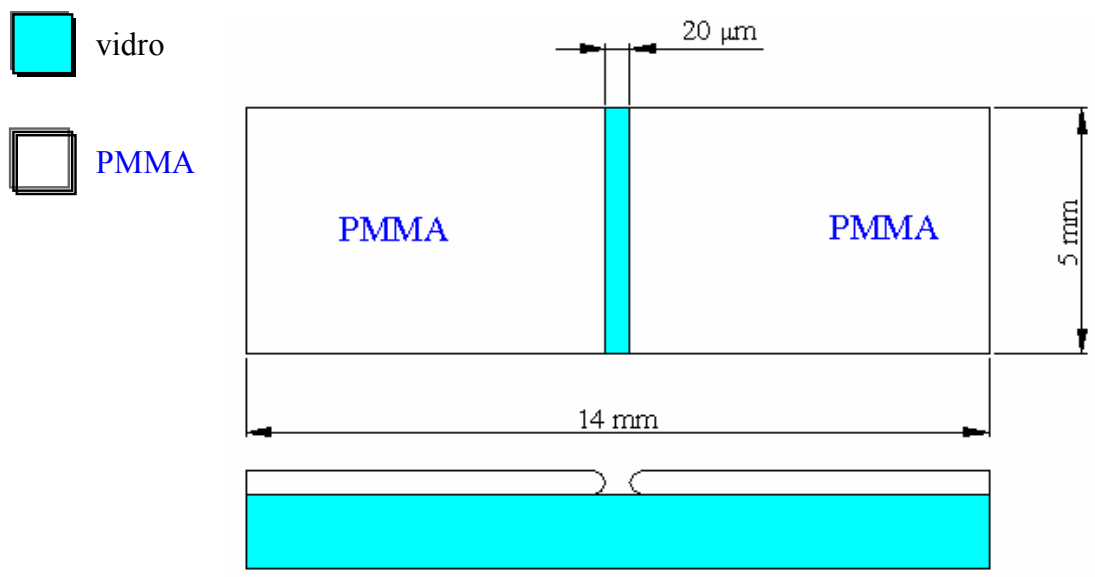

Figura 3.17 - Amostra para teste de condução.

Nas três amostras, o teste funcionou para espessuras de pelo menos $30 \mathrm{~nm}$, quando em duas amostras houve resistência da ordem de $\mathrm{M} \Omega$. A espessura máxima de interesse é menor do que $10 \mathrm{~nm}$.

\subsubsection{Nanolitografia por AFM de contato}

A nanolitografia deveria produzir o padrão senoidal, apresentado na Introdução, sobre a superfície do PMMA, na área entre microcanaletas de aproximadamente $(20 \mu \mathrm{m})^{2}$, como ilustrado na figura 3.9.

O objetivo inicial foi ter valores para o comprimento de onda $\Lambda$ de aproximadamente $20 \mathrm{~nm}$, com maior amplitude h possível. É válido salientar que não se pretendeu criar uma superfície perfeitamente senoidal, mas a mais próxima disso. Para se criar este perfil foi usada uma ponta de silício, tipicamente utilizada no AFM de contato intermitente (figura 3.18), mas no modo de AFM de contato para mecanicamente marcar a superfície. 
Esta técnica de modificação física da superfície do polímero, geralmente PMMA, aplicando-se força de contato suficiente, é utilizada para diversos processos de interesse em nanotecnologia, como criação de regiões para crescimento seletivo de nanofios de sílica [63], nano orifícios para crescimento seletivo de $\mathrm{ZnO}$ [64], alinhamento de cristal líquido e outras aplicações [65 - 67]. A vantagem da nanolitografia por AFM é a maior rapidez do processo e precisão com relação à nanolitografia por feixe de elétrons, principalmente devido a suas limitações por efeitos de proximidade e pelo processo de revelação $[55,56,68]$.
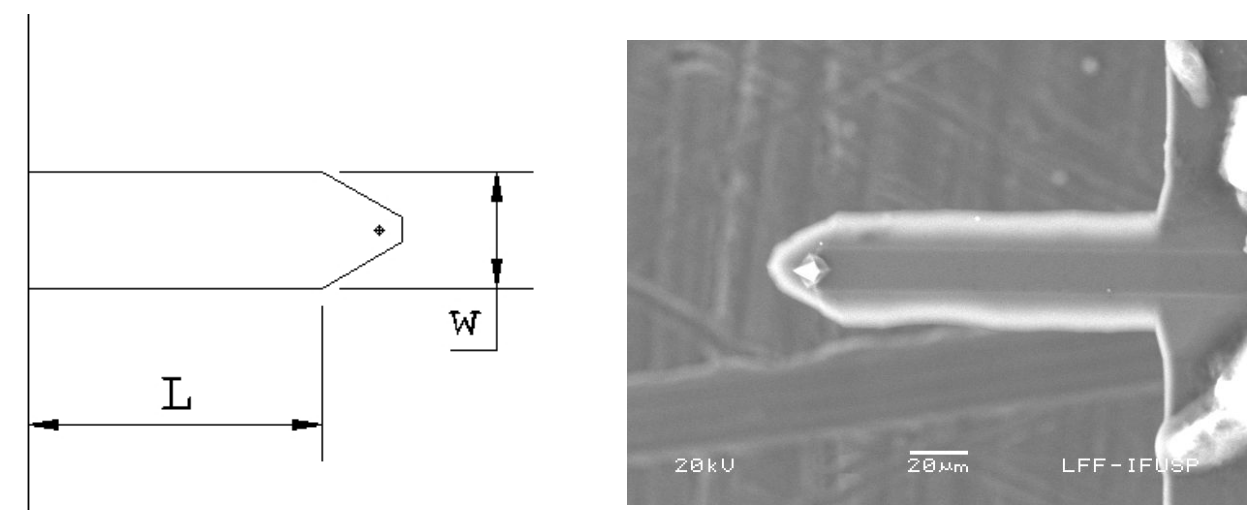

Figura 3.18 - Ponta de silício para AFM.

Para o cálculo da força aplicada na litografia foram utilizadas as seguintes equações [69]:

$$
\mathrm{f}^{2}=\frac{1,03}{(2 \pi)^{2}} \frac{e}{\mathrm{~L}^{4}} \frac{E}{\rho} \quad \rightarrow \quad e=\mathrm{fL}^{2} 2 \pi \sqrt{\frac{\rho}{1,03 E}}
$$

em que L e w são comprimento e largura do cantilever, respectivamente, que foram medidos utilizando uma imagem do $\mathrm{MEV}, E$ e $\rho$ são constantes (módulo elástico e densidade do silício), f é a freqüência de ressonância da ponta, medida pelo SPM, e $e$ é a espessura do cantilever. Este último parâmetro foi determinado (e não medido) através dos demais valores medidos por fornecer assim foi um valor de $e$ efetivo, visto que a Eq.(3.3) é definida para uma barra de secção reta retangular, o que não é esse caso.

Então a constante elástica $k_{\mathrm{e}}$ do cantilever pode ser determinada pela equação:

$$
k_{\mathrm{e}}=0,25 E \mathrm{~W} \frac{e^{3}}{\mathrm{~L}^{3}}
$$


Calculando-se a constante $k_{\mathrm{e}}$ e medindo-se o valor de deflexão do cantilever, pode-se então calcular a força em $\mu \mathrm{N}$ que é aplicada na nanolitografia, ou determinar a deflexão do cantilever a partir de uma força desejada:

$\mathrm{F}=k_{\mathrm{e}} \Delta \mathrm{z}$

Para determinar os melhores parâmetros para a nanolitografia, foi realizada a seguinte metodologia:

a) Configuração da força que deve ser aplicada na nanolitografia escolhendo-se a deflexão proporcional no gráfico de força;

b) Modo de contato com a força selecionada que corresponde a nanolitografia da superfície durante a varredura;

c) Imagem em AFM de contato intermitente da região riscada com ângulo de varredura de $45^{\circ}$ (para facilitar a observação) e inspeção desta imagem para avaliação da uniformidade da superfície;

d) Transformada de Fourier para filtrar a periodicidade principal da amostra e recriar uma imagem apenas com esta periodicidade;

e) Seleção de uma seção transversal da imagem para medição de $\Lambda$ e h.

Após montagem da amostra sobre o scanner e configurações do AFM, obtiveram-se primeiramente imagens de AFM de contato intermitente para centralizar a região onde deveria ser realizada a nanolitografia. Uma vez centralizada a ponta foi afastada e mudou-se o microscópio para o modo de AFM de contato.

A ponta foi aproximada à superfície da amostra. Quando a varredura estava prestes a começar, no centro da janela de varredura, era acionado o modo de gráfico de força (figura 3.19). Neste gráfico é possível observar a deflexão do cantilever em nanometros, proporcional ao setpoint em volts, que pode ser alterado. No exemplo, a deflexão do cantilever é de $3 \mathrm{x}$ $23 \mathrm{~nm}=69 \mathrm{~nm}$. Usando-se a Eq. 3.5 foi possível configurar a força desejada para a nanolitografia. 


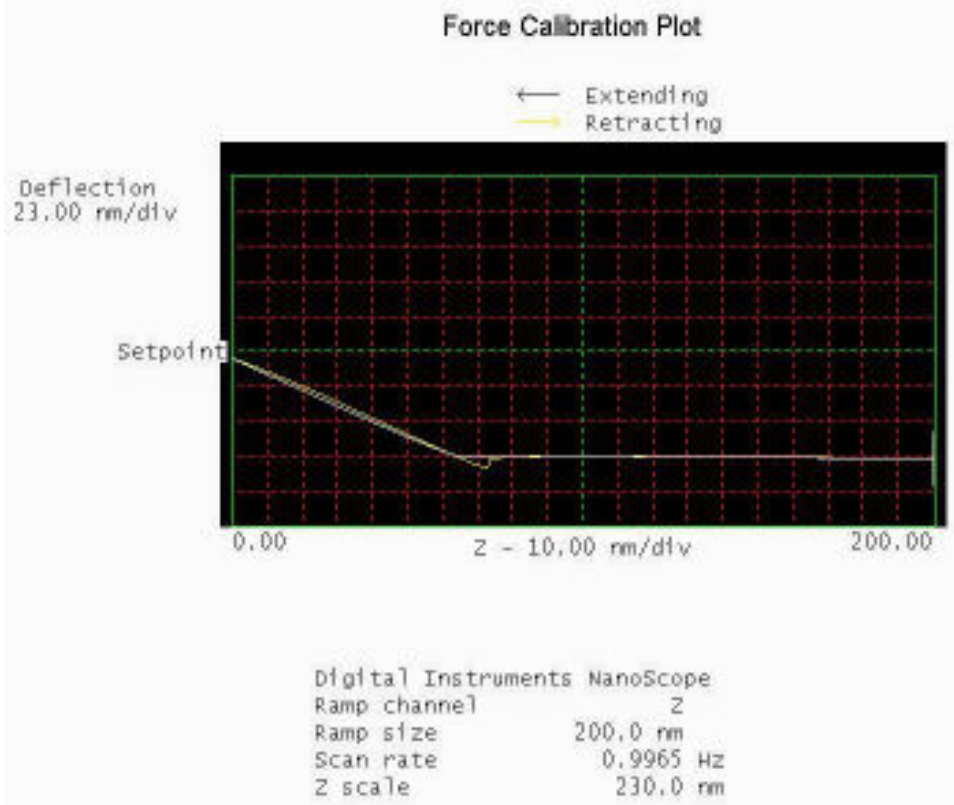

Figura 3.19 - Exemplo de gráfico de calibração de força do AFM de contato.

Os dados, que dependeram da ponta utilizada, estão listados na tabela 3.5.

Tabela 3.5 - Dados da nanolitografia por AFM de contato dependentes da ponta utilizada.

\begin{tabular}{|l|l|}
\hline Parâmetro & Valor \\
\hline L (medido usando MEV) & $118 \mu \mathrm{m}$ \\
\hline w (medido usando MEV) & $32,8 \mu \mathrm{m}$ \\
\hline $\mathrm{f}$ (medido pelo Nanoscope IIIA) & $242290 \mathrm{~Hz}$ \\
\hline$e$ (calculado) & $2,5 \mu \mathrm{m}$ \\
\hline$k_{\mathrm{e}}$ (calculado) & $12,71 \mathrm{~N} / \mathrm{m}$ \\
\hline$\Delta \mathrm{z}$ (medido no gráfico de força) & $69 \mathrm{~nm}$ \\
\hline F (calculado) & $0,9 \mu \mathrm{N}$ \\
\hline
\end{tabular}

Uma vez selecionada a força, voltava-se para o modo de varredura do AFM de contato, que devia ser iniciada na extremidade superior ou inferior da janela. Deviam já estar configurados outros parâmetros como o tamanho da janela de varredura, número de linhas e velocidade de varredura. Foi utilizado o mesmo mecanismo de obtenção de imagem (figura 3.20), porém com força suficiente para produzir linhas na superfície do PMMA. 


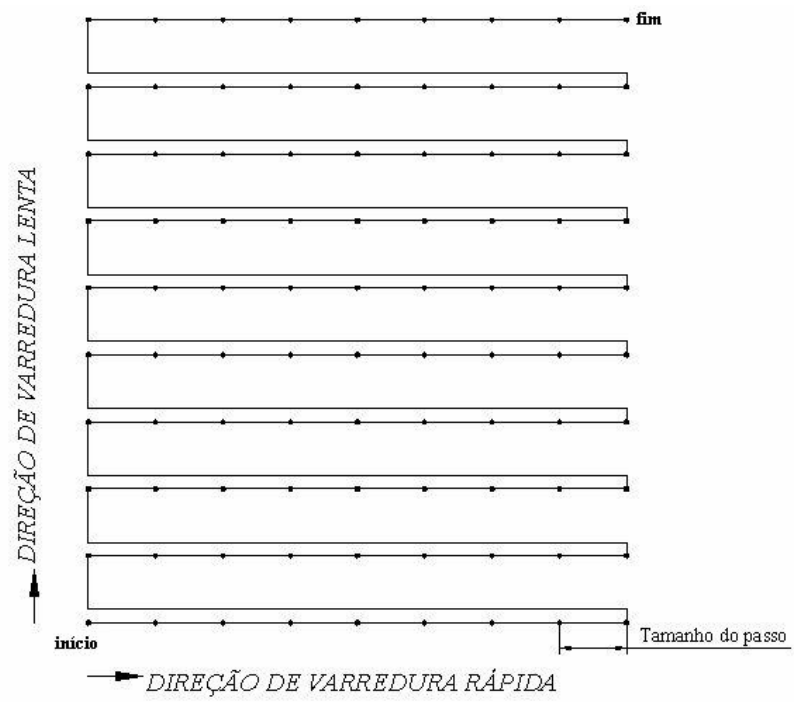

Figura 3.20 - Esquema de varredura para obtenção de imagens.

$\mathrm{Na}$ fase de testes foram realizadas nanolitografias com scan sizes de 10, 20 e $40 \mu \mathrm{m}$. Para a nanolitografia dos dispositivos 1 e 2 foi utilizado scan size de $40 \mu \mathrm{m}$, com os mesmos procedimentos de nanolitografia apresentados anteriormente. A única diferença foi que a amostra 2 foi girada de $90^{\circ}$ em relação à primeira para gerar a mesma morfologia, mas no sentido ortogonal.

Assim, todos os dispositivos estavam prontos para serem montados no arranjo experimental.

\subsubsection{Montagem do arranjo experimental}

$\mathrm{O}$ arranjo experimental consistiu dos três diferentes dispositivos, montados em um porta-amostras, cujas resistências entre terminais foram medidas (figura 3.21), lembrando que os dispositivos 1 e 2 possuem nanocomponentes com direções ortogonais de morfologias, enquanto que a amostra 3 é um dispositivo de compensação sem estruturas.

Os dispositivos ficaram presos por uma fita dupla face ao porta-amostras de teflon. A este porta amostras chegavam os fios de cobre de $1,8 \mathrm{~mm}$, bem presos por parafusos. Os fios de cobre de 0,4 $\mathrm{mm}$ foram soldados aos fios de 1,8 $\mathrm{mm}$ com estanho em uma extremidade e colados aos dispositivos pela outra extremidade com cola de prata. O porta-amostras de teflon foi desenvolvido com o objetivo de facilitar os contatos com os dispositivos. 


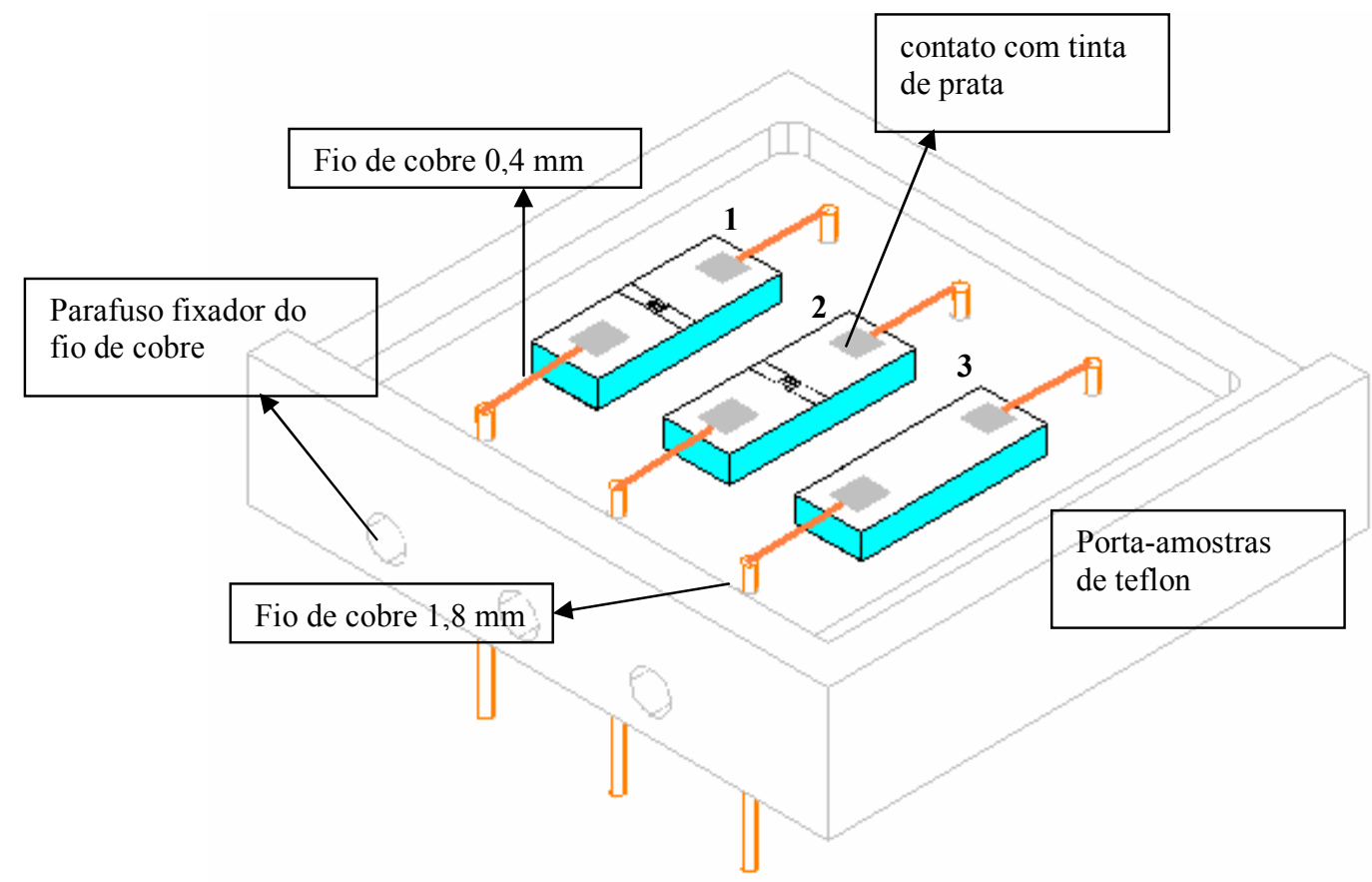

Figura 3.21 - Arranjo experimental com os três dispositivos e respectivos conectores. As regiões de micro e nanolitografia estão representadas nos dispositivos 1 e 2 fora de escala.
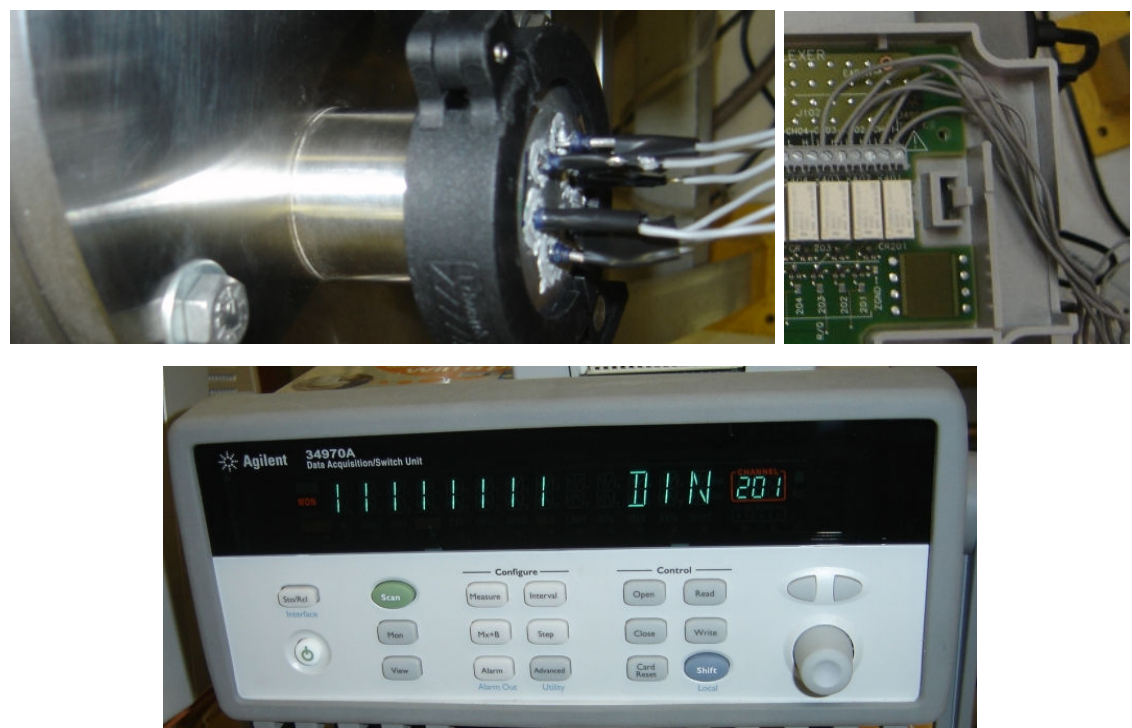

Figura 3.22 - a-) Flange com fios para medição de resistências b-) conexão com módulo eletrônico e c-) módulo de aquisição de dados.

O porta amostras foi posicionado na câmara de deposição do MePIIID, a $7 \mathrm{~cm}$ da saída do filtro de partículas. As outras extremidades dos fios de cobre de 1,8 mm chegavam a 
um flange passador de corrente com seis terminais, fabricado especialmente para esta aplicação, como pode ser visto na figura 3.22. Externamente à câmara, os fios foram conectados ao módulo eletrônico de aquisição de dados modelo 34970A da Agilent para medição das três resistências simultaneamente.

\subsubsection{Deposição do filme espesso}

A deposição do filme espesso de ouro, de aproximadamente $180 \mathrm{~nm}$ de espessura, teve a função de consolidar os contatos entre fios e substratos, de forma que houvesse uma interface de qualidade com o filme fino.

Antes da deposição do filme espesso, uma amostra de calibração foi utilizada para determinação da taxa de deposição do sistema MePIIID. Esta amostra consistia em um pedaço de lâmina de silício, com um traço de tinta atravessando-a (figura 3.23 a). Após serem depositados 2520 pulsos ( 42 minutos) de plasma de ouro (figura $3.23 \mathrm{~b}$ ), a tinta coberta com o filme foi removida da superfície com acetona, restando dois degraus entre o filme de ouro e a superfície do silício.
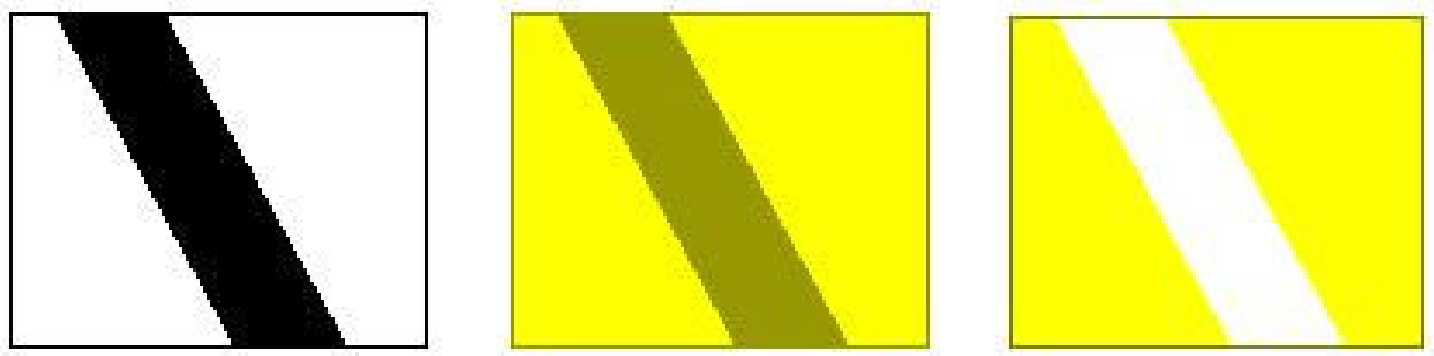

Figura 3.23 - Esquema de medição de espessura de filmes finos - a) Pedaços de silício com traço de tinta, b) após deposição e c) após remoção da tinta.

Três imagens, de $50 \mu \mathrm{m} \times 50 \mu \mathrm{m}$, de AFM de contato desses degraus foram capturadas e três medidas foram feitas em cada imagem. A espessura média calculada foi de $(126 \pm 2) \mathrm{nm}$, resultando em taxa de deposição de cerca de $0,54 \AA$ /pulso para o ouro em vácuo de base de $6 \times 10^{-6}$ torr.

O filme espesso deveria ser depositado apenas nas áreas dos contatos e também distante das bordas dos dispositivos, pois havia possibilidade de defeitos nas extremidades da superfície as quais poderiam provocar condução nestas áreas. Para isso foram utilizadas duas máscaras, cuja montagem no porta amostras é mostrada nas figuras 3.24 e 3.25. 
A máscara da figura $3.24 \mathrm{a}$, com cerca de $1,8 \mathrm{~mm}$ de espessura, selecionou uma região livre das bordas e a máscara da figura $3.24 \mathrm{~b}$, de largura de $5 \mathrm{~mm}$ selecionou a região onde foi depositado o filme fino posteriormente.

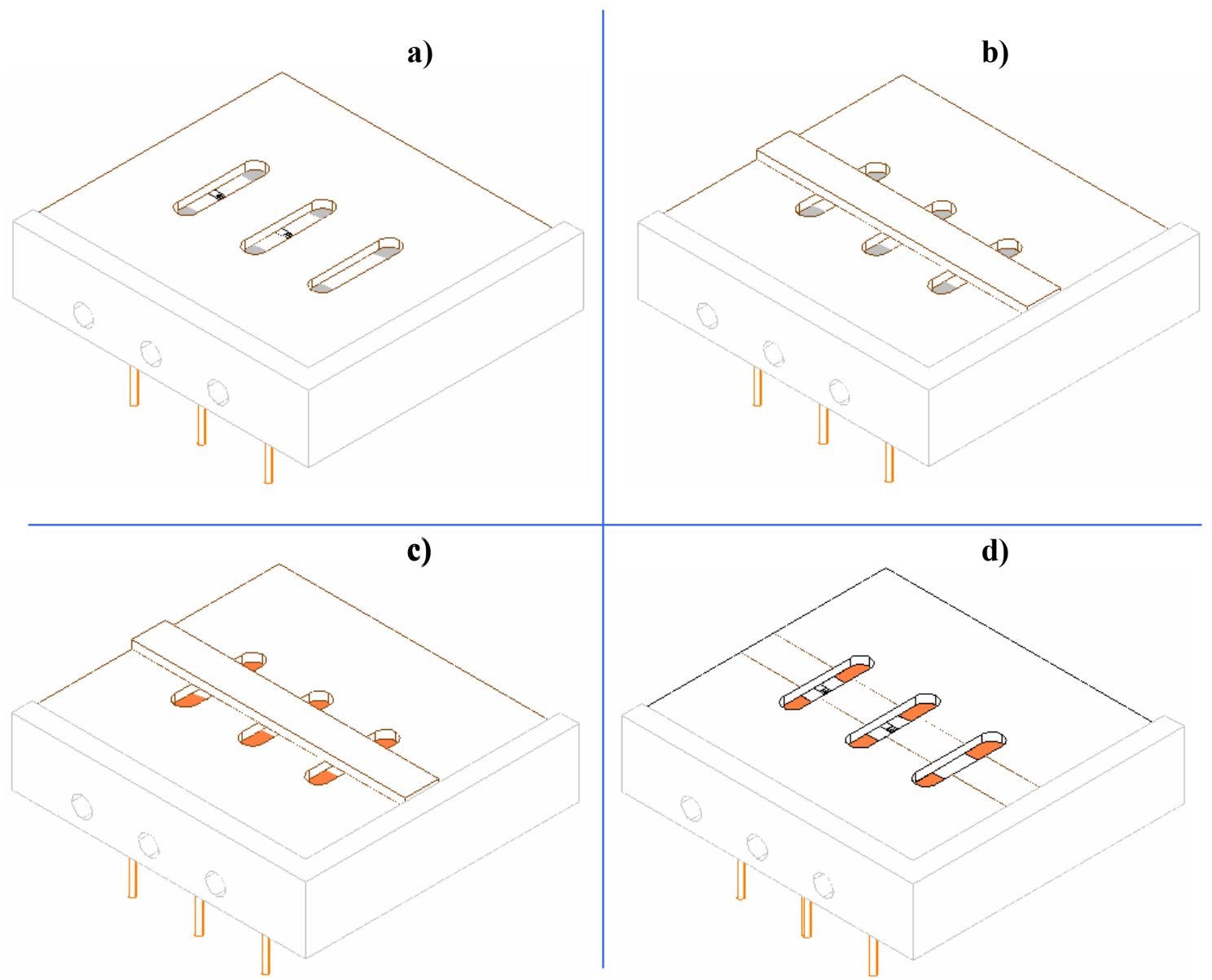

Figura 3.24 - a) Seleção de região livre de bordas, b) Seleção de região do filme fino a ser depositado posteriormente, c-) Deposição de camada espessa e d-) Amostras prontas para deposição do filme fino.

Note que a máscara menor indicada na figura $3.24 \mathrm{~b}$ estava afastada das superfícies das amostras de aproximadamente $2 \mathrm{~mm}$. O objetivo deste procedimento estava em criar uma pequena região difusa de filme de ouro, similar em todos os dispositivos, garantindo um contato de excelente qualidade entre os filmes ultrafinos que foram posteriormente depositados.

Na figura 3.25 é mostrada a montagem do porta amostras no suporte padrão com folha de acetato do MePIIID, onde os fios passam por trás.

Foram medidas as resistências entre cada filme espesso e a saída do seu respectivo fio, conectado ao módulo de aquisição de dados. Os valores foram inferiores a 0,4 ohm. 


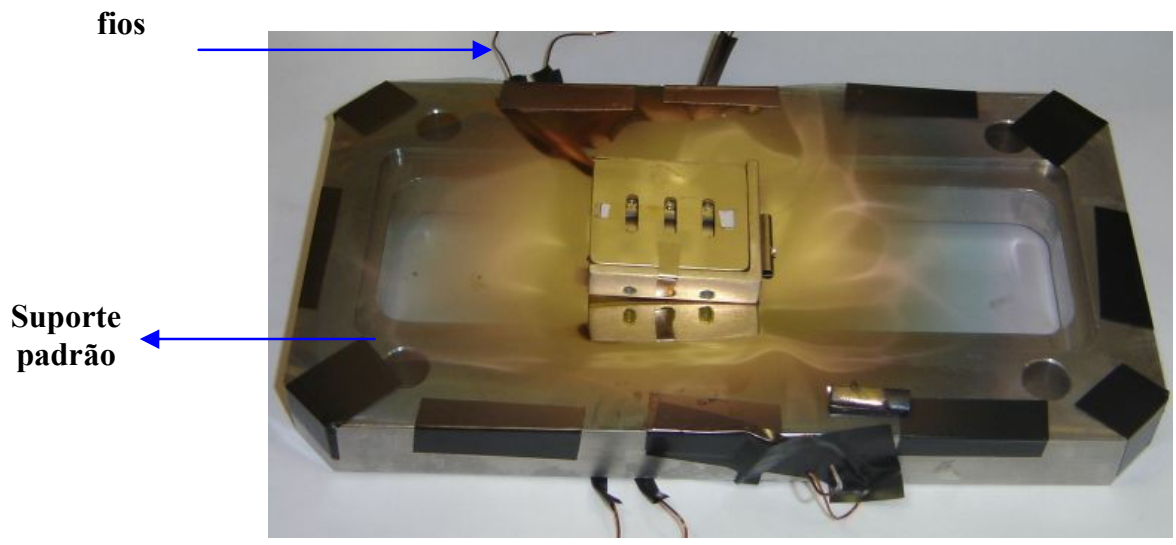

Figura 3.25 - Montagem do porta amostra em suporte de inox.

O arranjo estava pronto para a deposição do filme fino. Para esta etapa, a máscara maior (figura 3.24a) foi recolocada e foram medidas as resistências de cada dispositivo durante a deposição dos filmes finos de ouro, a cada três pulsos. Os resultados serão apresentados e discutidos no próximo capítulo. 


\section{CAPÍTULO IV \\ Resultados e Discussão}

\subsection{Nanolitografia por AFM de contato}

Em uma etapa inicial do trabalho foi necessário o desenvolvimento do processo de nanolitografia por AFM de contato, que acabou consistindo em um subproduto relevante.

Logo nos primeiros testes de nanolitografia foi observado que o tamanho do comprimento de onda $\Lambda$ era dado pela dimensão da janela de varredura (área nanolitografada) dividido pelo número de linhas de varredura. Portanto, para uma janela de varredura de $(20 \mu \mathrm{m})^{2}$ e 512 linhas se esperava uma periodicidade principal de $39 \mathrm{~nm}$.

Mas com o andamento de diversos testes foram observadas outras periodicidades não esperadas. A partir destas observações deduziu-se que para uma janela de $40 \mu \mathrm{m}$ x $40 \mu \mathrm{m}$ apareceria como periodicidade principal o valor de $\Lambda=78 \mathrm{~nm}(40 \mu \mathrm{m} / 512)$, mas também componentes adicionais de $39 \mathrm{~nm}, 27 \mathrm{~nm}$ e até $20 \mathrm{~nm}$. Assim, esta dimensão de janela foi utilizada para nanolitografia dos dispositivos 1 e 2 . A necessidade de usar essa maior área de varredura está na garantia de total preenchimento do espaço entre microcanaletas pela morfologia nanolitografada.

Para a obtenção de periodicidade principal de $\Lambda=20 \mathrm{~nm}$, deveria portanto ser usada uma área de varredura de $10 \mu \mathrm{m}(10 \mu \mathrm{m} / 512=19 \mathrm{~nm})$. Porém, experimentos mostraram total falta de uniformidade para esta janela nanolitografada. Considerando-se que a nanolitografia pelo contato mecânico da ponta com a superfície da amostra promova o alinhamento de aglomerados de cadeias poliméricas, uma possível justificativa é que, por causa das dimensões destes aglomerados, talvez não seja possível obter qualquer periodicidade desejada. A figura 4.1 mostra uma imagem de $543 \mathrm{~nm}$ x $543 \mathrm{~nm}$, obtida por AFM de contato intermitente, de uma região nanolitografada com $\Lambda=39 \mathrm{~nm}$. Nesta imagem é possível notar claramente a presença desses aglomerados, ou pequenos grãos.

Outra justificativa possível seria o fato da ponta ter raio da ordem de 10 a $20 \mathrm{~nm}$, o que levaria a uma superposição de linhas adjacentes na nanolitografia, o que gera desordem considerável. 


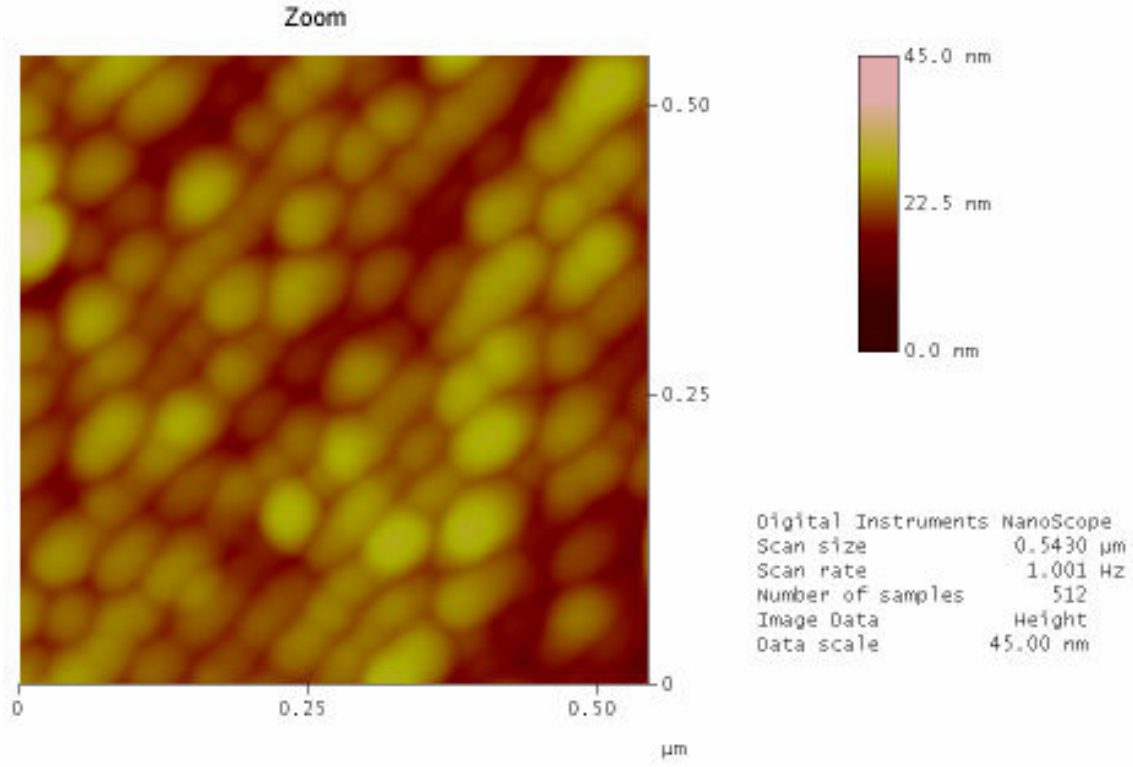

Figura 4.1 - Imagem sem processamento mostrando alinhamento de aglomerados.

A figura 4.2 mostra outra caracterização em AFM de contato intermitente do resultado da nanolitografia para $\Lambda=78 \mathrm{~nm}$, também com ângulo de varredura de $45^{\circ}$.

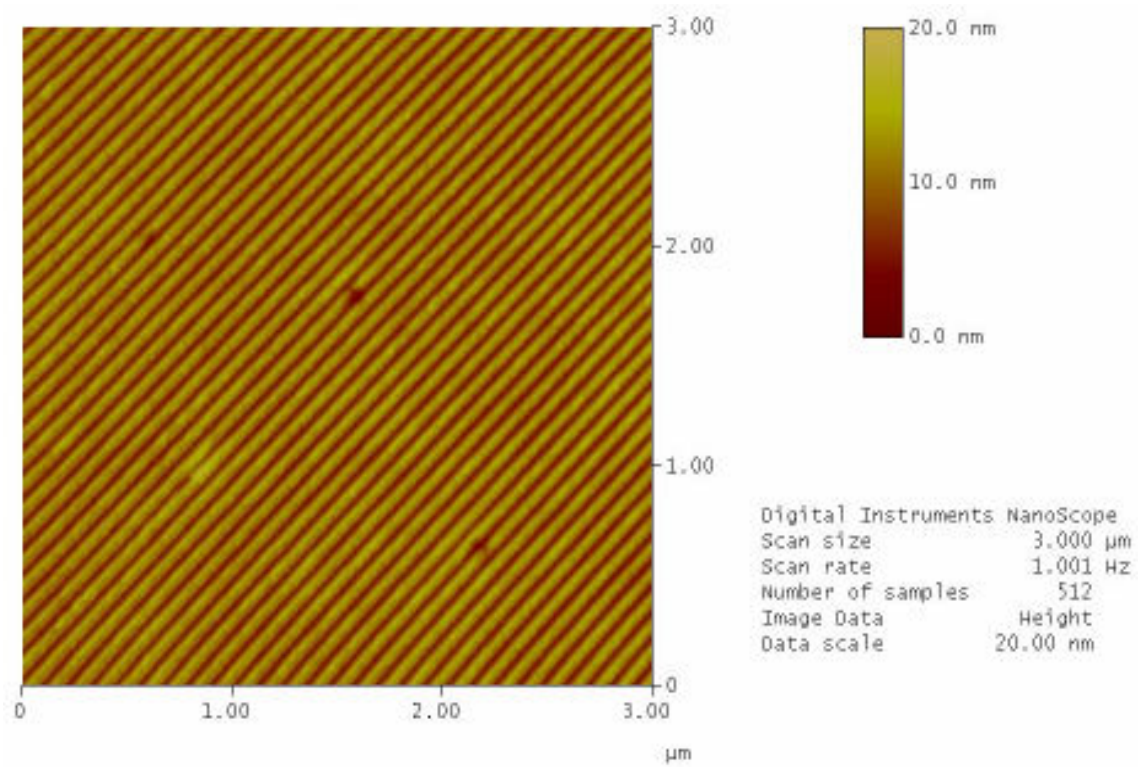

Figura 4.2 - Imagem sem processamento para observação da uniformidade da periodicidade.

Fazendo-se um corte de secção da imagem anterior, pôde-se medir a periodicidade principal $\Lambda=78 \mathrm{~nm}$, como indicado na figura 4.3. As amplitudes $\mathrm{h}$ correspondentes foram em média $8 \mathrm{~nm}$. Outras periodicidades não principais e amplitudes correspondentes, presentes na 
região nanolitografada, puderam ser determinadas a partir de processamento de imagem por filtro de Transformada de Fourier e estão listadas na tabela 4.1.

Tabela 4.1 - Periodicidades e amplitudes associadas presentes em região nanolitografada de $(40 \mu \mathrm{m})^{2}$.

\begin{tabular}{|l|c|}
\hline Periodicidade (nm) & Amplitude h (nm) \\
\hline 20 & 0,38 \\
\hline 27 & 0,80 \\
\hline 39 & 1,12 \\
\hline 78 & 8,00 \\
\hline
\end{tabular}

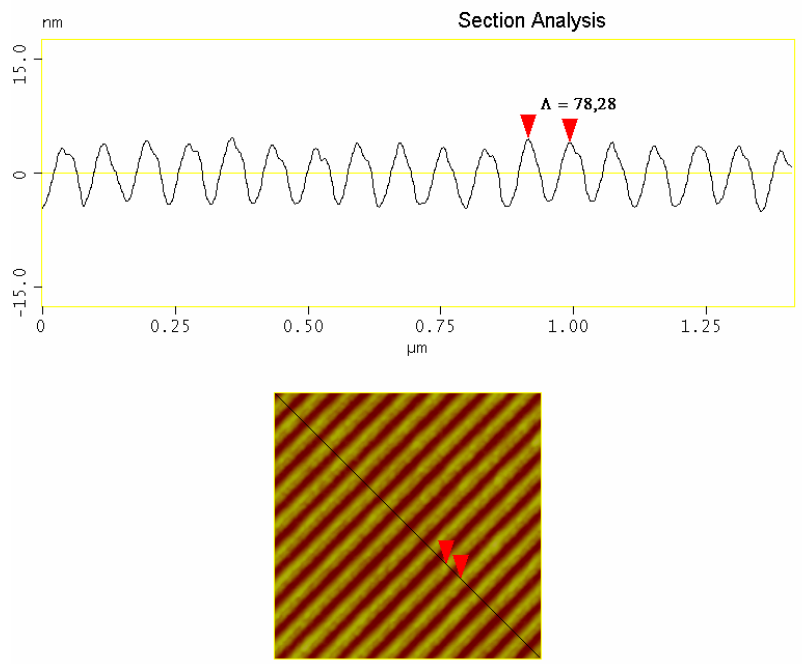

Figura 4.3 - Análise de seção da imagem processada de região nanolitografada.

Uma análise mais detalhada, que aborda de forma semi-quantitativa as relações entre janelas de varredura, periodicidades e amplitudes, está abordada na publicação que pode ser vista no Anexo A, já aceita para publicação pelo periódico Review of Scientific Instruments. Os resultados dos primeiros testes também foram publicados como resumo no V Encontro da Sociedade Brasileira de Pesquisa em Materiais [70].

\subsection{Deposição do filme fino de ouro}

Os contatos elétricos entre as extremidades dos três dispositivos apresentaram resistências iniciais infinitas. A medição foi iniciada com 16 pulsos, pois apenas a partir desse ponto é que as medidas de resistência passaram a apresentar estabilidade. Então, a cada 3 
pulsos a resistência de cada dispositivo foi medida, concluindo o experimento com um total de 201 pulsos. A precisão de medida de resistência no módulo de aquisição de dados é de até seis dígitos, o que foi absolutamente suficiente para as necessidades deste trabalho.

Um esquema ilustrando os dispositivos após a deposição do filme fino é mostrado na figura 4.4, com o filme fino na região central e o filme espesso nas extremidades. A figura 4.5a mostra as dimensões do mascaramento para a deposição dos filmes finos. A figura $4.5 \mathrm{~b}$ mostra as medidas das regiões onde se obteve os filmes finos. As medidas apresentadas são aproximadas, desde que nas bordas do mascaramento ocorreu no filme fino uma região difusa. Esse fato não afetou o experimento, pois o mesmo efeito estava presente nos três dispositivos.

O dispositivo 3 já foi citado como um dispositivo de compensação. Isto porque não é possível promover mascaramento para que apenas a região da nanolitografia, de $20 \mu \mathrm{m}$ x 20 $\mu \mathrm{m}$, receba a deposição de ouro. Portanto, deve-se descontar o efeito do filme fino fora da região de interesse. Assim:

$\mathrm{R}_{1}=r_{1}+\mathrm{R}_{3}$

$\mathrm{R}_{2}=r_{2}+\mathrm{R}_{3}$

onde $\mathrm{R}_{1}, \mathrm{R}_{2}$ e $\mathrm{R}_{3}$ são as resistências medidas a cada 3 pulsos e $r_{1}$ e $r_{2}$ as resistências dos nanocomponentes.

Nota-se em Eq. 4.1 e Eq. 4.2 que $\mathrm{R}_{3}$ é considerada simplesmente como uma resistência em série com as resistências das regiões nanolitografadas, já que o comprimento do filme fino $\mathrm{L}=5 \mathrm{~mm}$ é muito maior do que as regiões de microcanaletas $(\mu=20 \mu \mathrm{m})$, onde não há passagem de corrente e as quais não existem no dispositivo 3.

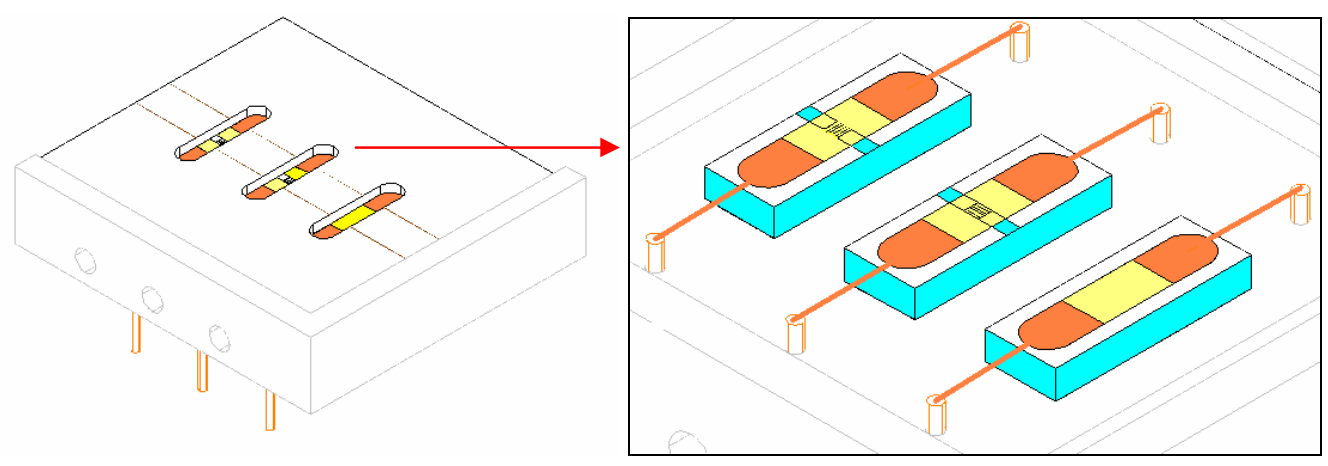

Figura 4.4 - Esquema dos dispositivos após deposição do filme fino. 

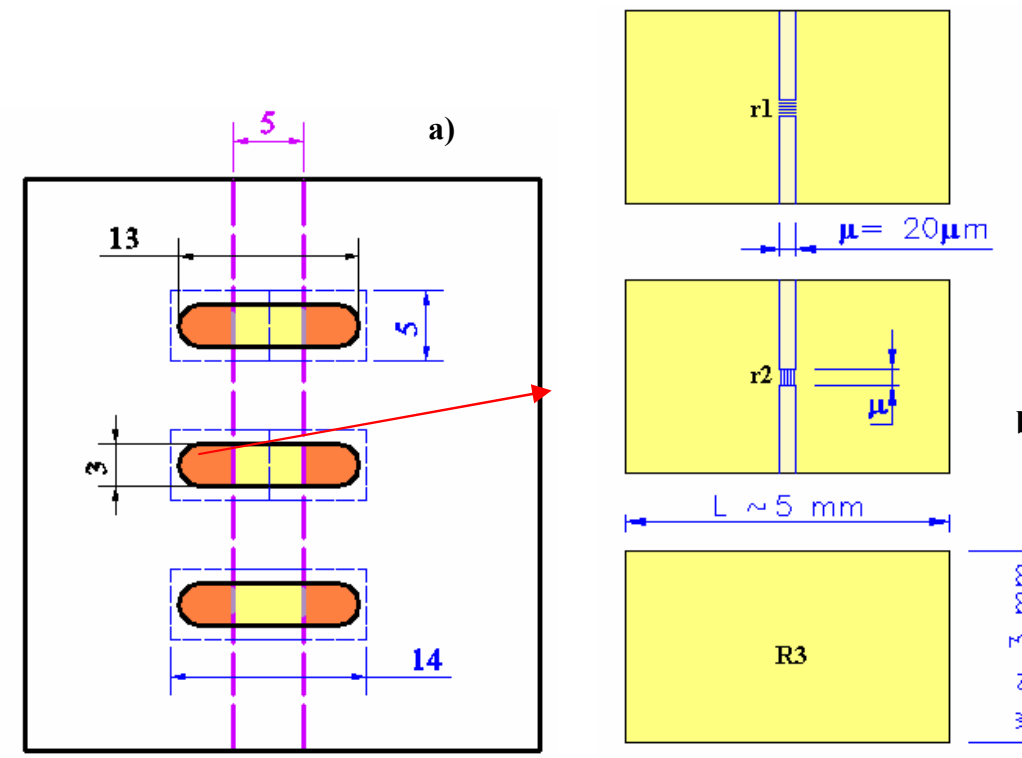

b)

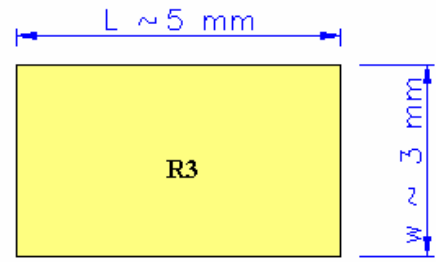

Figura 4.5 - a) Medidas de mascaramento (em mm) e b) medidas das regiões onde se depositou os filmes finos.

A resistência de um filme fino é dada por:

$\mathrm{R}=\frac{\rho \mathrm{L}}{\mathrm{wd}}$

onde $\rho$ é a resistividade, $\mathrm{d}$ a espessura do filme e L e w o comprimento e largura de um filme fino, respectivamente.

Portanto, a resistividade pode ser escrita como:

$\rho=\frac{\text { Rwd }}{\mathrm{L}}$

A resistividade do filme fino do dispositivo de compensação 3 é dada por:

$$
\rho_{3}=R_{3} \cdot d\left(\frac{w_{3}}{L_{3}}\right)
$$

Supondo $\mathrm{L}_{1}=\mathrm{L}_{2}=\mathrm{L}_{3}$ e $\mathrm{w}_{1}=\mathrm{w}_{2}=\mathrm{w}_{3}$, o que é garantido pela precisão de fabricação das máscaras $(0,1 \mathrm{~mm})$, temos: 
$\mathrm{R}_{1}=\frac{\rho_{1} \mu}{\mu \mathrm{d}}+\mathrm{R}_{3}=\frac{\rho_{1}}{\mathrm{~d}}+\mathrm{R}_{3}$

A resistividade do nanocomponente 1 é dada portanto por:

$\rho_{1}=\left(\mathrm{R}_{1}-\mathrm{R}_{3}\right) \mathrm{d}$

e, analogamente, a resistividade do nanocomponente 2:

$\rho_{2}=\left(R_{2}-R_{3}\right) d$

A espessura d em nanometros é definida como a taxa de deposição de ouro multiplicada pelo número de pulsos. Durante a deposição do filme fino, amostras de controle foram posicionadas sobre a máscara para posterior medida de degrau por AFM e cálculo da taxa de deposição. Após a deposição do filme fino, novas amostras de controle foram colocadas nos lugares dos dispositivos e receberam 180 pulsos de ouro. A taxa de deposição calculada para as duas situações foi de $0,54 \AA$, uniforme para as três posições e ainda a mesma determinada quando da deposição do filme espesso. Isso mostra a repetibilidade da deposição para uma mesma montagem e geometria.

De posse das espessuras e a partir das Eqs. 4.5, 4.7 e 4.8, são obtidos os gráficos da figura 4.6 e figura 4.7 , com a resistividade normalizada pelo valor de resistividade de bulk $\left(\rho_{\text {bulk }}=23,5 \Omega . \mathrm{nm}\right)$.

A primeira informação que podemos tirar dos gráficos a seguir é que a ordem de grandeza das resistividades normalizadas, de $10^{6}$, está bastante alta. Utilizando-se a Eq. 2.53 (Capítulo II) para o cálculo de resistividade elétrica para filmes finos de ouro, segundo modelo teórico apresentado, é obtido o gráfico da figura 4.8. Nota-se no gráfico que os valores de resistividade são muito menores do que os resultados obtidos. É válido salientar que o modelo teórico tem como alicerce dados experimentais muito precisos [14]. 


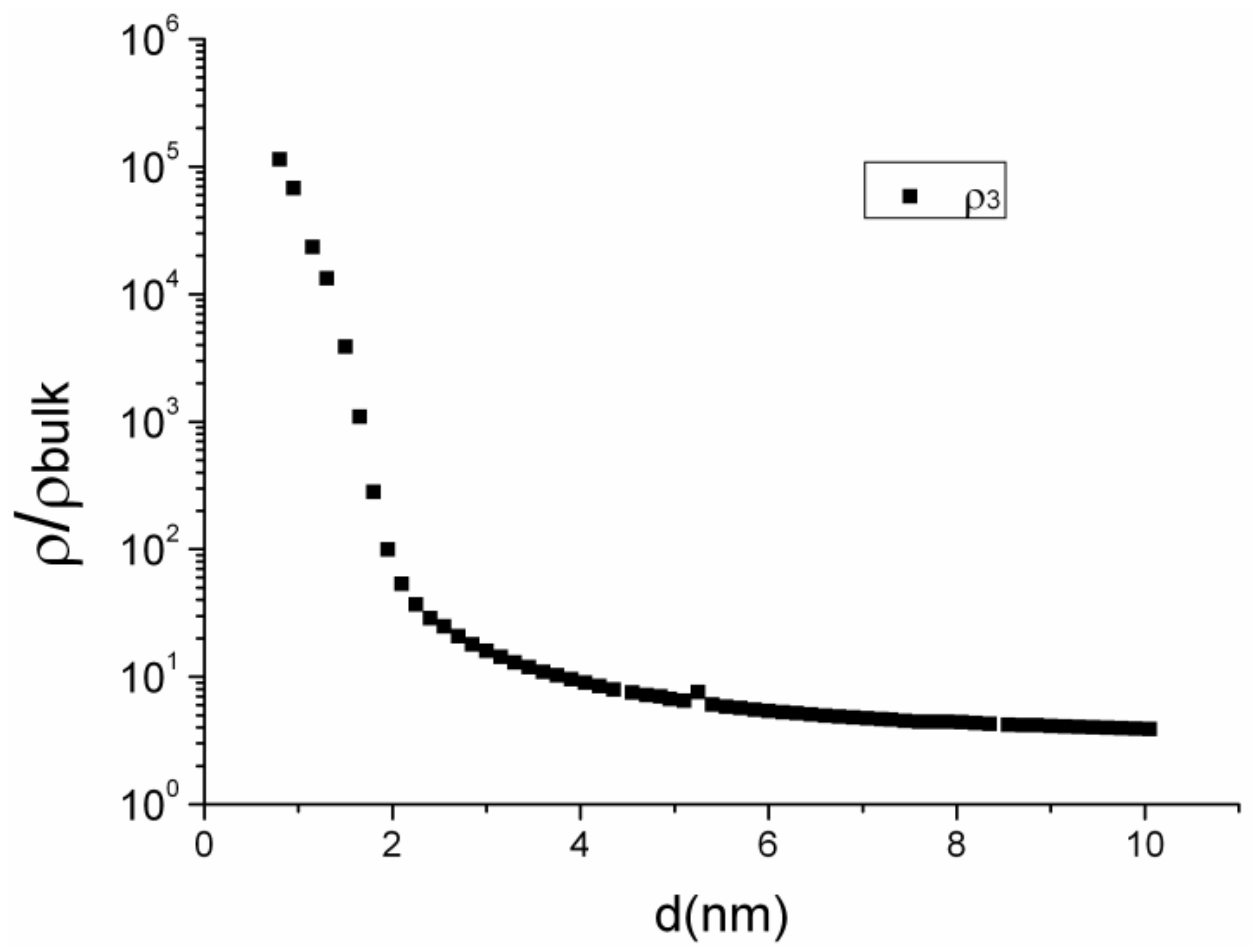

Figura 4.6 - Resistividade em função da espessura para dispositivo 3.

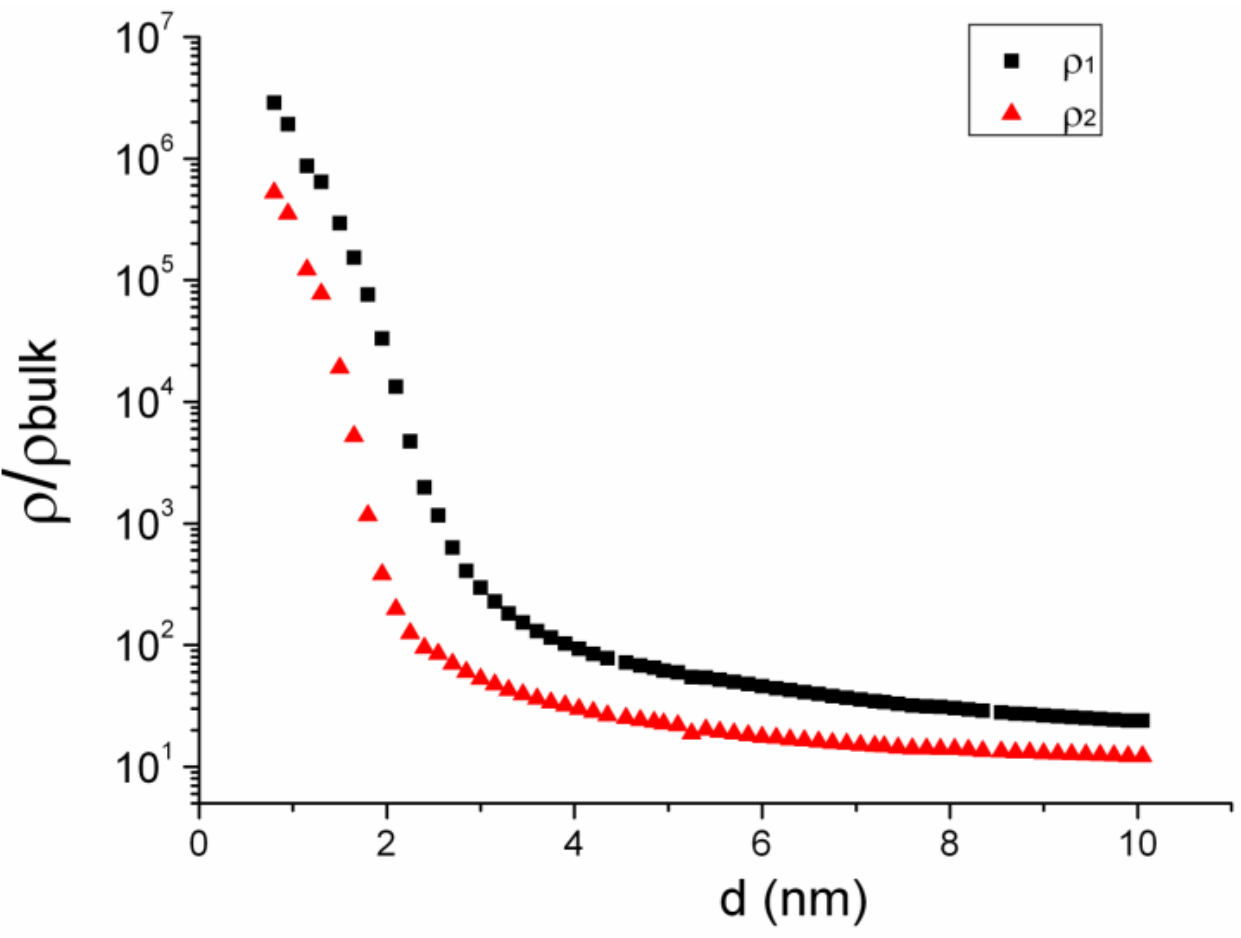

Figura 4.7 - Resistividade em função da espessura para dispositivos 1 e 2. 


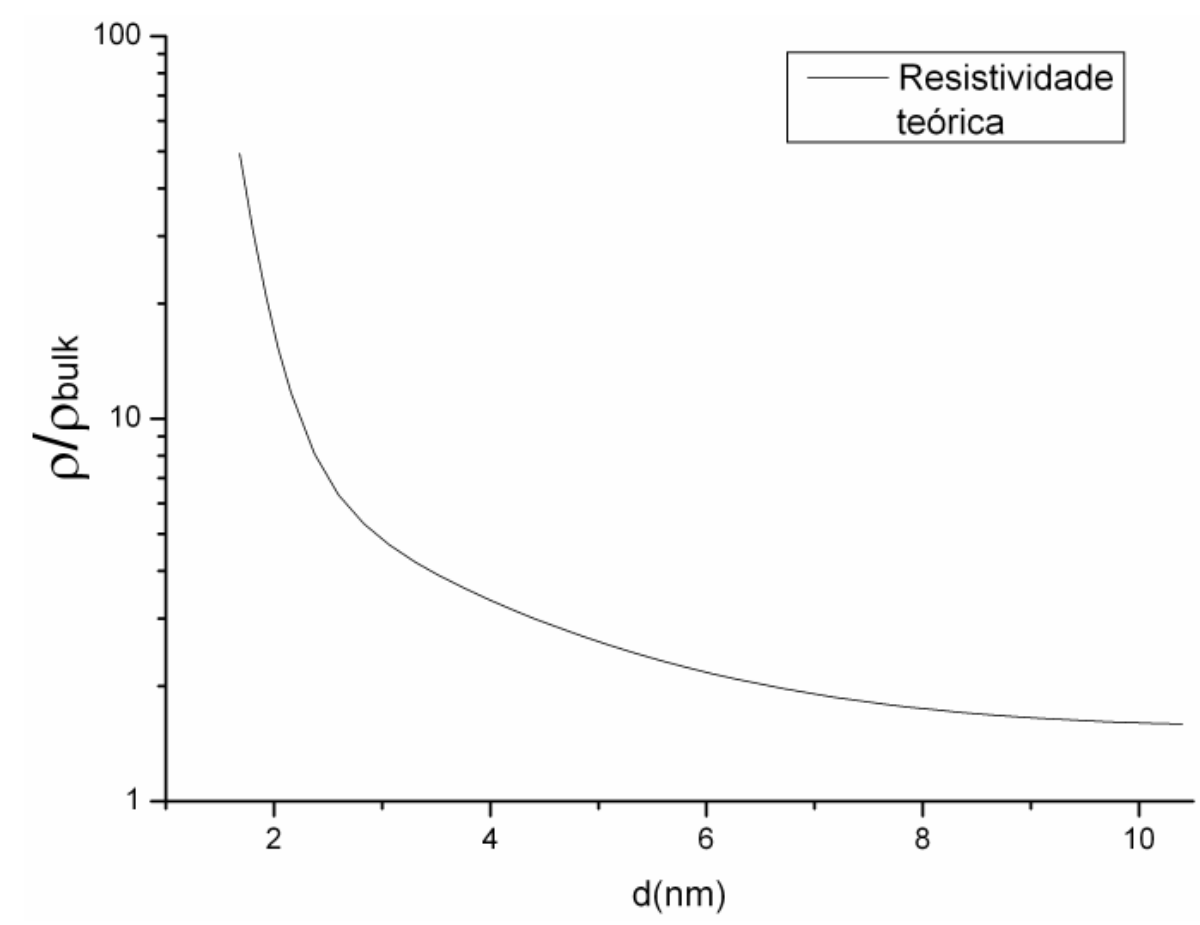

Figura 4.8 - Gráfico da resistividade utilizando modelos teóricos, segundo Eq.(2.53.)

Portanto, os resultados mostram que o material formado não apresenta as características de filmes finos de ouro.

Com o objetivo de constatar qual efeito poderia gerar estas diferenças, foi utilizado exatamente o mesmo arranjo experimental além dos mesmos procedimentos e condições de deposição para medir a resistência de três novas amostras. A diferença é que as amostras foram todas preparadas como o dispositivo 3, ou seja, sem litografias, apenas com o filme de PMMA. Outro detalhe mudado foi garantir o aterramento elétrico das amostras durante os pulsos de deposição para eliminar qualquer possível efeito de geração de potencial nas amostras.

O gráfico da figura 4.9 apresenta os dados obtidos neste novo experimento, confirmando a ordem de grandeza de resistividade e eliminando qualquer efeito indesejado que poderia influenciar nas medidas. 


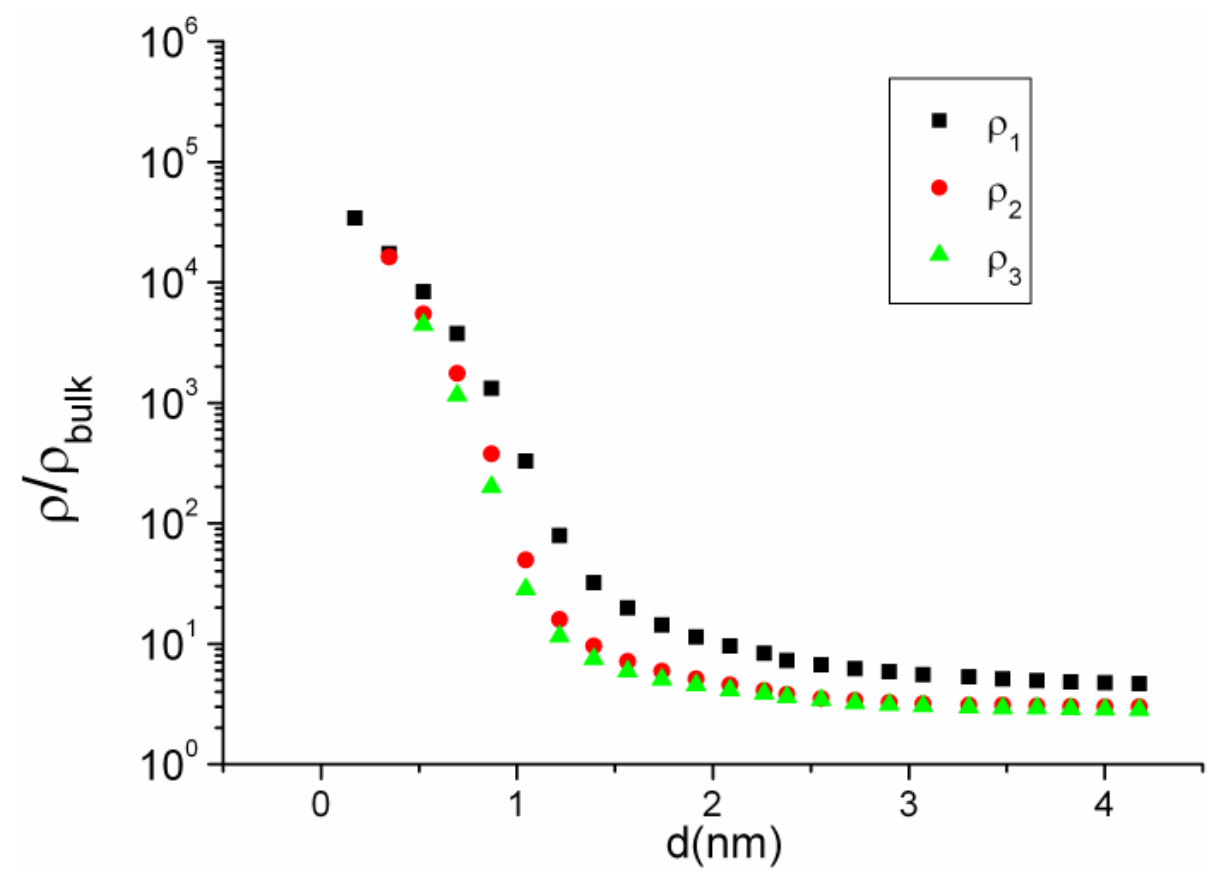

Figura 4.9 - Resistividades obtidas para experimento de comprovação de resultados.

Uma possibilidade para justificar o alto valor de resistividade encontrado seria a ocorrência de implantação iônica de ouro na matriz polimérica, no início da deposição. Especulando-se essa hipótese, foi realizada uma simulação utilizando o programa SRIM [71], onde foram considerados o ângulo de incidência normal e a energia cinética com que os íons de ouro chegam à superfície do polímero, que corresponde a $49 \mathrm{eV}[72,73]$. O resultado é apresentado na figura 4.10, indicando que a profundidade média de implantação, para esse caso específico, é estimada em $2,7 \mathrm{~nm}$. Perante esse resultado, começa a ficar clara a ocorrência de implantação iônica, especialmente na fase inicial do experimento.

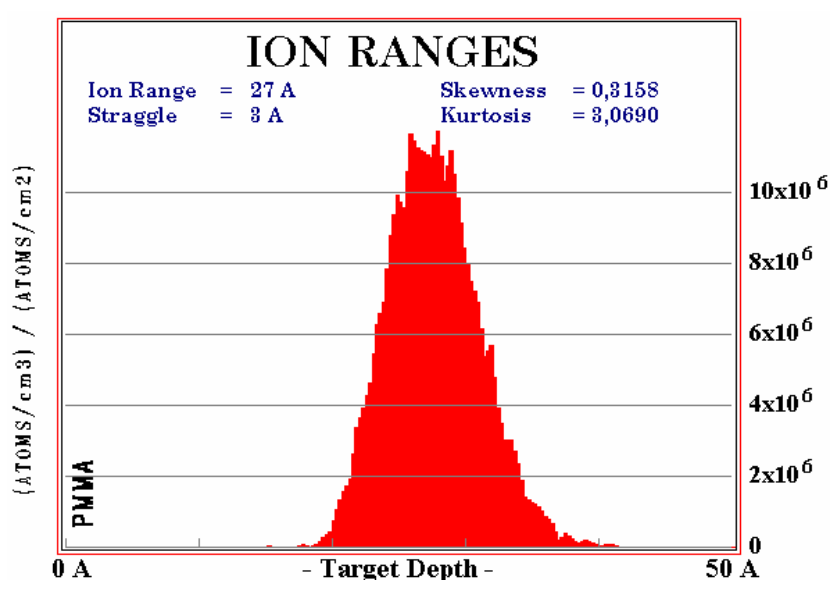

Figura 4.10 - Simulação da penetração dos íons de Au com energia cinética de 49 eV na matriz de PMMA. 
Um novo experimento foi realizado com a finalidade de verificar quantos pulsos produziram implantação iônica de ouro sobre PMMA, antes do início da formação do filme do filme de ouro propriamente dito.

O experimento consistiu em fabricar degraus em um filme de PMMA sobre vidro e depositar ouro sobre essa amostra. Inicialmente foi depositado um filme de $50 \mathrm{~nm}$ de PMMA sobre um substrato de vidro e, através de microlitografia por feixe de elétrons, foram criadas quatro estruturas de $30 \mu \mathrm{m} \times 100 \mu \mathrm{m}$, como indicado na figura $4.11 \mathrm{a}$, criando-se assim os 8 degraus numerados nessa figura. As alturas (h1) desses degraus foram então medidas (ver figura 4.11b) por AFM no modo contato intermitente. Em seguida a amostra foi levada ao MePIIID e, em condições idênticas às dos experimentos onde se mediu resistividade, foi depositado um filme de ouro de cerca de $100 \mathrm{~nm}$. Com as novas medidas realizadas nos degraus (h2), foi possível estimar quanto de ouro foi implantado na superfície através da simples subtração h1-h2 (figuras 4.11 b e 4.11 c).

Foram feitas três medições para cada um dos degraus, antes e após a deposição de ouro. A média destes valores e também a diferença h1-h2 são mostradas na tabela 4.2. Os resultados mostram que, em média, o equivalente a $14 \mathrm{~nm}$ de ouro são implantados até que se comece a formar um filme sobre a superfície.

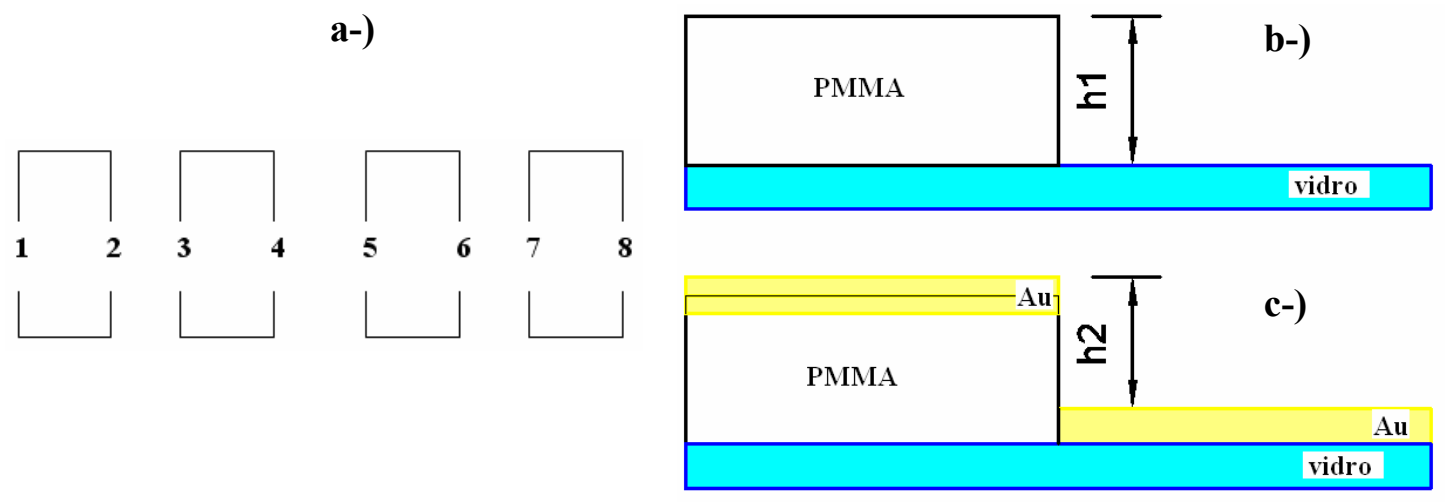

Figura 4.11 - a) Quatro estruturas de $30 \mu \mathrm{m}$ x $100 \mu \mathrm{m}$ usadas na litografia por feixe de elétrons e b-) Perfil gerado no PMMA sobre vidro c-) Representação do perfil após deposição de 100 nm de ouro.

Surpreende o fato de que o equivalente a $14 \mathrm{~nm}$ de filme seja implantado no PMMA, enquanto a simulação do SRIM prevê que a implantação se dá em média à cerca de $3 \mathrm{~nm}$ de profundidade. A justificativa para isso está no fato da simulação não considerar a condição de saturação do meio onde ocorre a implantação, prevendo corretamente apenas implantações com doses muito menores do que as usadas em nosso experimento. 
Tabela 4.2 - Média das medidas de altura dos degraus de PMMA antes e após deposição de ouro.

\begin{tabular}{|c|c|c|}
\hline h1 & h2 & h1-h2 \\
\hline 51,63 & 36,43 & 15,2 \\
\hline 51,89 & 36,95 & 14,94 \\
\hline 50,4 & 35,92 & 14,98 \\
\hline 46,69 & 36,73 & 12,96 \\
\hline 49,63 & 34,5 & 15,13 \\
\hline 49 & 35,22 & 13,78 \\
\hline 49,11 & 35,1 & 14,01 \\
\hline 48,7 & 35,91 & 12,79 \\
\hline
\end{tabular}

Portanto, os valores de resistividade obtidos nos três dispositivos descritos correspondem às medidas de resistência do PMMA implantado com ouro, desde que foi depositado um equivalente a 10,85 nm de ouro no experimento.

Mesmo considerando que se está lidando com um material diferente do inicialmente planejado, pode-se calcular os fatores de anisotropia $\rho_{1} / \rho_{2}$ e plotá-los em função do equivalente à espessura do filme, conforme figura 4.12. No gráfico é mostrado claramente um comportamento de anisotropia acentuado pelos nanocomponentes para o equivalente em espessuras menores do que $3 \mathrm{~nm}$, inclusive com um pico em 1,95 nm de equivalente em espessura.

Entretanto é importante notar que não é a espessura que varia, mas sim o material. A primeira mudança, uma vez constatada a implantação, é que o PMMA torna-se cada vez mais condutor durante a deposição dos íons. Além disso, como as ligações moleculares no polímero são da ordem de poucos elétron-volts, os íons de ouro com $49 \mathrm{eV}$ induzem a quebra de cadeias de PMMA nas regiões nanolitografadas, bastante superficiais, desorganizando o polímero e tornando a superfície isotrópica. Este dois fatores em conjunto podem ser responsáveis pela queda da anisotropia observada no gráfico da figura 4.12.

Outro resultado inesperado foi a obtenção de valores maiores de resistividade para o nanocomponente do dispositivo 1 , onde a corrente eletrônica passa no sentido ortogonal às modulações senoidais, uma vez que se esperava valor maior de resistividade no dispositivo 2 . Dessa forma, especula-se ainda que as cadeias poliméricas tenham sido alinhadas no sentido ortogonal ao alinhamento dos aglomerados. 


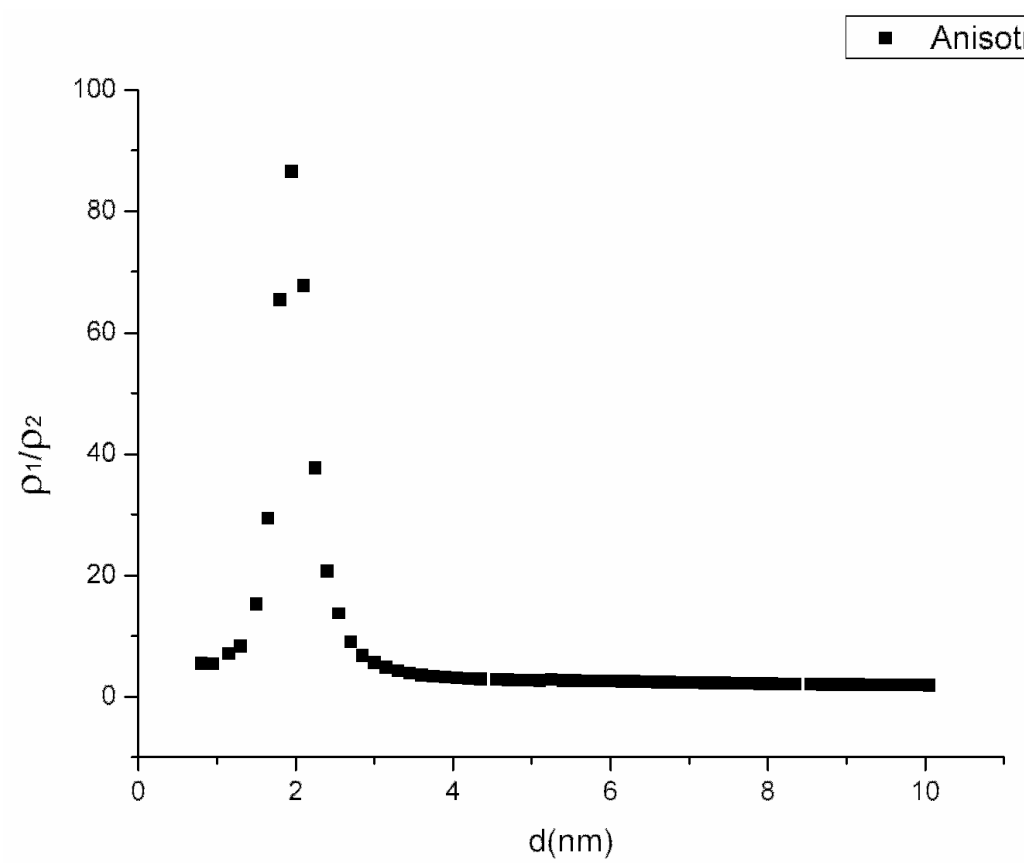

Figura 4.12 - Anisotropia $\rho_{1} / \rho_{2}$ em função da espessura.

O resultado também sugere que a periodicidade da superfície do PMMA, criada em uma das direções através de nanolitografia por AFM, apresenta comprimento de onda $\Lambda$ muito menor do que as medidas por AFM. Essa suspeita baseia-se nas previsões teóricas apresentadas no Capítulo II onde, para se conseguir anisotropias com fator ordem de 90, como apresentado na figura 4.12, os comprimentos de onda morfológicos envolvidos precisam ser da ordem do comprimento de onda de Fermi $\lambda_{\mathrm{F}}$.

Uma possível justificativa para esses comprimentos de onda tão pequenos está associada aos resultados da nanolitografia por AFM. Como já citado, as linhas paralelas criadas na superfície do PMMA parecem ser formadas a partir de um alinhamento de aglomerados de cadeias poliméricas. Assim as periodicidades da ordem de grandeza do comprimento de onda de Fermi podem ser as relacionadas a dimensão das cadeias poliméricas que compõem os aglomerados. Essas dimensões são da ordem de 0,8 nm [74-77].

Para dar suporte a essas idéias pode-se usar a Eq. (2.53) para o cálculo do fator de anisotropia $\rho_{1} / \rho_{2}$. Embora não se trate de um filme fino metálico, há uma superfície condutora anisotrópica. Esta superfície tem espessura da ordem de grandeza da profundidade média de implantação dada pela simulação $\operatorname{SRIM}(\sim 2,7 \mathrm{~nm})$. É válido mencionar que a teoria apresentada é também válida para materiais semicondutores [16]. 
Para poder aplicar a teoria, supõe-se que a espessura onde ocorre o efeito é constante. Além disso, como o material condutor (PMMA implantado com Au) dos dispositivos 1 e 2 é o mesmo, eles têm as mesmas propriedades. A única diferença entre os dispositivos é a anisotropia de morfologia da superfície nanolitografada.

Assim, o fator de anisotropia $\rho_{1} / \rho_{2}$ é dado por:

$$
\frac{\frac{\rho_{1}(\mathrm{~d})}{\rho_{\text {bulk }}}}{\frac{\rho_{2}(\mathrm{~d})}{\rho_{\text {bulk }}}}=\frac{1+\frac{\mathrm{C} \Delta_{1}{ }^{2}(\mathrm{~d}) \mathrm{g}_{1}(\mathrm{~d}) \ell_{\mathrm{s}}(\mathrm{d})}{\mathrm{d}^{2}(1-0,15 / \mathrm{d})}}{1+\frac{\mathrm{C} \Delta_{2}{ }^{2}(\mathrm{~d}) \mathrm{g}_{2}(\mathrm{~d}) \ell_{\mathrm{s}}(\mathrm{d})}{\mathrm{d}^{2}(1-0,15 / \mathrm{d})}}
$$

Como a ordem de grandeza da resistividade é muito maior do que 1, este fator somado no segundo membro da equação anterior é desprezível. Assumindo-se todas as condições anteriormente citadas e cancelando-se todos os parâmetros comuns aos dispositivos, o fator de anisotropia é dado por:

$$
\frac{\rho_{1}}{\rho_{2}}=\frac{\Delta_{1}{ }^{2}}{\Delta_{2}{ }^{2}} \frac{g_{1}}{g_{2}}
$$

Considerando-se a morfologia dos dois nanocomponentes, temos para a relação entre os fatores de forma $\mathrm{g}$ dos dois dispositivos:

$$
\frac{\mathrm{g}_{1}}{\mathrm{~g}_{2}}=\frac{\frac{1}{\mathrm{k}_{\mathrm{F}}}\left(\mathrm{h}_{1} / \Delta_{1}\right)^{2}\left(\lambda_{\mathrm{F}} / \lambda_{1}\right)^{2}}{\frac{1}{\mathrm{k}_{\mathrm{F}}}\left(\mathrm{h}_{2} / \Delta_{2}\right)^{2}\left(\lambda_{\mathrm{F}} / \lambda_{2}\right)^{2}} \Leftrightarrow \frac{\mathrm{g}_{1}}{\mathrm{~g}_{2}}=\frac{\left(\mathrm{h}_{1} / \Delta_{1}\right)^{2} \lambda_{2}{ }^{2}}{\left(\mathrm{~h}_{2} / \Delta_{2}\right)^{2} \lambda_{1}{ }^{2}}
$$

Ainda se levando em conta que se está lidando com dois materiais semelhantes e também que o valor médio da rugosidade de um perfil senoidal é dado por $\Delta^{2}=\mathrm{h}^{2} / 2$, obtém-se:

$$
\frac{g_{1}}{g_{2}}=\left(\frac{\lambda_{2}}{\lambda_{1}}\right)^{2}
$$


Substituindo-se a Eq. (4.12) na Eq. (4.10) é obtida simplesmente para a anisotropia de resistividade a relação:

$$
\frac{\rho_{1}}{\rho_{2}}=\left(\frac{h_{1}}{\lambda_{1}}\right)^{2}\left(\frac{\lambda_{2}}{h_{2}}\right)^{2}
$$

Para o dispositivo 1, considera-se como influente no processo da condução elétrica a morfologia dada pelo alinhamento de estruturas finas. Para o PMMA pode-se assumir $h_{1}=$ $\lambda_{1}=0,8 \mathrm{~nm}$ [74-77]. Portanto, para os dispositivos 1 e 2 a anisotropia é dada então por:

$$
\frac{\rho_{1}}{\rho_{2}}=\left(\frac{\lambda_{2}}{h_{2}}\right)^{2}
$$

Os parâmetros morfológicos $\lambda_{2}$ e $\mathrm{h}_{2}$ são as periodicidades e amplitudes, respectivamente, disponíveis na tabela 4.1 .

Adicionando-se aos dados da tabela 4.1 os fatores de anisotropia calculados com a Eq. (4.14), obtém-se a tabela 4.3 a seguir. Nota-se que a periodicidade que gera a anisotropia da ordem de grandeza do pico da figura 4.12 é $(\lambda=78 \mathrm{~nm} ; \mathrm{h}=8 \mathrm{~nm})$. Estes parâmetros de perfil senoidal correspondem à periodicidade principal obtida para a nanolitografia de uma área de $(40 \mu \mathrm{m})^{2}$.

Tabela 4.3 - Fatores de anisotropia para morfologia dos nanocomponentes.

\begin{tabular}{|c|c|c|}
\hline Periodicidade $\lambda(\mathrm{nm})$ & Amplitude $\mathrm{h}(\mathrm{nm})$ & Fator de anisotropia $\rho_{2} / \rho_{1}$ \\
\hline 20 & 0,38 & 2770 \\
\hline 27 & 0,80 & 1139 \\
\hline 39 & 1,12 & 1212 \\
\hline 78 & 8 & 95 \\
\hline
\end{tabular}

Portanto, os nanocomponentes induziram comportamento anisotrópico superficial no processo de condução elétrica, mostrando que a morfologia nanoestruturada é um fator influente. Entretanto, além da periodicidade principal dada pelo processo de nanolitografia por AFM de contato, estruturas muitas mais finas do que as planejadas inicialmente parecem ter gerado os altos fatores de anisotropia de resistividade elétrica. 
Como um estudo preliminar, foram registradas curvas V-I (tensão-corrente) de amostras com PMMA implantado com o equivalente em espessura de 1,95 nm de ouro. Para essas medidas foi utilizado o equipamento HP4140B pA Meter do Laboratório de Sistemas Integráveis (LSI) da Escola Politécnica da USP. A figura 4.13 mostra um dos gráficos obtidos, confirmando comportamento semicondutor das amostras na condição em que ocorreu o pico de anisotropia.

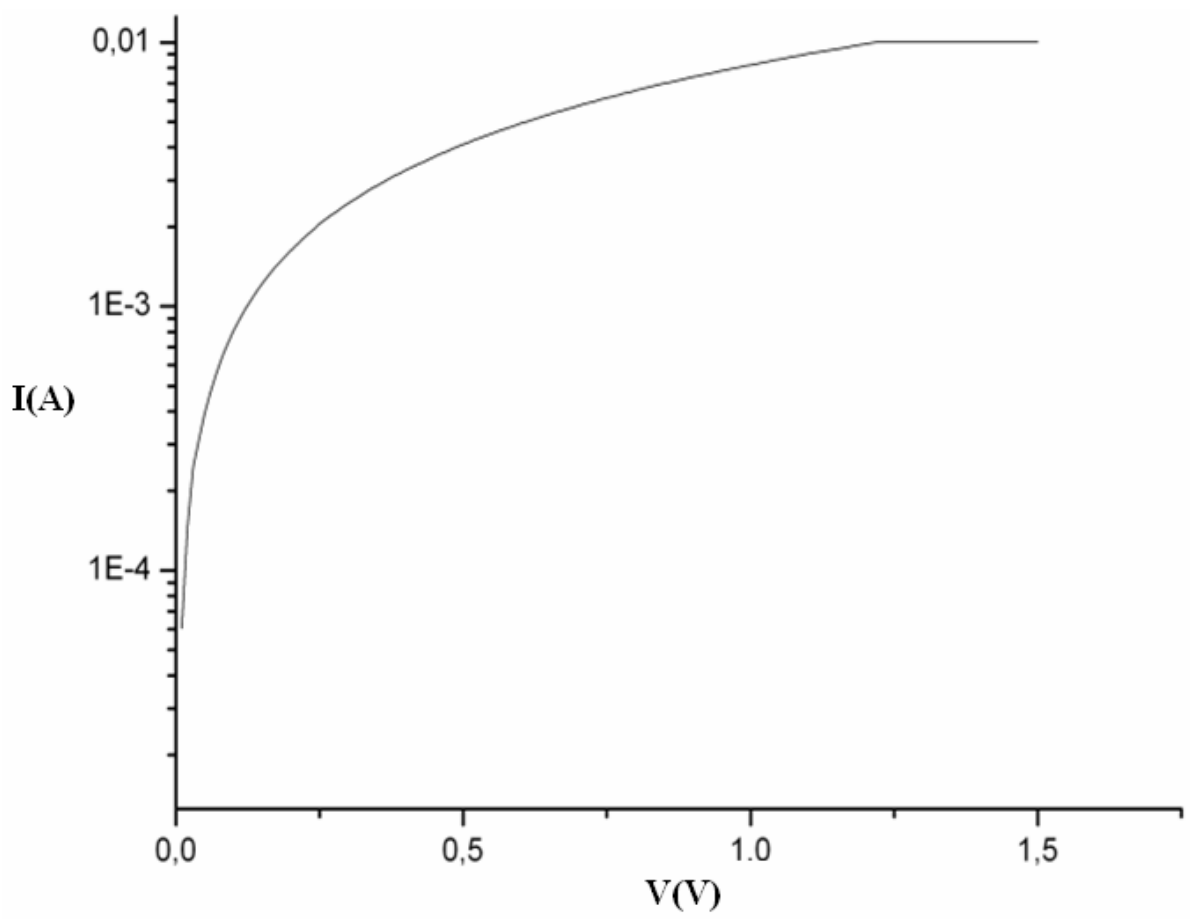

Figura 4.13 - Curva V-I de amostra com o equivalente em espessura de $1,95 \mathrm{~nm}$ de Au implantado no PMMA.

O mesmo tipo de medida foi realizado na amostra R3 com a espessura final equivalente a 10,85 $\mathrm{nm}$. Essa amostra apresentou comportamento condutor. 


\section{CAPÍTULO V}

\section{Conclusões}

Foram obtidos fatores de anisotropia de resistividade elétrica medindo-se as resistências de uma superfície nanofabricada de PMMA durante a deposição do ouro por plasma. Estes dados comprovam que uma morfologia senoidal de dimensões nanométricas tem influencia no mecanismo de resistividade, gerando valores diferentes para sentidos de condução elétrica ortogonais ao perfil.

Apesar de não ter havido o crescimento de um filme fino de ouro conformando-se à modulação senoidal do PMMA, o efeito de anisotropia de resistividade foi observado para a superfície anisotrópica de PMMA implantado com íons de ouro. De acordo com os experimentos que comprovaram a ocorrência da implantação do ouro no PMMA, a quantidade de ouro implantado corresponde ao equivalente a mais de $10 \mathrm{~nm}$ de filme de ouro. Assim, conclui-se que todos os valores de resistividade foram obtidos para um polímero semicondutor/condutor composto por PMMA com ouro implantado.

Mesmo não sendo um filme fino metálico, tudo indica que a anisotropia ocorre devido a efeitos quânticos. Entretanto este resultado é bastante difícil de ser modelado teoricamente. Uma das dificuldades seria a mudança de condutividade do polímero em função de uma distribuição lateral e em profundidade dos íons de ouro.

Ainda assim, o modelo teórico apresentado no trabalho foi utilizado para relacionar os fatores de anisotropia de resistividade obtidos às periodicidades que poderiam ser influentes. Os valores encontrados correspondem às dimensões dadas pela nanolitografia por AFM de contato, mas também às dimensões mais finas de cadeias poliméricas de PMMA. Essas dimensões, como encontrado na literatura, têm cerca de apenas 0,8 nm [74-77], da ordem do comprimento de onda de Fermi $\left(\lambda_{\mathrm{F}}\right)$.

\subsection{Sugestão para trabalhos futuros}

A primeira sugestão de trabalho futuro é a obtenção de filmes finos metálicos, modulando-se à superfície nanofabricada durante a deposição. Podem ser feitas novas medidas de resistência e determinada a anisotropia para o filme fino metálico, situação possível de ser modelada teoricamente. Todos os processos desenvolvidos para a produção dos dispositivos seriam mantidos, alterando-se apenas as condições de deposição dos filmes 
de ouro. Para evitar que ocorra a implantação dos íons na matriz polimérica pode ser incorporado um circuito para aplicação de potencial positivo nas amostras, de forma que os íons sofram desaceleração e não tenham energia suficiente para implantação.

Outra área que pode ser explorada é a aplicação de polímeros com íons metálicos implantados com baixa energia $(\sim 49 \mathrm{eV})$. Há grande interesse em filmes finos de polímeros condutores para áreas de microeletrônica, sensores, fotônica, particularmente quando há distribuição de nano partículas na matriz do polímero $[78,79]$. Existem outros métodos para incorporação de partículas de ouro no PMMA, mas não há na literatura informação sobre este tipo de material fabricado através de MePIIID. Neste contexto, dois tipos de caracterização são importantes, a determinação da granularidade do ouro implantado no polímero e a determinação de suas características elétricas, uma vez que há casos de comportamento semicondutor. A vantagem do PMMA como este polímero condutor é que ele pode servir ainda como elétron-resiste, possibilitando seu uso direto na criação de padrões litográficos para micro e nanodispositivos [80].

Ainda outra área que pode ser explorada é a de sensores com a resistividade elétrica como mecanismo transdutor, conforme apresentado na Introdução. Mais especificamente, a anisotropia poderia ser usada como sensor de direção de corrente, uma vez que a resistência elétrica é um parâmetro mensurável e que, como foi mostrado, pode ser diferente para direções ortogonais dado um valor de corrente. 


\section{Referências Bibliográficas}

[1] HUMMEL, R.E. Electronic Properties of Materials. 2. ed. New York: Springer-Verlag, 1993.

[2] MORIARTY, P. Nanostructured materials. Reports on Progress in Physics, v. 64, p. 297-331, 2001.

[3] COWLAM, N. Structure changes in Nanostructured Materials Solid State Phenomena, v. 56, p. 145-177, 1997.

[4] QIN, X.Y. et al. The elastic properties of nanostructured Ag measured by laser ultrasonic technique. Nanostructured Materials, v. 10, p. 661-672, 1998.

[5] LAYSON, A.R.; EVANS, J.W.; THIEL, P. A. Additive-enhanced coarsening and smoothening of metal films: Complex mass-flow dynamics underlying nanostructure evolution. Physical Review B, v. 65, p. 193409, 2002.

[6] MATHIOUDAKIS, C. et al. Nanomechanical properties of multilayered amorphous carbon structures. Physical Review B, v. 65, p. 205203, 2002.

[7] TESANOVIC, Z.; JARIC, M.V.; MAEKAWA, S. Quantum transport and surface scattering. Physical Review Letters, v.57, p. 2760, 1986.

[8] KARCH, J.; BIRRINGER, R.; GLEITER H. Ceramics ductile at low temperature. Nature, v. 330, p. 556, 1987.

[9] NEIMAN, G.W.; WEERTMAN, J.R.; SIEGEL, R.W. Tensile Strength and Creep Properties of Nanocrystalline Palladium. Scripta Metallurgica et Materialia, v. 24, p. 145, 1990.

[10] SALVADORI, M.C. et al. Measurement of the elastic modulus of nanostructured gold and platinum thin films. Physical Review B, v. 67, p. 153404, 2003.

[11] SALVADORI, M.C. et al. Nanostructures gold thin films: Young Modulus Measurement. Surface Review and Letters, v. 10, n. 4, p. 571-575, 2003. 
[12] VAZ, A.R; SALVADORI, M.C.; CATTANI M. Young Modulus Measurement of Nanostructured Metallic Thin Films. Journal of Metastable and Nanocrystalline Materials, v. 20 - 21, p. 758-762, 2004.

[13] SALVADORI, M. C. et al. Electrical resistivity of nanostructured platinum and gold thin films. Surface Review and Letters, v. 11, p. 223-227, 2004.

[14] CATTANI, M.; SALVADORI, M.C., Electrical resistivity of platinum and gold thin films: a theoretical approach. Surface Review and Letters, v. 11, p. $283290,2004$.

[15] CATTANI, M.; SALVADORI, M.C. Contribution of the morphological grain sizes to the electrical resistivity of platinum and gold thin films. Surface Review and Letters, v.11, p. 463-467, 2004.

[16] CATTANI, M.; SALVADORI, M.C.; BASSALO, J.M.F. Surface induced electrical resistivity of conducting thin films. Surface Review and Letters, v. 12, p. 221-226, 2005.

[17] FISHMAN, G.; CALECKI, D. Surface-induced resistivity of ultrathin metallic films: a limit law. Physical Review Letters, v. 62, p. 1302, 1989.

[18] FISHMAN, G.; CALECKI, D. Influence of surface roughness on the conductivity of metallic and semiconducting quasi-two-dimensional structures. Physical Review B, v. 43, p. $11581,1991$.

[19] PALASANTZAS G.; BARNAS J. Surface-roughness fractality effects in electrical conductivity of single metallic and semiconducting films. Physical Review B, v. 56, p. 7726, 1997.

[20] PALASANTZAS G. Surface roughness and grain boundary scattering effects on the electrical conductivity of thin films. Physical Review B, v. 58, p. 9685-9688, 1998.

[21] PALASANTZAS G. et al. Electrical conductivity and thin-film growth dynamics. Physical Review B, v. 61, p. 11109, 2000.

[22] WANG, J.; WOLF, D.; PHILlPOT, S.R. Computer simulation of the structure and thermo-elastic properties of a model nanocrystalline material. Philosophical Magazine A, v. 73, n. 3 , p. $517,1996$. 
[23] CLEMENS, B.M.; EESLEY, G.L. Relationship between interfacial strain and the elastic response of multilayer metal films. Physical Review Letters, v. 61, p. 2356, 1988.

[24] ANDERS, A. Metal plasma immersion ion implantation and deposition: a review. Surface and Coatings Technology, v. 93, p. 158-167, 1997.

[25] MONTEIRO, O.R. Plasma synthesis of hard materials with energetic ions. Nuclear Instruments and Methods in Physics Research Section B, v. 148, p. 12-16, 1999.

[26] BROWN, I.G. et al. Recent advances in surface processing with metal plasma and ion beams. Surface and Coatings Technology, v. 112, p. 271-277, 1999.

[27] ANDERS, A.; ANDERS, S.; BROWN, I.G. Transport of vacuum arc plasmas through magnetic macroparticle filters. Plasma Sources Science and Technology, v. 4, p. 1-11, 1995.

[28] TANG, Q.; SHI, S.Q.; ZHOU, L. Nanofabrication with atomic force microscopy. Journal of Nanoscience and Nanotechnology, v. 4, p. 948-963, 2004.

[29] LEE, C.; LEE, G. Micromachined-based humidity sensors with integrated temperature sensors for signal drift compensation. Journal of Micromechanics and Microengineering, v. 13, p. 620-627, 2003.

[30] FIREBAUGH, S.L.; JENSEN, K.F.; SCHMIDT, M.A. Investigation of high-temperature degradation of platinum thin films with an in situ resistance measurement apparatus. Journal of Microeletromechanical Systems, v. 7, p. 1, 1998.

[31] NAJAFI, N. et al. A micromachined ultra-thin-film gas detector. IEEE Transactions on Electron Devices, v. 41, p. 10, 1994.

[32] CHAURASIA, H.K, HUIZINGA, A.; VOSS, W.A.G. Optimum gold films for mercury detection. Journal of Physics D: Applied Physics, v. 8, p. 214, 1975.

[33] MAZZOLAI, B. et al. A microfabricated physical sensor for atmospheric mercury monitoring. Sensors and Actuators A, v. 113, p. 282-287, 2004.

[34] FENG, C.D. et al. TRANSDUCERS 95 - EUROSENSORES IX (THE 8TH INTERNATIONAL CONFERENCE ON SOLID-STATE SENSORS AND ACTUATORS), 1995 Stockholm. Impedance analysis of ultrathin platinum film immunosensors with different thickness and macro geometry. 1995, p. 538-541. 
[35] PATEL S.V.; GLAND J.L.; SCHWANK, J.W. Film structure and conductometric hydrogen-gas-sensing characteristics of ultrathin platinum films. Langmuir, v. 15, p. 3307$3311,1999$.

[36] RESNiCK, R.; HALlidAY, D. Física 4 - Ótica e Física Moderna. 4. ed. Rio de Janeiro: LTC - Livros Técnicos e Científicos, 1989.

[37] SERWAY, R.A. Física 3 para Cientistas e Engenheiros com Física Moderna. 4. ed. Rio de Janeiro: LTC - Livros Técnicos e Científicos, 1996.

[38] GARCIA, N.; DAMASK, A.; SCHWARZ, S. Physics for computer science students: with emphasis on atomic and semiconductor physics. 2 ed. New York: Wiley, 1986.

[39] ANDO, T.; FOWLER, A.B.; STERN, F. Electronic properties of two-dimensional systems. Reviews of Modern Physics, v. 54, p. 437, 1982.

[40] FARIAS, R.J.C. Resistividade Elétrica de Filmes Finos Nanoestruturados de Platina e Ouro. 2004. 51p. Dissertação (Mestrado) - Instituto de Fïsica, Universidade de São Paulo, São Paulo, 2004.

[41] SALVADORI, M. C.; MELO, L.L ; VAZ, A., R.; WIEDERKEHR, R.S.; TEIXEIRA, F.S.; CATTANI, M. Platinum and gold thin films deposited by filtered vacuum arc: morphological and crystallographic grain sizes. Surface \& Coatings Technology, v. 200, p. 2965-2969, 2006.

[42] BARABÁSI, A.L.; STANLEY, H.E. Fractal Concepts in Surface Growth. Cambridge Univ. Press, 1995.

[43] NAMBA, Y. Resistivity and temperature coefficient of thin metal films with rough surface. Japanese Journal of Applied Physics, v. 9, p. 1326-1329, 1970.

[44] FEDER, J. Fractals. New York: Plenum Press, 1998.

[45] Jeol Ltd. Manual de Operação do Microscópio Eletrônico de Varredura Jeol 6460LV. 2002. 
[46] GOLDSTEIN, J.I. et al. Scanning Electron Microscopy and X-ray Microanalysis: a text for biologists, materials scientists, and geologists. 2. ed. New York: Plenum Press, 1992.

[47] REIMER, L. Scanning Electron Microscopy - Physics of Image Formation and Microanalysis. 2. ed. Germany: Springer-Verlag Berlin Heidelberg, 1998.

[48] J.C. Nabity Lithography Systems. Manual de operação do NPGS (Nano Pattern Generation System). 2003.

[49] SALVADORI, M.C. Notas de aula do curso de pós-graduação do Departamento de Física Aplicada, FAP - 5753 - Microscopia de Força Atômica e Tunelamento, 2003.

[50] Veeco Instruments Inc. MultiMode SPM Instruction Manual. 2004.

[51] GLENDINNING, W.B.; HELBERT, J.N. Handbook of VLSI Microlithography Principles, Technology and Applications. New Jersey: Noyes Publications, 1991.

[52] MADOU, M.J. Fundamentals of Microfabrication - The Science of Miniaturization. 2. ed. New York: CRC Press, 2002.

[53] VIEU, C. et al. Electron beam lithography: resolution limits and applications. Applied Surface Science, v. 164, p. 111-117, 2000.

[54] HANG, Q. et al. Molecular patterning through high-resolution polymethylmethacrylate masks. Applied Physics Letters, v. 80, n.22, p. 4220, 2002.

[55] WENCHUANG, W.H. et al. Sub-10 nm electron beam lithography using cold development of poly(methylmethacrylate). Journal of Vacuum Science and Technology B, v. 22(4), p.1711, 2004.

[56] WENCHUANG, W.H. et al. High Resolution Electro Beam Lithography and DNA Nano-Patterning for Molecular QCA. IEEE Transactions On Nanotechnology, v. 4(3), p. $312,2005$.

[57] CALLISTER, W.D. Materials Science and Engineering - an Introduction. 5. ed. USA: John Wiley \& Sons, Inc, 2000. 
[58] SAWYER, L.C.; GRUBB, D.T. Polymer Microscopy. 2. ed. Oxford: Chapman \& Hall, 1996.

[59] MicroChem Corp. Apresenta informações e especificações de elétron-resistes. Disponível em < http://www.microchem.com > . Acessos em 2006.

[60] DOBISZ, E.A. et al. Effects of molecular properties on nanolithography in polymethylmethacrylate. Journal of Vacuum Science and Technology B, v. 18(1), p. 107, 2000 .

[61] AKTARY, M.; STEPANOVA, M.; DEW, S.K. Simulation of the spatial distribution and molecular weight of polymethylmethacrylate fragments in electron beam lithography exposures. Journal of Vacuum Science and Technology B, v. 24(2), p. 768, 2006.

[62] Allresist. Apresenta informações e especificações de elétron-resistes. Disponível em

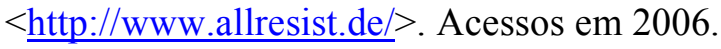

[63] HSU, J.H. et al. Selective growth of silica nanowires on nickel nanostructures created by atomic force microscopy nanomachining. Nanotechnology, v. 17, p. 170-173, 2006.

[64] HE, J.H. et al. Pattern and feature designed growth of $\mathrm{ZnO}$ nanowire arrays. Journal of Physical Chemistry B, v. 110, p. 50-53, 2006.

[65] PIDDUCK A.J. et al. Control of liquid crystal alignment by polyimide surface modification using atomic force microscopy. Applied Physics Letters, v. 71, p. 20, 1997.

[66] RASTEGAR, A. et al. Mechanism of liquid crystal alignment on submicron pattern surfaces. Journal of Applied Physics, v. 89, p. 2, 2001.

[67] NOTARGIACOMO, A. et al. Atomic force microscopy lithography as a nanodevice development technique. Nanotechnology, v. 10, p. 458-463, 1999.

[68] KHALID M.N.; YASIN, S.; KHAN, M.R. Effect of development time on polymer phase separation in PMMA resist. Turkish Journal of Physics, v. 28, p. 271-276, 2004.

[69] SADER, J.E. Parallel beam approximation for V-shaped atomiv force microscope cantilevers. Review of Scientific Instruments, v. 66, p. 4583, 1995. 
[70] TEIXEIRA, F.S.; SALVADORI, M.C; MANSANO, R.D.; CATTANI, M. A near sinusoidal surface morphology created by scan-induced contact AFM nanolithography on PMMA polymer. In V Encontro da Sociedade Brasileira de Pesquisas em Materiais, 2006, Florianópolis. Resumos. Res. M512.

[71] SRIM - Stopping and Range of Ions in Matter. Disponibiliza programa para simulações

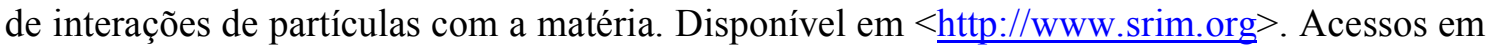
2006.

[72] MARTINS, D.R.; SALVADORI, M.C.; VERDONK, P; BROWN, I.G. Contamination due to memory effects in filtered vacuum arc plasma deposition systems. Applied Physics Letters, v. 81, n. 11, p. 1969-1971, 2002.

[73] ANDERS, A.YUSHKOV, G.Y. Ion flux from vacuum arc cathode spots in the absence and presence of a magnetic field. Journal of Applied Physics, v. 91, p. 8, 2002.

[74] HA, J.S. Structural study of poly(methylmethacrylate) Langmuir-Blodgett film on graphite surface by scanning tunneling microscope. Journal of Vacuum Science and Technology B, v.12(3), p. 1977, 1994.

[75] SHAO, Y. The effect of transfer printing on pentacene thin-film crystal structure. Journal of Applied Physics, v. 100, p. 044512, 2006.

[76] ALBRECHT, T.R. et al. Imaging and modification of polymers by scanning tunneling and atomic force microscopy. Journal of Applied Physics, v. 64(3), p. 1178, 1986.

[77] GENIX, A.C. et al. Local structure of syndiotactic poly(methyl methacrylate). A combined study by neutron diffraction with polarization analysis and atomistic molecular dynamics simulation. Macromolecules, v. 39, p. 3947-3958, 2006.

[78] ABYANEH, M.K. et al . Thermally assisted semiconductor-like to insulator transition in gold-poly(methylmethacrylate) nanocomposites. Nanotechonology, v. 17, p. 4129-4134, 2006.

[79] SMIRNOVA, L.A.; et al. UV-induced formation of gold nanoparticles in a poly(methyl methacrylate) matrix. Doklady Physical Chemistry, v. 400, p. 19-21, 2005.

[80] DONG, B. Patterning of conducting polymers based on a random copolymer strategy: toward the facile fabrication of nanosensors exclusively based on polymers. Advanced Materials, v. 17, p. 2736-2741, 2005. 


\begin{abstract}
ANEXO A
Artigo publicado no periódico Review of Scientific Instruments
\end{abstract}




\title{
Atomic force microscope nanolithography of polymethylmethacrylate polymer
}

\author{
F. S. Teixeira and R. D. Mansano \\ Laboratory of Integrated Systems, Polytechnic School, University of São Paulo, \\ Avenida Professor Luciano Gualberto, Travessa R-158, CEP 05508-900 São Paulo, Brazil \\ M. C. Salvadoria) and M. Cattani \\ Institute of Physics, University of São Paulo, C.P. 66318, CEP 05315-970 São Paulo, Brazil \\ I. G. Brown \\ Lawrence Berkeley National Laboratory, 1 Cyclotron Road, Berkeley, California 94720
}

(Received 28 February 2007; accepted 8 April 2007; published online 3 May 2007)

\begin{abstract}
We describe a nanolithography process for a polymethylmethacrylate (PMMA) surface using scanning contact atomic force microscopy. Parallel furrows were scribed with a pyramidal silicon tip using the same scan mechanism as used to image samples. The PMMA was first electron beam irradiated using a scanning electron microscope and developed. The topography formed is reproducible and predictable. Material from the region where the tip scribes is moved to nearby regions, and aligned, elongated PMMA fragments are seen to decorate the valleys between furrows. (C) 2007 American Institute of Physics. [DOI: 10.1063/1.2736311]
\end{abstract}

\section{INTRODUCTION}

Atomic force microscopy ${ }^{1-3}$ (AFM) is a powerful tool for imaging surface morphology at high spatial resolution. Essentially the same device can be used for creating surface nanostructures; this technique is called scanning probe lithography (SPL). A number of SPL techniques have been developed, based on nanomanipulation, ${ }^{4-6}$ mechanical modification, ${ }^{7-13}$ thermomechanical writing, ${ }^{14,15}$ local oxidation, ${ }^{16-20}$ electron exposure of resistance, ${ }^{21-23}$ dip-pen nanolithography (DPN), ${ }^{24-26}$ electrochemical dip-pen nanolithography (E-DPN),,$^{27,28}$ and rapid direct nanowriting of a conducting polymer by electrochemical oxidative nanolithography. ${ }^{29}$

Polymethylmethacrylate (PMMA) has been widely used as a photo- or electropositive resist for nano- and microscale fabrications. Thin, uniform layers of PMMA are deposited on a substrate and selected areas exposed to ultraviolet light or to a scanning electron beam. The irradiation creates scissions in molecular chains in the exposed areas of the polymer, decreasing their average molecular weight and allowing them to be removed through a development process. For nanodevice fabrication, it can be advantageous to form desired nanostructures on the PMMA surface after it has been irradiated and developed to create the nanostructures.

We describe here our use of an AFM nanolithography technique to mechanically modify PMMA surfaces previously irradiated and developed.

\section{EXPERIMENTAL PROCEDURE}

Glass microscope slides were cut into $14 \times 5 \mathrm{~mm}^{2}$ pieces, cleaned and baked at $150{ }^{\circ} \mathrm{C}$ for 10 min to remove

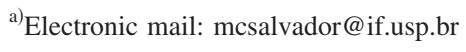

residual humidity, and PMMA then deposited on the samples using a spin coater. The samples were then baked again at $180{ }^{\circ} \mathrm{C}$ for $20 \mathrm{~min}$ to evaporate the polymer solvent. We used PMMA ARP671.06, with molecular weight of 950000 and concentration of $6 \%$ in clorobenzene, from Allresist. The average PMMA film thickness was $500 \mathrm{~nm}$.

A selected area of the PMMA was electron beam

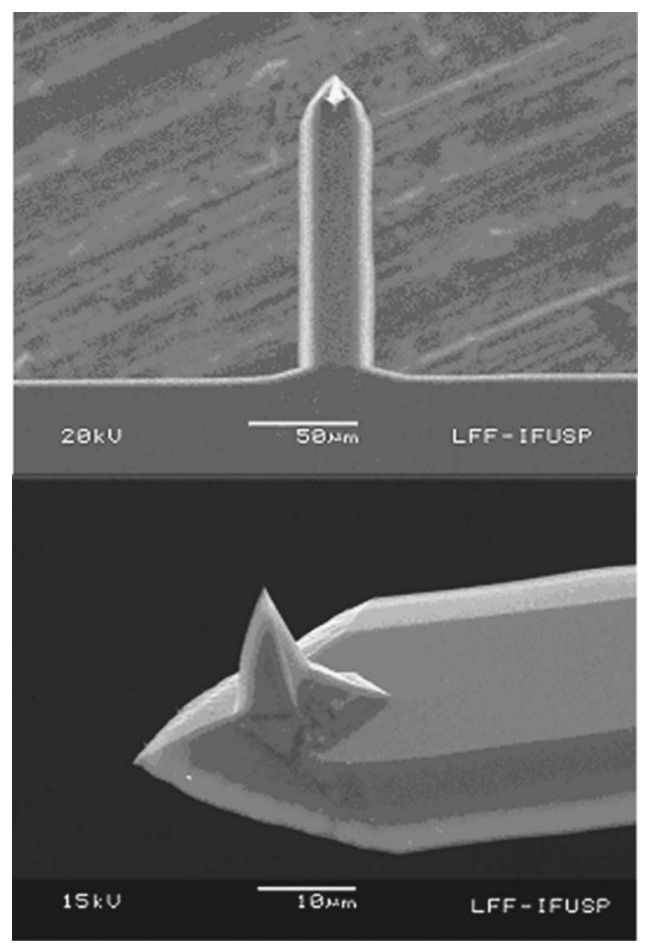

FIG. 1. SEM image of a typical AFM probe used here. In the upper image, in low magnification, one can see the cantilever with a small pyramidal tip. In the lower image, in higher magnification, the pyramidal silicon tip can be seen. 


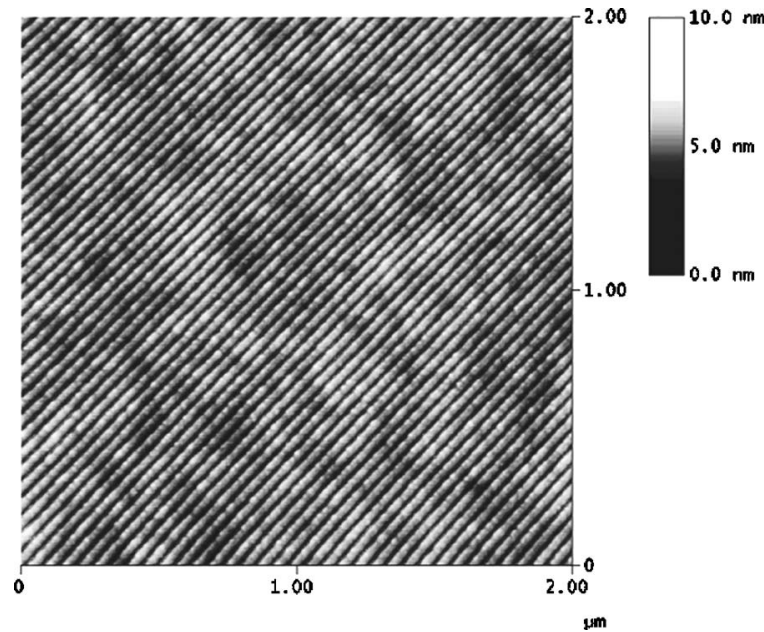

FIG. 2. AFM image of a nanolithographed region on PMMA surface. The scan was $20 \mu \mathrm{m}$ and contained 512 lines.

scanned in a scanning electron microscope (JEOL model JSM-6460 LV) using an e-beam nanolithography system (Nanometer Pattern Generation System, NPGS) to create micropatterns that allowed subsequent identification and location of smaller nanostructures to be formed by AFM. The e-beam lithography was performed with a $30 \mathrm{kV}, 50 \mathrm{pA}$ electron beam. The applied electron dose was $225 \mu \mathrm{C} / \mathrm{cm}^{2}$ with an exposure time of $362 \mu$ s at each scan point. The patterns consisted of two pads, each $20 \times 100 \mu \mathrm{m}^{2}$. The samples were then immersed in a developing solution of 1 part methyl isobutyl ketone (MIBK): 3 parts isopropyl alcohol (IPA) for $2 \mathrm{~min}$ and rinsed in IPA for $30 \mathrm{~s}$.

The atomic force microscope used was a NanoScope IIIa with a tapping mode probe. Our procedure was to first obtain a tapping mode image of a selected region, then to perform contact nanolithography, and finally to obtain a new tapping mode image to visualize the modified surface. To image a surface using the NanoScope IIIa in AFM tapping mode, the tip scans a maximum of 512 lines in a square area, interacting physically with 512 points along each of these lines. Importantly, note that the tip touches the surface only gently, and the polymer is not modified during image acquisition.

A SEM image of a typical AFM probe used in this work

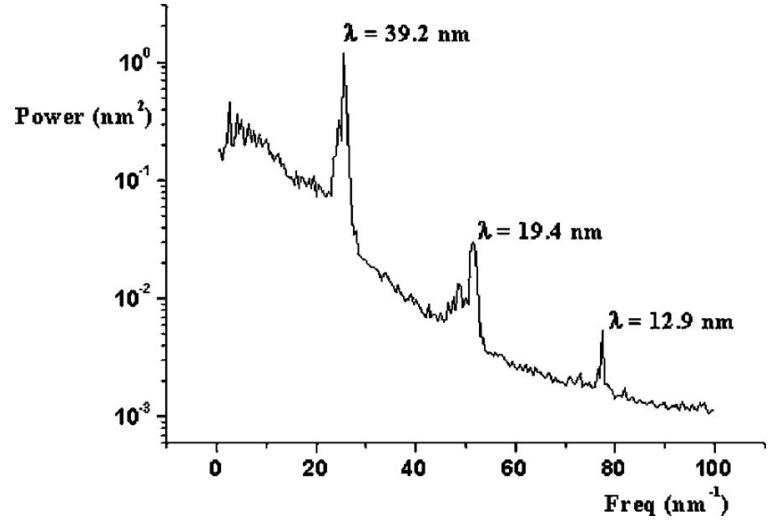

FIG. 3. PSD averaged over nine different samples (512 lines over a $20 \mu \mathrm{m}$ scan).

is shown in Fig. 1. The dimensions of each cantilever were measured (average dimensions were $120 \mu \mathrm{m}$ long, $33 \mu \mathrm{m}$ width, and $2.5 \mu \mathrm{m}$ thick), allowing calculation of its elastic constant. ${ }^{30} \mathrm{~A}$ force plot was then obtained so as to precisely determine the cantilever deflection to be used in the lithography process. A typical deflection used was about $70 \mathrm{~nm}$. In this way it was possible to define the force between the tip and the polymer. The force range was $0.5-1.0 \mu \mathrm{N}$.

Following calibration, the tip was engaged on the surface in contact mode and nanolithography initiated. The mechanism is similar to image acquisition, but with the scanning tip maintained in constant contact with the surface so as to scribe each scan line. The fabrication region was scanned just once, with $1 \mathrm{~Hz}$ scan rate and $0^{\circ}$ scan angle. Finally, a tapping mode image of the nanolithographed area was acquired, using a $45^{\circ}$ scan angle for better visualization of the surface morphology.

\section{RESULTS AND DISCUSSION}

A typical AFM image of a nanolithographed region of PMMA is shown in Fig. 2, where 512 lines were scribed in a $20 \mu \mathrm{m}^{2}$ and the periodicity was thus $39 \mathrm{~nm}$. The averaged power spectral density ${ }^{31}$ (PSD) for nine different samples is shown in Fig. 3, where the $x$ axis is the inverse wavelength $(\lambda)$ and the $y$ axis is the PSD. The measured average mor-

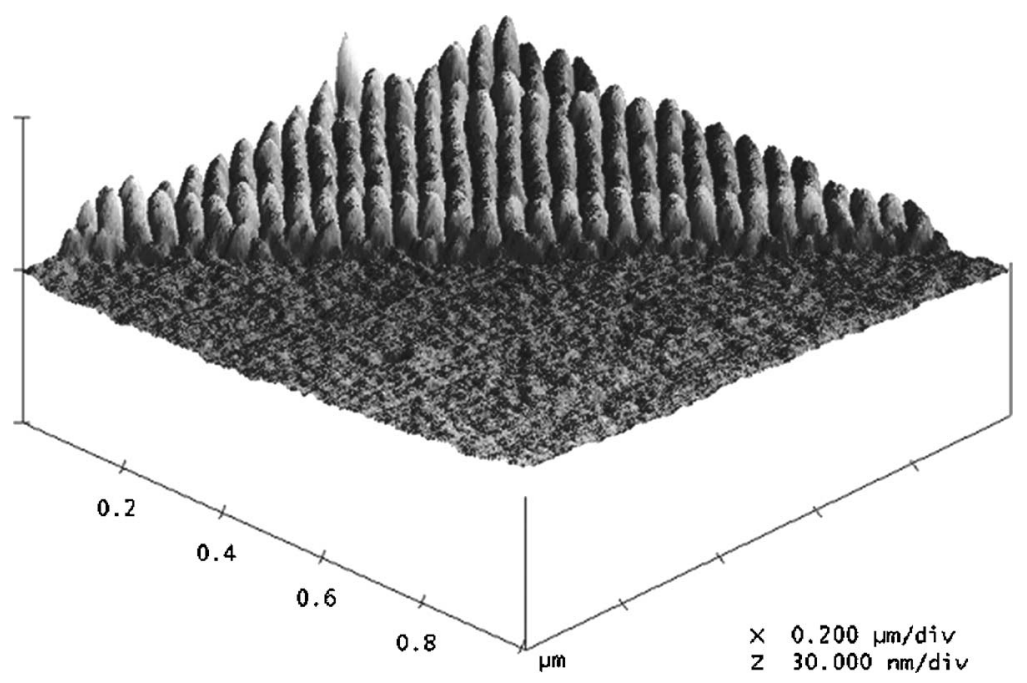

FIG. 4. AFM image showing both the nanolithographed region and the original, unlithographed surface. 


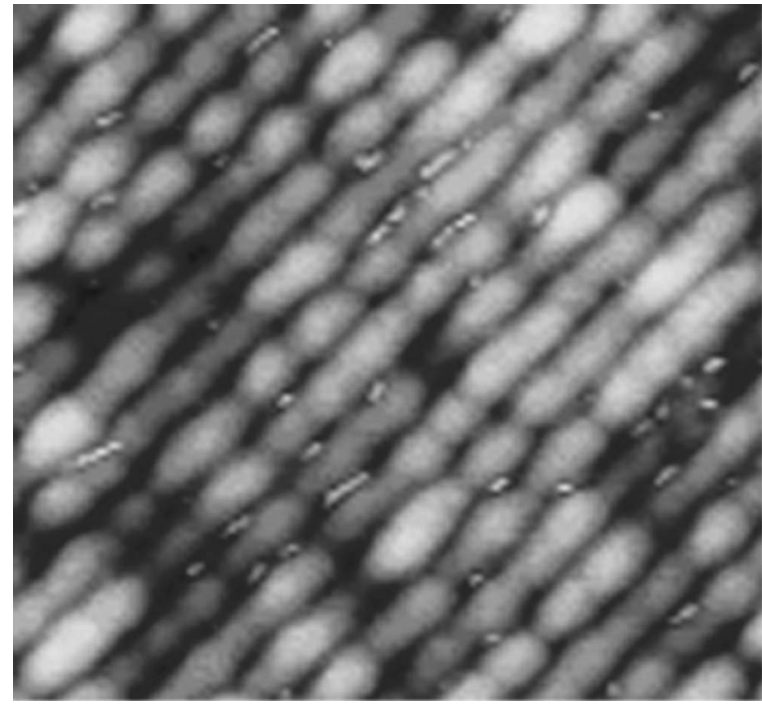

FIG. 5. AFM image showing aligned debris in the PMMA furrows. The image width is $500 \mathrm{~nm}$.

phological wavelengths are 39.2 and $19.4 \mathrm{~nm}$; the feature at $\lambda=12.9 \mathrm{~nm}$ is related to the tip radius. The PSD is given in $\mathrm{nm}^{2}$ and can be related to the roughness $\Delta$ (associated with a given wavelength) and to the amplitude $h$ of the surface Fourier transform as PSD $\propto \Delta^{2} \propto h^{2}{ }^{32}$ The reason for a wavelength component at half the scan line separation is that the tip does not execute a simple, single line, but follows a zigzag pattern, totaling two scribes for each line.

In the lithography process, material is moved from the region immediately below the tip to an adjacent site, quite similar to the macrotopography of the furrows in a plowed field, and the pattern profile obtained shows material above the original surface. This effect is clear from the image shown in Fig. 4.

In some samples an interesting fine structure is visible, as shown in Fig. 5, where small features can be seen between the scribed lines. We interpret this as being elongated nanodebris formed by the probe tip from the developed PMMA, ${ }^{33,34}$ which is aligned during the lithography process.

We also fabricated samples with 10, 30, and $40 \mu \mathrm{m}$ scan sizes and with 256 or 512 scribe lines. Similar results and features were obtained.

We have described a nanolithographic technique using scanning contact AFM to machine a PMMA surface with parallel lines scribed with a pyramidal silicon tip using the same scan mechanism as used to image samples. The PMMA was first electron beam irradiated using a scanning electron microscope (SEM) and developed. The formed topography is reproducible and predictable. The lithography mechanism in- volves moving material from the region where the tip scribes to immediately adjacent sites; the process creates not only valleys but also hills.

\section{ACKNOWLEDGMENT}

The authors are grateful to FAPESP and CNPq for financial support.

${ }^{1}$ R. Wiesendanger, Scanning Probe Microscopy and Spectroscopy (Cambridge University Press, Cambridge, England, (1994).

${ }^{2}$ R. J. Colton et al., Procedures in Scanning Probe Microcopies (Wiley, New York (1998)

${ }^{3}$ Selected Papers on Scanning Probe Microscopy Design and Applications, edited by Y. M. Martin and B. J. Thompson SPIE Optical Engineering Press, Washington, (1995).

${ }^{4}$ C. Baur et al., Nanotechnology 9, 360 (1998).

${ }^{5}$ P. H. Beton, A. W. Dunn, and P. Moriarty, Appl. Phys. Lett. 67, 1075 (1995).

${ }^{6}$ M. T. Cuberes, R. R. Schlitter, and J. K. Gimzewski, Appl. Phys. Lett. 69, 3016 (1996)

${ }^{7}$ J.-M. Chen, S.-W. Liao, and Y.-C. Tsai, Synth. Met. 155, 11 (2005).

${ }^{8}$ R. Magno and B. R. Bennett, Appl. Phys. Lett. 70, 1855 (1997).

${ }^{9}$ V. Bouchiat and D. Esteve, Appl. Phys. Lett. 69, 3098 (1996).

${ }^{10}$ L. L. Sohn and R. L. Willett, Appl. Phys. Lett. 67, 1552 (1995).

${ }^{11}$ S. Hu, S. Altmeyer, A. Hamidi, B. Spangenberg, and H. Kurz, J. Vac. Sci. Technol. B 16, 1983 (1998).

${ }^{12}$ U. Kunze and B. Klehn, Adv. Mater. (Weinheim, Ger.) 11, 1473 (1999).

${ }^{13}$ B. Klehn and U. Kunze, J. Appl. Phys. 85, 3897 (1999).

${ }^{14}$ H. J. Mamin and D. Rugar, Appl. Phys. Lett. 61, 1003 (1992).

${ }^{15}$ H. J. Mamin, Appl. Phys. Lett. 69, 433 (1996).

${ }^{16}$ E. S. Snow and P. M. Campbell, Appl. Phys. Lett. 64, 1932 (1994).

${ }^{17}$ L. Tsau, D. Wang, and K. L. Wang, Appl. Phys. Lett. 64, 2133 (1994).

${ }^{18}$ P. M. Campbell, E. S. Snow, and P. J. McMarr, Appl. Phys. Lett. 66, 1388 (1995).

${ }^{19}$ P. A. Fontaine, E. Dubois, and D. Stiévenard, J. Appl. Phys. 84, 1776 (1998).

${ }^{20}$ H. Dai, N. Franklin, and J. Han, Appl. Phys. Lett. 73, 1508 (1998).

${ }^{21}$ K. Wilder and C. F. Quate, Appl. Phys. Lett. 73, 2527 (1998).

${ }^{22}$ S. W. Park, H. T. Soh, C. F. Quate, and S.-I. Park, Appl. Phys. Lett. 67, 2415 (1995).

${ }^{23}$ D. C. Tully, K. Wilder, J. M. J. Fréchet, A. R. Trimble, and C. F. Quate, Adv. Mater. (Weinheim, Ger.) 11, 314 (1999).

${ }^{24}$ R. D. Piner, J. Zhu, F. Xu, S. Hong, and C. A. Mirkin, Science 283, 661 (1999).

${ }^{25}$ S. Hong, J. Zhu, and C. A. Mirkin, Science 286, 523 (1999).

${ }^{26}$ K. B. Lee, S.-J. Park, C. A. Mirkin, J. C. Smith, and M. Mrksich, Science 295, 1702 (2002).

${ }^{27}$ Y. Li, B. W. Maynor, and J. Liu, J. Am. Chem. Soc. 123, 2105 (2001).

${ }^{28}$ B. W. Maynor, S. F. Filocamo, M. W. Grinstaff, and J. Liu, J. Am. Chem. Soc. 124, 522 (2002).

${ }^{29}$ S. Y. Jang, M. Marquez, and G. A. Sotzing, J. Am. Chem. Soc. 126, 9476 (2004).

${ }^{30}$ J. E. Sader, Rev. Sci. Instrum. 66, 4583 (1995).

${ }^{31}$ W. K. Pratt, Digital Image Processing: PIKS, 3rd ed. (Wiley, New York, 2001).

${ }^{32}$ Command Reference Manual, Software version 5.12r3, Nanoscope IIIa, Veeco.

${ }^{33}$ E. A. Dobisz, S. L. Brandow, E. Snow, and R. Bass, J. Vac. Sci. Technol. B 15, 2318 (1997).

${ }^{34}$ E. A. Dobisz, S. L. Brandow, R. Bass, and L. M. Shirey, J. Vac. Sci. Technol. B 16, 3695 (1998). 